Document downloaded from:

http://hdl.handle.net/10251/101125

This paper must be cited as:

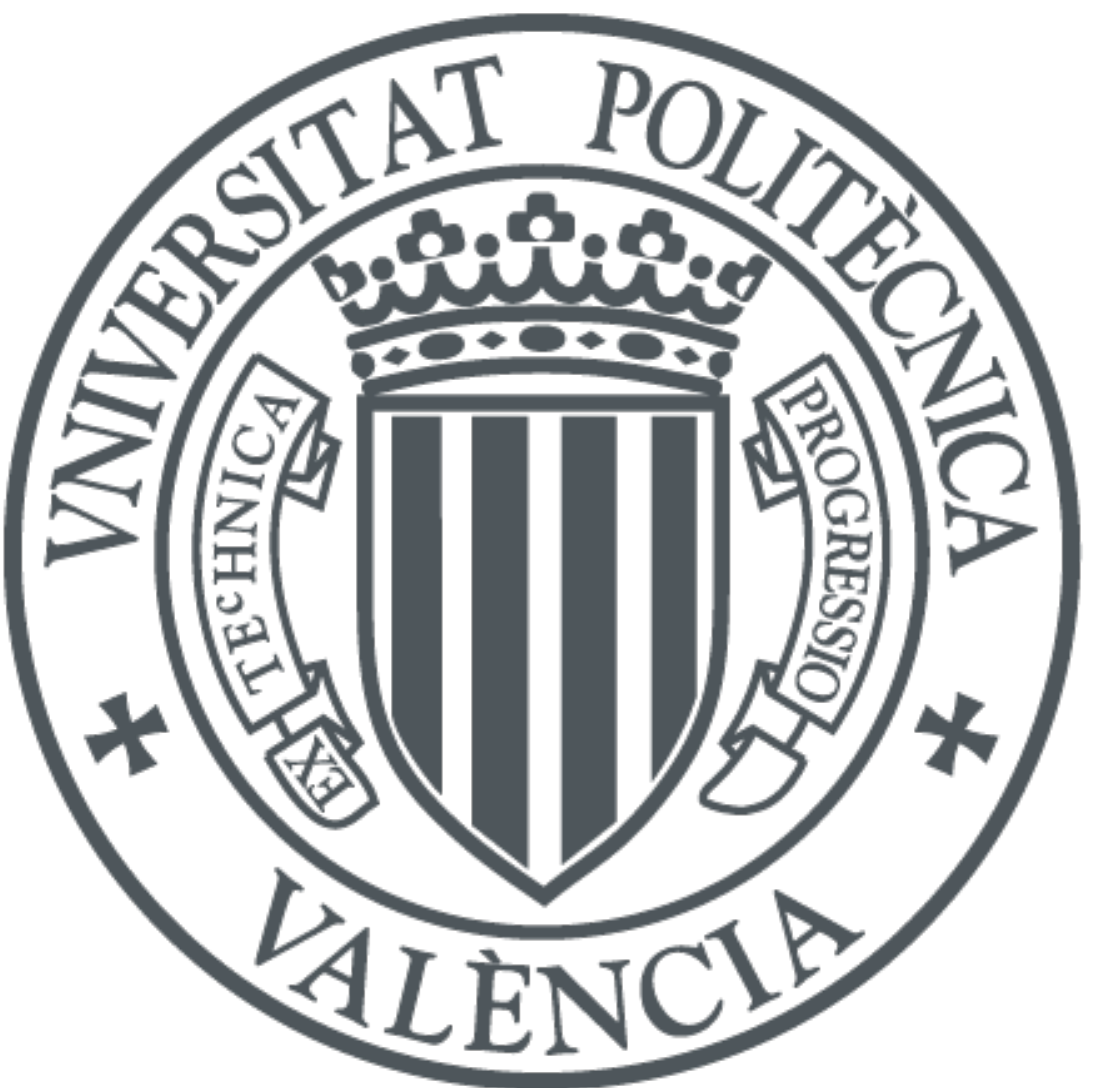

The final publication is available at

http://doi.org/10.1016/j.microc.2015.12.022

Copyright Elsevier

Additional Information 


\section{Analytical study of waterlogged ivory from the Bajo de la campana site (Murcia, 2 Spain)}

3 María Teresa Doménech-Carbó ${ }^{(1)^{*}}$, Milagros Buendía-Ortuño ${ }^{(2)}$, Trinidad Pasies4 Oviedo $^{(3)}$, Laura Osete-Cortina ${ }^{(1)}$

5 (1) Instituto de Restauración del Patrimonio. Universitat Politècnica de València. 6 Camino de Vera s/n, 46022-Valencia, Spain

7 (2) Museo Nacional de Arqueología Subacuática, Paseo del Muelle Alfonso XII, 22. 830202 Cartagena. Murcia, Spain

9 (3) Museu de Prehistòria de València, Corona 36, 46003 Valencia, Spain

*Corresponding author

Keywords: waterlogged ivory, FESEM-EDX, XRD, Fourier-Self Deconvolution Curve fitting, FTIR spectroscopy, GC-MS, spectrophotometry, light microscopy.

Abstract

This work reports an analytical study conducted prior to the conservation intervention of a collection of elephant tusks excavated from a wreck site of a 700-600 BC Phoenician trading vessel in Bajo de la campana (Murcia, Spain). The conservation state of ivory, determined by prolongated immersion in a marine environment, was established by a multi-technique methodology: light microscopy, field emission scanning electron microscopy-X-ray microanalysis (FESEM-EDX), X-ray diffraction (XRD), Fourier transform infrared spectroscopy (FTIR), spectrophotometry and gas chromatography-mass spectrometry (GC-MS). The analyses demonstrated that the structure and composition of both tusk parts, namely the inner ivory and outer cementum, were altered due to characteristic diagenetic processes of a marine environment. $\mathrm{Ca}$ enrichment was observed in both tusk parts, which gave higher $\mathrm{Ca} / \mathrm{P}$ molar ratio values than for ideal hydroxyapatite. Mg leaching was observed, together with uptake of exogenous elements (F, Cl, Si, Al, S, Na, Fe, Cu, Sr, Pb, Sn, Ag, V, Ni, Cd and Zn), which were prevalently identified in the external tusk part. Uptake of $\mathrm{S}$ and Fe was associated with the neoformation of pyrite framboids. The high carbonate content measured by FTIR, which agreed with the higher $\mathrm{Ca} / \mathrm{P}$ ratios found in the archaeological tusk, was ascribed to the carbonate substitution of phosphate groups (type-B) in the bioapatite accompanied by some authigenic calcium carbonate that infilled ivory. An increased degree of crystallinity was observed when comparing the values of several crystallinity indices found in the archaeological bioapatite with those of a modern tusk, used as the reference material. Increased crystallinity prevalently took place in the cementum. In accordance with increased crystallinity, the $\mathrm{HPO}_{4}{ }^{2-}$ content index indicated that the hydrated layer of bioapatite nanocrystals diminished in the archaeological tusk, and prevalently in the cementum. All these changes correlated with the significant organic matter loss reported for the archaeological tusk. Interestingly, remaining collagenous matter noticeably altered with enrichment in glycine and depletion in acid amino acids. Changes in the secondary structure of proteins were also recognised and associated with collagen gelatinisation. In addition to proteinaceous materials, small amounts of long-chain fatty acids, monoglycerides and cholesteryl oleate were identified by GC-MS. Cholesteryl oleate was associated with blood, which could have precipitated at the time of specimen death. The identification of large amounts of pyrite framboids and the high oleic acid/palmitic acid ratio in the archaeological tusk suggested minimal oxidative degradation processes, probably due to the slightly anoxic conditions of the underwater Bajo de la campana site environment. 


\section{Introduction}

48

Archaeological bones, teeth and, to a lesser extent antlers and tusks, have been the subject of numerous studies into their characterisation with a view to establishing the extent and mechanism of degradation, and to relating it to their environmental conditions [1-5], and to taxonomical differentiation [6-9], dating [10-15], provenance $[4,12,16,17]$ palaeoclimatology [18], palaeopathological [19-21] or dietary studies, $[14,22-26]$, and eventually to the problem of developing suitable conservation treatment $[27,28]$.

The aim of some studies has been to establish diagenetic mechanisms (this term refers to the postmortem changes that alter the antemortem state of bones/teeth/tusks) that affect these materials. They have attracted the attention of specialists as they contribute to better characterise the changes undergone by the artifact. The information embodied in these materials can also be altered differently depending on the nature of the archaeological material and the environmental conditions in which it has been preserved over time [1]. For this reason, many research works have examined this subject prevalently to describe the diagenesis processes that take place with buried materials [1,2,29-35] and in underwater environments [36-39].

Proboscidean tusks are composed of a main core of ivory covered with a thin cementum layer. Enamel is restricted to a conical layer located at the tip [40]. Ivory is a highly porous acellular mineralised tissue that is arranged with dentinal tubules, whose diameter falls within the $1-2 \mu \mathrm{m}$ range, embedded in a granular matrix [41,42]. Like bone, ivory is a composite material made of poorly crystalline non-stoichiometric carbonated apatite (60-70\%) with a slightly higher $\mathrm{Mg}$ content than bone [6]. This bioapatite ensures bone rigidity in the form of mineral crystallites [43], which are intimately joined on a nanoscale with fibrous proteinaceous material ( 30\% per dry weight), mainly collagen type I ( $90 \%$ per weight) $[44,45]$. Other organic materials that compose ivory include non-collagenous proteins, lipids and mucopolysaccharides $[2,28]$. 
Very few studies have been carried to study the characterisation of the changes ascribed to diagenetic processes on buried $[12,27,46-48]$ and waterlogged elephant tusks $[28,49$ 51]. Similar multi-technique methodologies to those used for bone studies have been applied to such instances, and have enabled the excellent characterisation of ivory and its alterations. For waterlogged ivory, Albéric et al. [49] used micro-small angle X-ray scattering ( $\mu \mathrm{XAS}$ ) to reveal submicroscopic structural modifications of ivory related to hydroxyapatite particle thickness, as well as the arrangement and orientation of mineralised collagen fibres. This technique is combined with non-invasive microparticle induced X-ray emission spectroscopy ( $\mu \mathrm{PIXE}$ ), gamma-ray particle induced X-ray emission spectroscopy (PIGE), Rutherford backscattering spectroscopy (RBS) and elastic backscattering spectroscopy (EBS) to identify changes in the chemical composition of both the organic fraction and the mineral part. The combined use of XRD, FTIR, inductively coupled plasma-atomic emission spectrometry (ICP-AES), nuclear magnetic resonance spectroscopy (NMR) and scanning electron microscopy (SEM) enabled Godfrey et al. [28] to demonstrate that collagen is notably lost from ivory, and that this organic matter that still remains in the tusk is better preserved in outer parts than in the core. Changes in chemical composition, such as local enrichment/decay in the different elements that compose the tusk, relative proportions of components, and the identification of the structure and composition of eventually neoformed mineral phases, such as pyrite and vivianite, were also determined in this work.

Recovery and characterisation of organic matter, particularly proteins and, more specifically collagen, as the most abundant compound that remains in archaeological and paleontological bone and tooth specimens has been a method frequently used for dating, as have other palaeobiology and palaeoecology studies, such as dies, migration, disease or climate. The determination of the elemental abundance and amino acid profile of collagen is a commonly used indicator of changes caused by diagenesis in the quality of collagen or amino acid razemisation [52,53]. In studies into diagenetic trajectories, different analytical strategies have been applied to identify the organic matter that is still embedding bone bioapatite and, to a lesser extent, ivory, and have established the degree of alteration. A number of papers in the literature have established the compositional changes in the organic fraction due to diagenesis 
112 processes that determine the $\mathrm{C} / \mathrm{N}$ content ratio, along with $\mathrm{C}$ and $\mathrm{N}$ loss, in bone $[30,54]$ and ivory $[28,49]$. In other works, degradation and loss of collagenous material has been studied by determining differences in thermogravimetric curves by TG-DTG [15], or by calculating the relative intensity of phosphate and amide bands from FTIR [28,46,5557] and Fourier transform Raman spectroscopy [30]. Non-collagenous matter in ancient archaeological skeletal remains has been identified by immunological and electrophoresis techniques [52-54,58-60]. Determination of the amino acid profile of ancient bone and teeth, and comparisons with the amino acid profile of collagen from recent specimens, have also been carried out by spectrophotometric [54] gas chromatography [53,57,61-63], the chromatographic/spectroscopic technique [54] and proteomics [64]. We found no works in which the changes in the secondary structure of collagenous material have been studied in association with diagenesis processes. On the other hand, characterisation of lipids in ancient bone has been scarcely provided. The interest shown in studying these compounds is based on their use as palaeodietary markers or as materials used alternatively to detect animal inhumations [65]. The works of Colonese et al [66] and Evershed et al. $[65,67,68]$ are noteworthy which determined total lipids content by gas chromatography-mass spectrometry (GC-MS) [65-68] and gas chromatography-combustion-isotope radio mass spectrometry (GC-C-IRMS) [66]. These studies have shown that lipids are dominated by acyl lipids, such as triacylglycerols and free fatty acids. Cholesterol and its diagenetic degradation products have also been identified in small amounts together with cholesteryl fatty acyl esters [69]. These studies have also aimed to characterise the organic matter that has survived in archaeological remains. Experiments on temporal bone and tooth collagen of surviving organic matter.

The present analytical study was carried out as planned as the first phase of a conservation project which aimed to exhibit the tusks collection after applying an appropriate consolidation treatment based on the plastination method [73-75]. It aimed to offer a better understanding of the diagenesis processes that affected waterlogged 
ivory, found as part of a Phoenician shipwreck cargo (700-600 BC), located in Bajo de la campana (Murcia, Spain) and currently stored in the Museo Nacional de Arqueología Subacuática (Cartagena, Spain). This was done by applying a multi-technique approach based on micro-invasive and non-destructive techniques. The characterisation of the changes in the structure and chemical composition of the inorganic bioapatite and seabed sediment was achieved by conventional XRD, FESEM-EDX, FTIR spectroscopy and spectrophotometry. Besides, FTIR spectroscopy with curve fitting was applied herein to characterise the conformational changes undergone by the proteinaceous material that remained in the waterlogged ivory due to diagenetic processes. The study was completed by determining the amino acid profile and characterising the lipid fraction in the waterlogged tusk by GC-MS.

\section{Experimental}

157

\subsection{The marine archaeological site}

159

Bajo de la campana is one of several archaeological sites included in the archaeological area of Cabo de Palos, located on the continental shelf of the Eastern Spanish coast in the Murcia Region (Spain) between the town of San Pedro del Pinatar and the Palos cape (Latitude: $37^{\circ} 43^{\prime} \mathrm{N}$; Longitude: $00^{\circ} 48^{\prime} \mathrm{W}$ ) (see Figure 1). During the Phoenician period, this southeast Spanish region was a strategic economical enclave given its abundance in metal deposits, which resulted in the development of maritime commercial routes that connected this region with other cities around the Mediterranean Basin.

The geology of the Bajo de la campana site is determined by the coastal plain of Campo de Cartagena, formed by calcareous material from the Quaternary, which is interrupted by volcanic andesitic rocks that outcrop from the Mar Menor Lagoon and the archaeological area of Cabo de Palos [76]. The marine environment of Bajo de la campana is characterised by shallow depths as it is placed on the continental shelf, which hinders the direct influence of oceanic water. Notwithstanding, heavy sea occurs for one third of the year, which promotes the continual mixing of water and high turbidity. A composition of standard seawater is assumed $\left(55.04 \% \mathrm{Cl}^{-}, 30.66 \% \mathrm{Na}^{+}\right.$, 
7.71\% $\mathrm{SO}_{4}{ }^{2-}, 3.65 \% \mathrm{Mg}^{2+,} 1.17 \% \mathrm{Ca}^{2+}, 1.14 \% \mathrm{~K}^{+}, 0.3 \% \mathrm{HCO}^{3-}, 0.2 \% \mathrm{Br}^{-}, 0.04 \% \mathrm{CO}_{3}^{2}$ - and $0.023 \% \mathrm{Sr}^{2+}$ ) [77] and $\mathrm{pH}$ over 8 . The seawater of this region has temperatures that range from 14.4 to $27.9^{\circ} \mathrm{C}$, with a mean salinity of $37 \mathrm{~g} / \mathrm{L}$ [78].

The elemental, anionic and mineralogical composition of slime materials found in the pulp cavity of the tusk associated with seabed sediments, obtained by FESEM-EDX, spectrophotometry, XRD and FTIR spectroscopy is summarised in Table 1. The highest wt\% value found by FESEM-EDX was for $\mathrm{Ca}$, followed by $\mathrm{Si}$. $\mathrm{Na}, \mathrm{Mg}, \mathrm{Al}, \mathrm{S}, \mathrm{Cl}, \mathrm{K}$ and Fe were also present in amounts below $5 \mathrm{wt} \%$. The XRD and FTIR analyses (see Table 1 a supplementary electronic material) enabled the identification of aragonite, calcite, and quartz, accompanied by gypsum, bassanite and small amounts of plagioclase. A complementary spectrophotometry analysis confirmed the presence of $1.63 \mathrm{wt} \%$ of $\mathrm{Cl}$, probably in the form of chloride salts. This analysis also indicated that $\mathrm{S}$ was present mainly as sulphate $\left(\mathrm{SO}_{4}{ }^{2-}, 2.11 \mathrm{wt} \%\right)$. Interestingly, a number of small-sized pyrite framboids was also recognized in sediments through FESEM examination. It is wellknown that these particles commonly form in slightly anoxic bottom waters or on the oxic/anoxic boundary [79-81].

\subsection{Description of the archaeological materials studied}

The present research was performed on one elephant tusk from a collection of 53 pieces found as part of a Phoenician shipwreck cargo (700-600 BC), located in Bajo de la campana (Murcia, Spain). This ancient merchant ship transported raw materials and manufactured goods and luxury items [82]. Tusks were recovered from the seabed between 2007-2011 by the Museo Nacional de Arqueología Subacuática as part of a project supported by the Spanish Ministry of Culture and the Institute of National Archaeology of Texas (USA). Currently, the tusks collection is stored in the Museo Nacional de Arqueología Subacuática (Cartagena, Spain).

The studied tusk retrieved from a wreck, Inv. No. SJBC_11_2471, is $21 \mathrm{~cm}$ long and weighs $408 \mathrm{~g}$ (Fig. 2a, in color in supplementary material). Macroscale biological colonisation on the external tusk surface was almost absent. Characteristic formations associated with colonisation were almost absent on the tusk, probably due to the fact 
210 that it was buried in the seabed and these biological organisms had no easy access to it.

211 Nevertheless, microplankton remains, namely coccolithophores and diatomea, were 212 identified on the ivory by a microscale tusk study (vide infra). It is worth mentioning 213 that other tusks from the collection, which were partially buried in the seabed, exhibited 214 characteristic formations associated with colonisation, such as channels excavated by 215 polychaeta or porifera (sponges) and litophaga mollusks [83]. The studied tusk conserved most of the outer cementum layer (see Fig. 2a), which exhibited a uniform orange-brownish colour. Where the cementum layer was lost, the ivory was dyed a dark blackish colour. The external tusk surface evidenced crevasses and longitudinal cracks and, eventually, small white concretions. The ivory in a transverse section obtained from the tusk (Figure $2 \mathrm{~b}$ ) showed strong discoloration and some radial cracks that ran inwardly to the inner ivory layer. Circular cracks were centred on the tusk axis, particularly in the junction between the ivory and the cementum, and were all easily distinguishable as they were filled with black-greyish microcrystalline materials.

It is also noteworthy that the archaeological site is found in an area owned by the Spanish Ministry of Defence, which is used as a shooting range where military manoeuvres have been performed since 1950. A number of companies frequently recover and recycle scrap from the remains of other modern shipwrecks near the archaeological sites. These tasks include, among others, controlled explosions. All these activities, which have been performed until tusks were recovered between 2007 and 2011, could contribute to the damage evidenced on them as a result of the detachment of stone fragments and increased seawater turbidity.

After the archaeological tusks had been recovered, they were subjected to treatment that consisted in removing the materials deposited on the surface, as well as the sediments inside the pulp cavity. Then tusks were transferred to cisterns that contained a mixture of seawater $(75 \%)$ and spring water $(25 \%)$ and remained in them for 8 weeks. These waters were successively changed to 50\%:50\% and 25\%:75\%, and 100\% spring water at 8-week intervals. Afterwards, a second series of changes in water composition was carried out by progressively adding deionised water in increasing proportions, starting with $25 \%$ deionised water and $75 \%$ spring water, and after 8 weeks, 50\%:50\% and 
25\%:75\% and 100\% deionised water. Tusks are currently stored immersed in pure deionised water.

\subsection{Sample preparation}

According to prior analytical studies carried out on the buried and waterlogged archaeological tusks $[28,46,49]$, the main criteria for sampling were: a) characterisation of the mineral phases in the different parts of the tusk, namely ivory, cementum and b) characterisation of the organic matter that still remained in tusk. The analytical study was performed on a transverse section of the tusk, obtained with a saw (see Fig. 2b). Several microsamples were excised using a scalpel and needles from different parts of the transverse section. Figure 3 (in color in supplementary material) shows the sampling points: DA samples were excised from the ivory core (ivory) (Fig. 3a), CAI samples were excised from the inner part of the cementum layer (Fig. 3b), CAO samples were excised from the external surface of the cementum layer (Fig. 3b) and DCJ samples were excised from the black-greyish material deposited inside the fissures formed in the ivory-cementum junction (Fig. 3a). This material was also infiltrated in some radial fissures, which formed as a result of the diagenesis processes undergone by tusks. In parallel, the samples excised in the ivory (DM) and the cementum layer (CM) from the transverse section of a modern elephant tusk were analysed and used as reference material for comparative purposes. The modern tusk was provided by Mercedes Lasso Liceras, Coordinadora Nacional de la Autoridad Administrativa CITES de España (Subdirección General de Inspección, Certificación y Asistencia Técnica del Comercio Exterior, Dirección General de Comercio e Inversiones, Secretaría de Estado de Comercio del Ministerio de Economía y Competitividad) for scientific purposes. The EC certificate number of this piece is ESAA0000813C, which was obtained from a seizure that resulted from a breach of the Spanish Convenio sobre el Comercio Internacional de Especies Amenazadas de Fauna y Flora Silvestres (CITES) and other Regulations that apply in the European Community.

Samples (DM, CM, DA, CAI and CAO) of a first series were excised with a scalpel and directly mounted on a suitable support for examination by optical microscopy and FESEM-EDX. A cross section of ivory was also prepared by embedding the sample in 
polyester resin and polishing. This sample was also examined and analysed by optical microscopy and FESEM-EDX. Samples (DM, CM, DA, CAI and CAO) of a second and third series, which were analysed by XRD and ATR-FTIR, were finely powdered in an agate pestle and mortar. For the modern ivory and cementum samples, IR spectra were run before and after powdering to ensure that any slight heat produced while using the pestle and mortar did not affect the sample's spectral characteristics. It must be taken into account that the transversal section of the archaeological tusk had to be kept wet to avoid the material from collapsing due to loss of water. For this reason, the samples from the archaeological tusk were air-dried after powdering. Finally, the samples (DM, CM, DA, CAI and CAO) of a fourth series were powdered and then subjected to a hydrolysis procedure prior to the GC-MS analysis.

\subsection{Instrumentation}

Light microscopy.- A Leica GZ6 (X10-X50) stereoscopic light microscope was used to select the samples to be analysed. A Leica DM2500 P polarised light microscope (Leica Microsystems. Heidelberg, Germany) was employed for the morphological examination of the cross section prepared from the archaeological ivory. A Leica Digital FireWire Camera (DFC), with the Leica Application Suite (LAS) software, was used to acquire and process digital images.

Field emission scanning electron microscopy X-ray microanalysis.- Samples were examined under a Zeiss model ULTRA 55 field emission scanning electron microscope, which operated with an Oxford-X Max X-ray microanalysis system. Image acquisition was done at the $3 \mathrm{kV}$ accelerating voltage. The minerals' chemical composition was obtained at the $20 \mathrm{kV}$ accelerating voltage and 6-7 $\mathrm{mm}$ was the working distance for the $\mathrm{X}$-ray detector. Samples were carbon-coated to eliminate charging effects. A semiquantitative microanalysis was carried out by the ZAF method to correct interelemental effects. The counting time was $100 \mathrm{~s}$ for major and minor elements alike. Element percentages were generated by the ZAF method on the Oxford-Link-aztec EDX software, which was performed to exclude $\mathrm{C}$ to avoid erroneous quantification because the signal detected for this element mainly came from the $\mathrm{C}$ coating applied to samples to suppress charge effects. 
309 The average chemical sample composition, which consisted in several microcrystalline 310 mineral phases, corresponded to the mean value obtained from the triplicate 311 semiquantitative measurements taken from a sample area at ca. 50-100 $\mu \mathrm{m}^{2}$. The 312 application of the ZAF method of semiquantification to the measurements taken in the 313 sample areas provided a zero-rated wt\% value for some elements due to their low 314 content. Standard deviation values (SD) were obtained from the individual 315 measurements taken from different sample areas. SD values are indicative of the 316 variability of the distribution of each element along the sample and, therefore, of the 317 degree of microheterogeneity of the analysed materials. In parallel, the spot analyses 318 (s.a.) that consisted in taking punctual measurements on individual grains and 319 aggregates enabled some diagenetic processes of the apatitic lattice to be recognised, the 320 elements present in the sample in small amounts to be identified and, in some cases, the 321 stoichiometry of the material that composed the grain to be determined. The EDX measurement errors were estimated to be between $5-1 \%$. The limit of detection (LOD) for the studied elements was $0.01 \%$. Clay standards were used to check the FESEMEDX measurements.

\section{X-ray diffraction}

327 Instrumentation.- XRD diffractograms were acquired by a Bruker D8 Advanced A25 328 diffractometer equipped with a Lynxeye fast detector. XRD patterns that covered 5-80 $2 \theta$ were collected in an exposure time of $0.8 \mathrm{~s}$. $\mathrm{Cu} \mathrm{K} \alpha$ radiation was used $(40 \mathrm{kV}$ and 40 $\mathrm{mA})$. The diffrac 3.1 software was used to process diffractograms.

Crystallinity index $(C I)$.- The CI is a parameter that provides an estimate of the degree of crystallinity (measure of the crystal size and homogeneity [84]), in such a way that the degree of order of the bioapatite structure increases when the CI value is higher. The CI for the series of studied samples was calculated herein following the method proposed by Pearson et al. [84]. According to these authors, the CI is defined as:

$$
\mathrm{CI}=\frac{\sum\{\mathrm{H}[202], \mathrm{H}[300], \mathrm{H}[112]\}}{\mathrm{H}[211]}
$$


where $H[202], H[300], H[112]$ and $H[211]$ are the heights of the diffraction peaks that correspond to reflections [202], [300], [112] and [211], calculated after subtracting the baseline taken between $34.5^{\circ}$ and $40.5^{\circ}$.

\section{FTIR spectroscopy}

Instrumentation.- FTIR spectroscopy in the ATR mode was considered a suitable technique for studying bone and tooth $[85,86]$. The IR spectra in the ATR mode of the tusk samples were obtained in a Vertex 70 (Bruker Optik GmbH, Germany) Fouriertransform infrared spectrometer with an FR-DTGS (fast recovery deuterated triglycine sulphate) temperature-stabilised coated detector and a MKII Golden Gate Attenuated Total Reflectance (ATR) accessory. Thirty-two scans were collected at a resolution of 4 $\mathrm{cm}^{-1}$ and spectra were processed by the OPUS 5.0/IR software (Bruker Optik GmbH, Germany).

Composition monitoring.- An analysis of the IR bands ascribed to proteinaceous matter, carbonate and phosphate groups, can provide complementary information about the structural aspects of both the organic and inorganic parts of ivory, bone and tooth, and their diagenetic changes, such as degradation and loss of organic matter, precipitation of secondary minerals, uptake of exogenous ions like carbonate or processes such as dissolution and recrystallisation (Ostwald ripening [55,87]), which result in modified degrees of biapatite lattice crystallinity. Ante-mortem processes of ivory, bone and teeth ivory maturation, which take place over a lifetime with progressive hydoxyapatite nanocrystal growth, can also be considered by this method [29,88-92]. One of the most important properties of these nanocrystals is their high specific surface area, which contributes to the reactivity of nanocrystals $[88,89]$. This hydrated layer is characterised by the presence of bivalent ions $\left(\mathrm{CO}_{3}{ }^{2-}, \mathrm{HPO}_{4}{ }^{2-}, \mathrm{PO}_{4}{ }^{3-}, \mathrm{Ca}^{2+}\right.$, etc. $)$, which lies in the socalled non-apatitic environments associated with less stable locations than those of the apatitic lattice $[88,89,93,94]$. It has been demonstrated that the ionic replacement of $\mathrm{PO}_{4}{ }^{3-}$ ions with $\mathrm{CO}_{3}{ }^{2-}$, or $\mathrm{Ca}^{2+}$ with $\mathrm{Mg}^{2+}$ and $\mathrm{Sr}^{2+}$, in the hydrated layer on the surface of nanocrystals takes place over a specimen's lifetime (bone, tooth, ivory)[91]. The above-mentioned diagenetic processes of dissolution/recrystallisation, which involve ion exchange and changes in the degree of perfection of the bioapatite lattice and crystal size, can also be monitored by considering the differences in the composition of this 
hydrated layer [95]. The relative intensities and peak areas of the IR bands provided by the OPUS 5.0/IR software enabled the calculation of several indices associated with the structural properties linked to the state of preservation of the different materials that composed the tusk:

a) Carbonate to phosphate ratio $(C / P)$.- An estimate of the relative carbonate content in each tusk sample can be obtained from the peak area $[29,96]$ or the intensity ratio $[28,29,31,46,85,95,97]$ of the $v_{3}\left(\mathrm{CO}_{3}\right)$ to $v_{3} v_{1}\left(\mathrm{PO}_{4}\right)$ band ascribed to carbonate and phosphate, respectively (Fig. 4a). This parameter has been related to the chemically measured carbonate/phosphate content [96]. In this study, the C/P ratio was calculated by measuring the peak area of the $v_{3}\left(\mathrm{CO}_{3}\right)$ band $\left(1540-1340 \mathrm{~cm}^{-1}\right)$ to the $v_{3} v_{1}\left(\mathrm{PO}_{4}\right)$ band $\left(1160-900 \mathrm{~cm}^{-1}\right)$, for which the best linear regression between band area ratios and the carbonate content of apatite standards has been reported [96].

b) Carbonate content.- The quantitative assessment of the carbonation level of apatitic materials can be made with the C/P index by the linear correlation by Grunenwald et al. [96] between the absolute carbonate content in a bioapatite expressed as wt\% and the $\mathrm{C} / \mathrm{P}$ index given by this equation:

$$
\mathrm{wt} \% \mathrm{CO}_{3}=28.62 \mathrm{C} / \mathrm{P}+0.0843
$$

c) $v_{1} v_{3} \mathrm{PO}_{4}{ }^{3-}$ domain. -The broad band within the $900-1200 \mathrm{~cm}^{-1}$ range is associated with the symmetric $\left(v_{1}\right)$ and antisymmetric $\left(v_{3}\right)$ P-O stretching vibrations of the $\mathrm{PO}_{4}{ }^{3-}$ group. Prior studies have established correlations between mineral composition and the underlying components of the band. Subdomain $1020-1100 \mathrm{~cm}^{-1}$ is associated with phosphate groups in apatitic environments, whereas subdomain $1100-1200 \mathrm{~cm}^{-1}$ is associated with non-apatitic environments and $\mathrm{HPO}_{4}{ }^{2-}$ (Fig. 4b) $[89,90,92,95]$.

- $I_{1030} / I_{1020}$ ratio. - Calculated as the relative intensity [95] or the peak area [92] of the individual bands measured after the curve fitting process on the $v_{3} v_{1}\left(\mathrm{PO}_{4}\right)$ band. The band at $1020 \mathrm{~cm}^{-1}$ has been correlated with non-stoichiometric apatites that contain $\mathrm{CO}_{3}{ }^{2-}$ and/or $\mathrm{HPO}_{4}{ }^{2-}$ and most inmature systems [29], while the band at $1030 \mathrm{~cm}^{-1}$ has 
been correlated with phosphates in stoichiometric apatites [89,90,92,95] and becomes more significant for mature systems [29]. In this study, the $\mathrm{I}_{1030} / \mathrm{I}_{1020}$ ratio was calculated by measuring the peak area of the individual band at $1030 \mathrm{~cm}^{-1}$ to the individual band at $1020 \mathrm{~cm}^{-1}$, obtained after the curve fitting of the $v_{3} v_{1}\left(\mathrm{PO}_{4}\right)$ band (see Fig. $4 \mathrm{~b}$ and table $1 \mathrm{~S}$ in supplementary electronic material).

The curve fitting process applied to the $v_{3} v_{1}\left(\mathrm{PO}_{4}\right)$ band started by subtracting the protein bands in the IR spectra of all the studied samples in order to avoid erroneous calculations due to the contribution of protein bands that overlapped the phosphate band $[89,90,92,95]$. Afterwards, the positions of the overlapped IR bands, which appeared as shoulders of the $v_{3} v_{1}\left(\mathrm{PO}_{4}\right)$ band, were made to correspond to the frequency of the minima in the second derivative of the undeconvolved spectra with a 9-point SavitskyGolay smoothing filter. The selected band frequency values, which agreed with the former study of Gadaleta et al. [90], were further used as starting parameters for the curve fitting analysis. Prior to curve fitting, a straight base line that passed through the ordinates on the left- and right-hand sides of the band was subtracted [98]. The Levenberg-Marquardt algorithm was used for the curve fit of the Gaussian band shape profiles. This band shape function was used herein as it yields slightly better results than the Lorentzian band shape function. The base line was remodified by the least-squares curve-fitting programme, which allows for a horizontal baseline to be adjusted as an additional parameter to obtain the best fit.

$-\mathrm{HPO}_{4}{ }^{2-}$ content.-Acid phosphate content was evaluated by measuring the area ratio of the subdomains of the $v_{3} v_{1}\left(\mathrm{PO}_{4}\right)$ band within the ranges $1100-1020 \mathrm{~cm}^{-1}$ (apatitic environment $\mathrm{PO}_{4}{ }^{3-}$ ) and $1150-1100 \mathrm{~cm}^{-1}$ (non-apatitic environment and $\mathrm{HPO}_{4}{ }^{2-}$ ) from the IR spectrum of the samples with the method suggested by Lebon et al. [95]. Curve fitting procedure applied to the $v_{3} v_{1}\left(\mathrm{PO}_{4}\right)$ band followed to obtain the $\mathrm{I}_{1150-1100} / \mathrm{I}_{1100-1020}$ ratio was described in the above section.

d) $v_{4} \mathrm{PO}_{4}^{3-}$ domain.- The $v_{4}$ mode gave two main bands at 605 and $565 \mathrm{~cm}^{-1}$ with a shoulder at $575 \mathrm{~cm}^{-1}$ (Fig. $4 \mathrm{c}$,d) which were associated with the phosphate groups in the apatitic environments, a shoulder at $c a .617 \mathrm{~cm}^{-1}$ were associated to phosphate groups in 
437 the non apatitic environments while the bands at 550 and $530 \mathrm{~cm}^{-1}$ were assigned to $438 \mathrm{HPO}_{4}{ }^{2-}$ in the apatitic and non-apatitic environments (Fig. 4c) according to other 439 studies [88,91].

440

441 - Infrared splitting factor (IRSF).- This parameter, also the so-called crystallinity index, 442 is a measurement of the degree of crystallinity, which is related to the relative size of 443 crystals and the degree to which the atoms in the lattice are ordered [99]. The degree of 444 crystallinity of bioapatite can be quantified in terms of the degree of individualisation of 445 the IR bands that form the main doublet of stretching vibration $v_{4}\left(\mathrm{PO}_{4}\right)$ at 565 and 605 $446 \mathrm{~cm}^{-1}$ (Fig. 4d). According to the procedure proposed by Weiner and Bar-Yosef [100] 447 and Shemesh [101], based on a former work of Termine and Posner [102], the IRSF is defined by this mathematical expression:

449

$$
\operatorname{IRSF}=\frac{(a+b)}{c}
$$

451

where $a$ and $b$ are the heights of the IR bands at 605 and $565 \mathrm{~cm}^{-1}$. The $c$ value is the height of the valley between both IR bands. The baseline was drawn between the closest minima on either side of the measured peaks (at ca. 495 and $750 \mathrm{~cm}^{-1}$, respectively).

- Ratio of the relative amounts of the apatitic and non-apatitic hydrogenphosphate

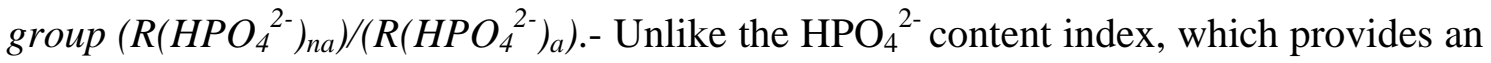
estimate of the total amount of $\mathrm{HPO}_{4}{ }^{2-}$ present in the sample, this parameter enables a picture of the distribution of $\mathrm{HPO}_{4}{ }^{2-}$ between non-stoichiometric apatitic and nonapatitic environments (hydrated layer) [88,91]. The relative amounts of apatitic and non-apatitic $\mathrm{PO}_{4}{ }^{3-}$ and $\mathrm{HPO}_{4}{ }^{2-}$ were calculated as the quotient between the band areas assigned to each species and the total area of the $v_{4}\left(\mathrm{PO}_{4}\right)$ band. A similar procedure to that applied to the $v_{3} v_{1}\left(\mathrm{PO}_{4}\right)$ band was followed, which was based on calculating the areas of the individual bands obtained after the curve fitting process on the $v_{4}\left(\mathrm{PO}_{4}\right)$ band following the procedure proposed in other studies [29,91] (Fig. 4c and see also table $2 \mathrm{~S}$ in supplementary electronic material). 

materials in the samples can be obtained from the peak area [29] or intensity ratio $[35,55-57,86,92,95,97]$ of amide $\mathrm{I}$ to the $v_{3} v_{1}\left(\mathrm{PO}_{4}\right)$ band ascribed to proteinaceous matter and phosphate, respectively (Fig. 4a). In this study, the PM/P ratio was calculated by integrating the areas under the peaks at $1720-1585 \mathrm{~cm}^{-1}$ (amide I) and $1160-900 \mathrm{~cm}^{-1}\left(v_{3} v_{1}\left(\mathrm{PO}_{4}\right)\right)$.

f) Secondary structure of proteins.-The positions of the overlapped IR bands, which appeared as the shoulders of amide I band in the IR absorption spectra of the samples from tusks, were made to correspond to the frequency of the minima in the second derivative of the undeconvolved spectra with a 9-point Savitsky-Golay smoothing filter. The values of the selected band frequencies were further used as starting parameters for the curve fitting analysis. In a second step, Fourier self-deconvolution (FSD) of the IR spectra was performed using the Lorentzian line shape. Apodisation by the BlackmanHarris function was always performed automatically in the software at the same time. FSD was performed using a bandwidth at a half height of $13 \mathrm{~cm}^{-1}$ and a resolution enhancement factor of 2.4. These values, commonly used to semiquantitatively estimate protein secondary structures [103-105], were selected in an attempt to avoid possible indistinguishable random noise artifacts from the bands that appeared in the samples $[98,105]$. Prior to curve fitting, a straight base line that passed through the ordinates on the left- and right-hand sides of the band was subtracted [98]. Curve fitting was performed in a final step. As previously mentioned, the number and position of the fitted bands were taken by combining the peaks found in the deconvolved spectrum and the second derivative spectrum. The Levenberg-Marquardt algorithm was used for the curve fit of the Gaussian band shape profiles. This band shape function was used as it yields slightly better results than the Lorentzian band shape function. The base line was remodified by the least-squares curve-fitting programme, which allows for a horizontal baseline to be adjusted as an additional parameter to obtain the best fit. For amide I band, the areas of all the bands assigned to a given secondary structure were summed up and divided by the total area. The number obtained in this way was taken as the proportion of the protein chains in that conformation. The assignation of wavenumber intervals to each conformation was performed as set out in the literature $[98,103$, 500 $106,107]$. 
502 Spectrophotometer.- Spectrophotometer Spectroquant Nova 60 (Merck) was used: test 503 for $\mathrm{Cl}^{-}$with a detection range between 2.5-250 mg. $\mathrm{L}^{-1}$, test for $\mathrm{NO}_{3}{ }^{-}$with a detection 504 range between 10-500 mg. $\mathrm{L}^{-1}$ and test for $\mathrm{SO}_{4}{ }^{2-}$ with a detection range between 25-300 505 mg. $\mathrm{L}^{-1}$.

506

507 Gas chromatography-mass spectrometry.-

508 Reagents.- $\mathrm{HCl}$, chloroform, ethyl chloroformate, pyridine, ethanol, N,O509 Bis(trimethylsilyl)trifluoro-acetamide (BSTFA) and trimethylchlorosilane (TMSCS) 510 were supplied by Sigma.

511

512 Instrumentation.- Gas chromatograph Agilent 6890N (Agilent Technologies, Palo Alto, 513 CA, USA) was coupled to an Agilent 5973N mass spectrometer (Agilent Technologies) 514 and used. A capillary column HP-5MS (5\% phenyl-95\% methylpolysiloxane, $30 \mathrm{~m}$, $5150.25 \mathrm{~mm}$ i.d., $0.25 \mu \mathrm{m}$ film thickness, Agilent Technologies) was used to adequately 516 separate components. Samples were injected in the split mode (split ratio 1:20). 517 Chromatographic conditions were: initial temperature of $50^{\circ} \mathrm{C}$ held for 2 min, increased 518 by $20^{\circ} \mathrm{C} \cdot \mathrm{min}^{-1}$ up to $300^{\circ} \mathrm{C}$ and held for $30 \mathrm{~min}$. The helium gas flow was set at 1.3 519 mL. $\min ^{-1}$. Electronic pressure control was set to the constant flow mode with vacuum 520 compensation. Ions were generated by electron ionisation $(70 \mathrm{eV})$. The mass 521 spectrometer was scanned from m/z 20 to $\mathrm{m} / \mathrm{z} 800$ in a 1-second cycle time. Mass 522 spectrometer tuning was checked using perfluoro-tributylamine. EI mass spectra were 523 acquired by the total ion monitoring mode. The interface and source temperatures were $524280^{\circ} \mathrm{C}$ and $150^{\circ} \mathrm{C}$, respectively. Agilent Chemstation software G1701CA MSD was used 525 for the GC-MS control, peak integration and mass spectra evaluation. Wiley Library of 526 Mass Spectra and NIST were used to identify compounds. Proteins and lipids were 527 analysed by the hydrolysis procedure, followed by derivatisation with ethyl 528 chloroformate, as described elsewhere [108]. $1.5 \mu \mathrm{L}$ of the chloroformic solution were 529 injected into the GC-MS system. Possible presence of cholesterol was checked by a 530 second series of analyses performed directly on the samples. Demineralisation was not 531 performed to preserve lipid extract integrity. Derivatisation was carried out by adding $53212 \mu \mathrm{L}$ of BSTFA and $6 \mu \mathrm{L}$ of TMSCS to about $10 \mathrm{mg}$ of sample. After $1 \mathrm{~h}$ at $70^{\circ} \mathrm{C}$, 533 samples were concentrated to near dryness under a $\mathrm{N}_{2}$ stream to eliminate any excess 
derivatisation reagent. Finally, $50 \mu \mathrm{L}$ of chloroform were added and $1.5 \mu \mathrm{L}$ of the chloroformic solution were injected into the GC-MS system.

The chromatograms for DM, DA, and CA were obtained according to the procedure described above. The results obtained are presented thereafter. The chromatogram obtained in sample CM was of poor quality, which we attributed to the smaller amount of sample obtained given the difficulty of mechanically separating the necessary amount of this thin layer (at $c a .0 .5 \mathrm{~mm}$ ) without contaminating the sample with ivory. Therefore, we did not present the results of this sample.

\section{Results and Discussion}

\subsection{Micromorphological features}

Figure 3a shows the layered morphology of the transverse section of the wreck-derived tusk observed by optical microscopy. A Schreger pattern is seen in the creamy-white ivory region (Fig. 3a). According to the measurements taken by the image analysis on microphotographs, a tentative ascription to a modern taxa proboscidea was carried out [109] and a more precise analysis is currently underway. As seen in Fig. 3b the outer cementum part was orange-brownish, whereas the internal cementum layer part was lighter in colour. The average thickness of the cementum layer ranged between 1200 to $400 \mu \mathrm{m}$. On the external tusk surface, crevasses and longitudinal cracks were observed and, eventually, white concretions (Fig. 2a). A fracture formed radially, which started on the external surface and connected other fissures which developed along the incremental layers, had been dyed black from the infiltration of exogenous materials (Fig. 2b). The ivory-cementum junction (DCJ) was also filled with a black-greyish microcrystalline matter (Fig. 2b and Fig. 3a). Occasionally the outer part of the ivory layer (DA) was dyed orange-brown or black (Fig. 3a). The latter was observed in more detail by examining a cross section prepared from a sample taken from the outer ivory part. An optical microphotograph of the cross section taken using polarised light (Fig. 5a) showed that the ivory was dyed orange-brown at a depth of $c a .300 \mu \mathrm{m}$, and black microcrystals appeared to infill the ivory underneath at a depth of $c a .1150 \mu \mathrm{m}$. 
568 The FESEM examination of samples excised from the different layers of both modern and archaeological tusks enabled a comparison to be made of the micromorphologies of the ivory and cementum of both tusks. Figures 6a-d shows the micromorphology of the ivory layer of the modern and archaeological tusks. The modern tusk exhibited a 572 characteristic collagenous fibrilar structure for the ivory (Fig. 6a). Lumina or cross573 sectioned dentinal tubules were recognised as semicircular shaped voids with a diameter of a few $\mu \mathrm{m}$. These same morphological structures were observed in the archaeological ivory (Fig. 6b). Figures 6c,d show details of the fibrous structure of the ivory of both tusks, with intertubule spacing falling within the 3-18 $\mu \mathrm{m}$ range for the modern specimen, and 3-12 $\mu \mathrm{m}$ for the archaeological one. Collagen fibrils were clearly distinguishable in the modern dentin, whose width was 50-100 nm (Fig. 6c) according to former studies by other authors [42]. Interestingly, the fibrils in the archaeological ivory seemed to have lost part of their characteristic fibrous morphology (Fig. 6d). Figure $5 \mathrm{~b}$ shows the micromorphology of the ivory in the ivory-cementum junction. The straight channels ascribed to the longitudinally sectioned dentinal tubules [40] can be seen. Coccoliths, which are individual plates of calcite that form external mineralised structures (coccospheres) of marine algal coccolithophores, also infilled the outer ivory part (Fig. 5b). Diatomea of the genus navicula (see Fig. 1S provided as supplementary electronic material) were also identified in the ivory of the tusk studied on the microscale to infiltrate the outer part of the ivory. Abundant black pyrite microcrystals (Fig. 5a,c) infilled the ivory at a depth of between 300 and $1150 \mu \mathrm{m}$. Figure 7 shows the outer cementum surface of the modern (Fig. 7a) and archaeological (Fig. 7b) tusks. The modern cementum exhibited a smooth outer surface with characteristic striations, whereas the external surface of the archaeological cementum seemed microeroded. Microalveoli were observed, with diameter of a few $\mu \mathrm{m}$, probably caused by marine colonisation organisms. A similar alveolar structure showed the cementum layer of the archaeological tusk on its inner surface to have come into contact with the materials deposited in the ivory-cementum junction (Fig.7c,d). Small rounded apatitic grains within the 1-2 $\mu \mathrm{m}$ range (Fig. $7 \mathrm{c}$ and Fig. 8a) and protoframboids of pyrite $(1-10 \mu \mathrm{m})$ [81,110] (Fig. 7d and Fig. 8b) filled most alveoli. 


\subsection{Elemental composition}

602

Table 2 summarises the averaged elemental composition of the major and minor

604

605

606

607

608

609

610

611

612

613

614

615

616

617

618

619

620

621

622

623

624

625

626

627

628

629

630

631

632 elements detected in triplicate areas of the samples (at ca. 50-100 $\mu \mathrm{m}^{2}$ ) of the modern and wreck tusks obtained by FESEM-EDX. Higher values for both $\mathrm{Ca}$ and P contents were found in the cementum than in ivory layer of the modern tusk. A comparison made between the values of the elemental composition of both the modern and archaeological tusks suggested that some compositional change had taken place in the archaeological tusk. A slightly higher content was found for P in the ivory layer (14.3 wt\%) whereas a lower content was found for $\mathrm{P}$ in cementum layers (10.7 wt\% and $11.8 \mathrm{wt} \%)$ of the archaeological tusk compared with the value found in the modern tusk (13.5 wt $\%$ and $14.6 \mathrm{wt} \%$, respectively). Reduced P content can be associated with phosphate depletion or/and carbonate substitutions for phosphate. A notable increase in Ca content (34.5 wt $\%$ ) was found in the ivory layer of the archaeological tusk compared with that found in the modern ivory (19.7 wt\%), whereas a moderate increase at ca. 4-5 wt\% was observed for the cementum layers. This Ca enrichment of ivory and, to a lesser extent, of the cementum, would be associated with authigenic materials that infilled all the tusk parts, particularly calcite and aragonite, and remains of coccolithophores. Diagenetic processes that resulted in the disaggregation of the apatitic structure also seemed to have taken place in the cementum. Figures 8a,b show the backscattered electron images of both the inner and outer cementum layer surfaces, in which small rounded apatitic grains, accompanied by pyrite protoframboids, were visible. The spot analyses performed by FESEM-EDX showed differences between the chemical composition of the alveolar surface of the apatitic bulk and the small rounded apatitic grains (data summarised in Table 3). When we compared the composition of the bulk and grains, grains were depleted in $\mathrm{Na}, \mathrm{Mg}, \mathrm{P}$ and $\mathrm{Ca}$, enriched in $\mathrm{Si}$, and also exhibited variable behaviour for F. S and Fe contents were associated with spurious X-ray emission from the surrounding pyrite framboids. A comparison of the data in Table 2 and Table 3 suggested that the averaged chemical composition of cementum was mostly the result of the contribution of both the bulk bioapatite and the disaggregated grains, along with that of authigenic minerals. 
633 The values reported for $\mathrm{Ca}$ and $\mathrm{P}$ content determined the values of the $\mathrm{Ca} / \mathrm{P}$ molar ratios

634 (Tables 2 and 3) calculated for the different layers of both tusks. Firstly, we should note

635

636

637

638

639

640

641

642

643

644

645

646

647

648

649

650

651

652

653

654

655

656

657

658

659

660

661

662

663

664

665

that the $\mathrm{Ca} / \mathrm{P}$ ratio values for the modern tusk $\left(\mathrm{Ca} / \mathrm{P}_{\text {ivory }}: 1.13, \mathrm{Ca} / \mathrm{P}_{\text {cementum: }}\right.$ 1.30) fell below the theoretical stoichiometric value for calcium hydroxylapatite (1.67). The $\mathrm{Ca} / \mathrm{P}$ ratios below the theoretical stoichiometric value of 1.67 have been found in other studies for modern ivory $\left(\mathrm{Ca} / \mathrm{P}_{\text {ivory }}: 1.15, \mathrm{Ca} / \mathrm{P}_{\text {cementum: }} 1.22\right)[28]$ and bone $(\mathrm{Ca} / \mathrm{P}: 1.48)$ [29]. These low values agree with the values reported in the present study and indicate the non-stoichiometry of the apatite phase in these modern tusks. These values may be consistent with the general formulae of bony apatite $\mathrm{Ca}_{(1-\mathrm{x})} \square_{\mathrm{x}}\left(\mathrm{PO}_{4}\right)_{(1-}$ y) $\left(\mathrm{HPO}_{4}, \mathrm{CO}_{3}\right)_{\mathrm{y}}(\mathrm{OH})_{(1-\mathrm{z})} \square_{\mathrm{z}}[\mathrm{x}]$, if prevalent $\mathrm{PO}_{4}{ }^{2-}$ substitution is assumed.

The $\mathrm{Ca} / \mathrm{P}$ ratio value increased in all the archaeological samples compared with their counterparts in the modern tusk (see Table 2). Thus a value of 1.86 was found for the archaeological ivory, and values of 2.10 and 1.85 were obtained in the inner and the outer archaeological cementum, respectively. Values up to 1.67 confirmed that replacement of phosphate ions with carbonate ions (type B substitution) could have occurred in the archaeological tusk. Nevertheless, we should consider that presence of authigenic minerals, such as calcium carbonate that infills all tusk layers, which were identified by FESEM-EDX, also contributes to deviate the $\mathrm{Ca} / \mathrm{P}$ values found in the tusk from ideal values.

Table 3 shows the $\mathrm{Ca} / \mathrm{P}$ ratios calculated from the spot analyses performed on the alveolar apatitic bulk and the small apatitic grains that composed both the cementum sublayers. Interestingly, the apatitic bulk gave values of 1.78 and 1.76 , which were slightly higher than those for ideal calcium hydroxyapatite, whereas higher values of up to 2 were reported in grains. It is worth noting that the apatitic grains identified in the cementum exhibited the highest $\mathrm{Ca} / \mathrm{P}$ molar ratio, indicative that the replacement of phosphate ions with carbonate ions should take place more extensively in these features.

The average $\mathrm{Ca} / \mathrm{P}$ ratios (see Table 2) obtained in the Bajo de la campana tusk (DA: 1.86 and CA: 1.85 and 2.10) fell within the same range as those reported in other studies into waterlogged ivory and bone. Alberich et al. [49] reported higher values for the $\mathrm{Ca} / \mathrm{P}$ molar ratios than that of an ideal apatite $\left(\mathrm{Ca}_{10}\left(\mathrm{PO}_{4}\right)_{6}(\mathrm{OH})_{2}, \mathrm{Ca} / \mathrm{P}: 1.67\right)$ within the 1.78- 
1.86 range in blue-dyed parts of ivory of three waterlogged tusks. Arnaud et al. [36] reported values within the 1.67-1.79 range for waterlogged bone. In contrast, Alberich et al. [49] and Godfrey et al. [28] found lower values, 1.51 and 1.62, respectively, in orange-dyed and non-dyed parts of waterlogged ivory. Values that fell below and over the theoretical stoichiometric value of 1.67 have also been obtained by Grunenwald et al. [29] (Ca/P ranging between 1.48-1.83) for a series of buried bones and teeth.

The comparison made of $\mathrm{Mg}$ content between the modern and archaeological tusks (see Table 2) showed less $\mathrm{Mg}$ content in the latter for both the ivory and cementum layers. This suggests that leaching of this ion has taken place due to its high-mobility $[3,28]$. The lowest values found in ivory $(0.41 \mathrm{wt} \%)$ have been attributed to the most porous microstructure exhibited by this layer, with abundant dentinal tubules, which favours the migration of soluble species. Similar behaviour has been reported in waterlogged ivory [28,49] and bone [79].

The uptake of elements from the marine environment was also observed. $\mathrm{K}$ is recognized in spot analyses performed on grains of authigenic potassium feldspars infilling ivory. This same origin is attributed for the average $\mathrm{K}$ content $(0.07 \mathrm{wt} \%)$ found in cementum as this element is not found in spot analysis performed on the apatitic bulk. Other ions presenting high mobility andsolubility in seawater have been adsorbed at the tusk. Enrichment in $\mathrm{Na}$ was found in both the archaeological ivory $(0.51$ wt $\%)$ and the cementum $\left((0.63\right.$ and $0.70 \mathrm{wt} \%)$. Protonation of $\mathrm{PO}_{4}{ }^{3-}$ and $\mathrm{OH}^{-}$on the surface of the crystals of bioapatite can open up the lattice to substitution for $\mathrm{CO}_{3}{ }^{2-}$, which may allow other anions, such as $\mathrm{F}^{-}$or $\mathrm{Cl}^{-}$, instead of $\mathrm{OH}^{-}[49,111]$. $\mathrm{Cl}$ was also identified in the ivory of the archaeological tusk (0.02 wt \%). Presence of F in all the layers of the archaeological specimen at a significant concentration (0.6 wt\% in ivory and 0.8-1.4 wt\% in cementum) was quite remarkable. Hydroxyapatite readily takes up fluorine as fluoride ions, and is transformed into the more stable and water insoluble fluorapatite (FAP, $\left.\mathrm{Ca}_{5}\left(\mathrm{PO}_{4}\right)_{3} \mathrm{~F}\right)$, with a fluorine concentration of 4.8 at\% ( 3.7 wt\%) [13]. Although fluorine content cannot be compared between different sites $[10,12]$, the high values reported herein, and compared to those observed of other studies [12,13], suggest that the studied tusk has been altered by diagenetic processes. This higher $\mathrm{F}$ content value found in the cementum correlated with the increased crystallinity observed 
in this outer layer of the archaeological tusk (vide infra) [1]. Another element whose concentration increased in the archaeological tusk was S. This element was detected in both the ivory $(0.38 \mathrm{wt} \%)$ and cementum layers $(0.51$ and $0.47 \mathrm{wt} \%)$. Its presence in the tusk is associated with pyrite formation, as described thereafter. $\mathrm{Al}$ and $\mathrm{Si}$ were also detected in the cementum sublayers (Al, 0.06 and $0.40 \mathrm{wt} \%$ and $\mathrm{Si}, 0.36$ and $0.85 \mathrm{wt} \%$ ). Presence of $\mathrm{Al}$ is associated mainly with minerals from the volcanic seabed, such as silica or plagioclase, which infilled this layer. These minerals were identified in the materials deposited in the ivory-cementum junction and in the sediments deposited in the pulp cavity. Although most Si content has been associated with authigenic minerals, the identification of this element in the spot analyses that have been performed on the alveolar apatitic bulk of cementum and apatitic micrograins suggests that some Si may be integrated into the apatitic lattice as silicate ions, which substitute phosphate ones [112].

A number of metallic elements was found in the outer cementum layer. Among them, iron had the highest concentration $(0.57-0.69 \mathrm{wt} \%)$. It is likely that this higher iron level was due to the presence of iron artifacts in the surrounding seawater environment. Most detected iron was associated with sulphur in pyrite crystals. In the analysed samples, pyrite grains typically appeared as smaller subspherical clusters of poorly formed cubic particles of pyrite (protoframboids), with a maximum diameter of between 2-9 $\mu \mathrm{m}$ [81,110] (Fig. 7d and 8b), which infilled bioapatite in both the outer ivory and inner cementum layers that came into contact with the materials deposited in the ivorycementum junction. Spot X-ray microanalyses provided the calculated average formula of $\mathrm{Fe}_{1.10-1.15} \mathrm{~S}_{2}$ for these pyrite framboids. The examination of a cross section of a sample excised from the materials deposited in the ivory-cementum junction (DCJ) also enabled the recognition of pyrite and other authigenic minerals, such as calcium carbonate and silica from marine sediments (features not showed). Pyrite framboids have been identified in the samples of slime found in the pulp cavity of tusks. Pyrite formation is not unusual in sea sediments [28]. This process may have taken place given the metabolic activity of sulpho-reducing bacteria, which are known to be involved in reducing dissolved sulphate, or catalysed by the extracellular enzymes released by bacteria or other microorganisms [79]. Two different mechanisms have been proposed: a) oxidation of iron sulphide by hydrogen sulphide $\left(\mathrm{FeS}+\mathrm{H}_{2} \mathrm{~S} \rightarrow \mathrm{FeS}_{2}+\mathrm{H}_{2}\right.$ ) [113]; b) 
732 oxidation of iron sulphide by polysulphides $\left(\mathrm{FeS}+\mathrm{S}_{\mathrm{x}}{ }^{2-} \rightarrow \mathrm{FeS}_{2}+\mathrm{S}_{\mathrm{x}-1}{ }^{2-}\right)$ [114]. The

733 former has been reported as a fast reaction (days) responsible for the formation of 734 framboids [110] that predominate in anoxic sediments, with a $\mathrm{pH}$ of around 7 [115], or 735 in slightly anoxic environments [79]. The latter is a slower process (years) that enables 736 the formation of isolated crystals [110] and takes place in sediments with a low pH 737 [115]. According to the $\mathrm{pH}$ values found in the marine environments $(\mathrm{pH} \sim 8)$ and the 738 prevalence of pseudoframboidal features that infilled the archaeological tusk and the sediments located in the pulp cavity, the first mechanisms were presumed to be the main pathway responsible for pyrite formation, which evidenced the slightly anoxic conditions that predominate at the Bajo de la campana site [79,80,81].

An analogous origin to iron was attributed to $\mathrm{Cu}, \mathrm{Sn}, \mathrm{Pb}$ and $\mathrm{Ag}$, identified by a spot analysis by FESEM-EDX with the small particles deposited in the alveoli formed on the outer cementum surface. $\mathrm{Sr}$ and $\mathrm{Zn}$ contents could have attributed to both dietary absorption antemortem and postmortem diagenesis. Nevertheless in this case, these elements were considered contaminants which had been introduced into the tusk from the surrounding environment, as shown by their location in the grains deposited on the external tusk surface and their absence in more internal layers. Other elements identified in the individual grains deposited on the external cementum surface were $\mathrm{Ni}, \mathrm{V}, \mathrm{Ti}, \mathrm{Mn}$ and $\mathrm{Cd}$. Their uptake is associated with the presence of these elements in the marine environment as part of sediment minerals, soil solution [39] and water pollutants [116].

FESEM-EDX also provided a first approach to the chemical composition of the blackgreyish microcrystalline matter that filled the ivory-cementum junction (Table 2). The high $\mathrm{Ca}$ content $(43.8 \mathrm{wt} \%)$ suggested that this material was composed mainly of calcium carbonate, accompanied by pyrite (Fe, $8.8 \mathrm{wt} \%$ and $\mathrm{S}, 10.0 \mathrm{wt} \%$ ), quartz or siliceous minerals ( $\mathrm{Si}, 1.22 \mathrm{wt} \%)$.

\subsection{Structural characterisation of bioapatite}

761

IR spectra.- Figure 9 shows the IR absorption spectra of the ivory (DM) and cementum (CM) from the modern tusk. Characteristic features at 3278, 3069, 1637, 1544 and 1243 $\mathrm{cm}^{-1}$, ascribed to amide bands A, B, I, II and III were identified in both the spectra of the 
modern tusk. The band at $1412 \mathrm{~cm}^{-1}$ was assigned to $v_{3}\left(\mathrm{CO}_{3}\right)$ of the carbonate ions at the B-sites (substituting the phosphate ions in the hydroxyapatite lattice) and the band at $1446 \mathrm{~cm}^{-1}$, associated with the $v_{3}$ vibration of the carbonate ion at both the B- and Asites (substituting the hydroxyl groups). Prevalence of the band at $1412 \mathrm{~cm}^{-1}$ in the cementum, which is characteristic of B-type hydroxyapatites, suggested that carbonate ions were preferentially located at the B-sites on this layer [101,117]. The band at 873 $\mathrm{cm}^{-1}$ was ascribed to the $v_{2}\left(\mathrm{CO}_{3}\right)$ vibration in the hydroxyapatite lattice $[35,101,117]$. Spectra were dominated by the band ascribed to the $v_{3} v_{1}\left(\mathrm{PO}_{4}\right)$ vibration. The featurelessness of this band denoted a notable overlapping of sub-bands. The $v_{3}\left(\mathrm{PO}_{4}\right)$ band showed a maximum at $1021 \mathrm{~cm}^{-1}$ for the ivory and at $1005 \mathrm{~cm}^{-1}$ for the cementum. The band at this lower wavenumber has been previously reported in apatites type B, which contain carbonate, and in apatites that contain $\mathrm{HPO}_{4}{ }^{2-}[89]$. In both the IR spectra, the $v_{1}\left(\mathrm{PO}_{4}\right)$ band was also visible as a shoulder at ca. $960 \mathrm{~cm}^{-1}$. The $v_{4}\left(\mathrm{PO}_{4}\right)$ band exhibited two maxima at ca. 605 and $565 \mathrm{~cm}^{-1}$ (with a shoulder at $577 \mathrm{~cm}^{-1}$ ), ascribed to the apatitic phosphate groups, and a third maximum at ca. $540 \mathrm{~cm}^{-1}$ (with a shoulder at ca. $530 \mathrm{~cm}^{-1}$ ), assigned to $\mathrm{HPO}_{4}{ }^{2-}$ located in the apatite lattice and the hydrate layer. The IR spectra of the samples of the ivory (DA) and cementum (CAI and CAO) layers from the archaeological tusk (Fig. 4a and 10) were also dominated by bands associated with the phosphate group, with an abundant diversification of functionalities, as denoted by the abundant overlapping of sub-bands. Maxima at $1017 \mathrm{~cm}^{-1}$ for DA and 1022 and $1019 \mathrm{~cm}^{-1}$ for CAI and CAO and the sub-band at ca. $960 \mathrm{~cm}^{-1}$ were found. The bands at ca. 565 and $605 \mathrm{~cm}^{-1}$ dominated the $v_{4}\left(\mathrm{PO}_{4}\right)$ domain, in which the other secondary maxima observed in the IR spectrum of the modern tusk overlapped. The $v_{3}\left(\mathrm{CO}_{3}\right)$ band from the three archaeological samples showed a maximum at $1412 \mathrm{~cm}^{-1}$. This sub-band was sharper than that exhibited by its counterparts from the modern tusk, which confirms that B-type hydroxyapatite was also prevalent in the archaeological tusk. This was supported by the absence of a shoulder up to $1545 \mathrm{~cm}^{-1}$, characteristic of type-A hydroxyapatites $[101,117]$. A sharper $v_{2}\left(\mathrm{CO}_{3}\right)$ band at $873 \mathrm{~cm}^{-1}$ was also found in the archaeological samples. The bands associated with proteinaceous matter notably decreased, and only one weak amide I band was recognised in the three IR spectra $\left(1633 \mathrm{~cm}^{-1}\right)$. Interestingly, a weak band at $710 \mathrm{~cm}^{-1}$ was recognised in the DA sample, which suggests the presence of authigenic calcium carbonate that infilled the 
archaeological ivory $[55,56]$. The main difference between the IR spectra from the archaeological or the modern tusk was the blueshifting of the $\mathrm{v}_{3}\left(\mathrm{PO}_{4}\right)$ band of cementum (CM: $1005 \mathrm{~cm}^{-1}$, CAI: $1022 \mathrm{~cm}^{-1}$ and CAO: $1019 \mathrm{~cm}^{-1}$ ). Minor differences were related chiefly to variation in the relative intensity of the bands rather than to the appearance or absence of bands. Finally, the FTIR analysis of the black-greyish microcrystalline matter that filled the ivory-cementum junction (DCJ) (Fig. 10) confirmed that calcium carbonate of the aragonite-type (the $v_{3}\left(\mathrm{CO}_{3}\right)$ vibration at $1450 \mathrm{~cm}^{-1}$, the $v_{1}\left(\mathrm{CO}_{3}\right)$ vibration at $1085 \mathrm{~cm}^{-1}$, the $v_{2}\left(\mathrm{CO}_{3}\right)$ doublet at 873 and $857 \mathrm{~cm}^{-1}$, and the $v_{4}\left(\mathrm{CO}_{3}\right)$ doublet at 713 and $700 \mathrm{~cm}^{-1}$ ) was the main component of these materials, and was accompanied by hydroxyapatite to a lesser extent.

Structural indices.- Table 4 summarises the several diagenetic indices calculated in the present study, which were previously described in the Experimental Section; namely: the crystallinity index $(\mathrm{CI})$ obtained by XRD, the band area ratio $v_{3}\left(\mathrm{CO}_{3}\right)$ to $v_{3} v_{1}\left(\mathrm{PO}_{4}\right)$ $(\mathrm{C} / \mathrm{P})$, the band area ratio of the individual band at $1030 \mathrm{~cm}^{-1}$ to $1020 \mathrm{~cm}^{-1}\left(\mathrm{I}_{1030} / \mathrm{I}_{1020}\right)$ in the $v_{3} v_{1}\left(\mathrm{PO}_{4}\right)$ domain, the $\mathrm{HPO}_{4}{ }^{2-}$ content $\left(\mathrm{HPO}_{4}{ }^{2-}\right.$ content $)$ given by the area ratio for the $1150-1100 \mathrm{~cm}^{-1}$ to $1100-1020 \mathrm{~cm}^{-1}$ subdomains in the $v_{3} v_{1}\left(\mathrm{PO}_{4}\right)$ domain, the Fourier transform splitting factor (IRSF) from the $v_{4}\left(\mathrm{PO}_{4}\right)$ domain and the ratio of the relative

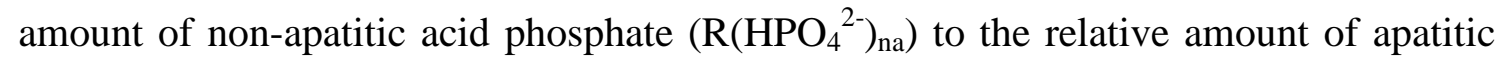
acid phosphate $\left(\mathrm{R}\left(\mathrm{HPO}_{4}{ }^{2-}\right)_{\mathrm{a}}\right)$ in the $\mathrm{v}_{4}\left(\mathrm{PO}_{4}\right)$ domain $\left(\mathrm{R}\left(\mathrm{HPO}_{4}{ }^{2-}\right)_{\mathrm{na}} / \mathrm{R}\left(\mathrm{HPO}_{4}{ }^{2-}\right)_{\mathrm{a}}\right.$ ratio $)$. They were all obtained by FTIR. The Ca/P molar ratio obtained by FESEM-EDX is included in Table 4 to compare it with the FTIR indices. The values of the band area percentages of the underlying bands obtained by curve fitting in the $v_{3} v_{1}\left(\mathrm{PO}_{4}\right)$ and $v_{4}\left(\mathrm{PO}_{4}\right)$ domains, from which some of the above-mentioned indexes were calculated, are provided as Supplementary Electronic Material (see Tables 1S and 2S).

CI.- The CI value found in the modern ivory sample (0.07) was similar to that found in the archaeological ivory (0.08), and was notably lower than those found in the archaeological cementum samples $(0.22$ and 0.45$)$. The diffractogram of the modern cementum sample exhibited poor features that hindered CI calculations. 
828 The CI found in both ivory samples came close to those reported for bone by

829 Grunenwald et al. [29], and fell within the 0.02-0.11 range. The CI found in the 830 archaeological cementum came close to those values of the more crystalline ivory tooth 831 (with a CI of between 0.27-0.37).

832

833 Carbonate-to-phosphate ratio $(C / P)$. - The $\mathrm{C} / \mathrm{P}$ values calculated for modern ivory and 834 the cementum were similar $\left(\mathrm{C} / \mathrm{P}_{\mathrm{DM}}: 0.14, \mathrm{C} / \mathrm{P}_{\mathrm{CM}}: 0.15, \sim 4 \mathrm{wt} \%\right)$, but were lower than 835 that calculated from the intensity data by Godfrey et al [28] for a modern tusk (0.23836 0.24), and those of carbonate content reported by Grunenwald et al. [29] for modern 837 bones (5.4-6.6wt\%). These results confirm the non-stoichiometry of the apatite phase in 838 these modern tusks, with a slightly more marked presence of carbonate ions in the 839 cementum.

The $\mathrm{C} / \mathrm{P}$ value calculated for the ivory $\left(\mathrm{C} / \mathrm{P}_{\mathrm{DA}}: 0.37, \sim 11 \mathrm{wt} \%\right)$ was slightly higher than those calculated for the cementum in the archaeological tusk $\left(\mathrm{C} / \mathrm{P}_{\mathrm{CAI}}: 0.31\right.$ and $\mathrm{C} / \mathrm{P}_{\mathrm{CAO}}$ : 0.30). These values were higher than their counterparts in the modern tusk. The $\mathrm{C} / \mathrm{P}$ value found in the Bajo de la campana ivory was higher than those found by Godfrey et al. [28] in waterlogged ivory (0.11) and those reported by Large et al in buried ivory (0.10-0.11) [46]. No cementum data have been reported in other studies. More similarity was found for the Bajo de la campana samples (9-11 wt\%) compared with the values reported by Grunenwald et al. [29] for buried bones and teeth, which fell within the $2.8 \mathrm{wt} \%-7 \mathrm{wt} \%$ range. Nevertheless for comparative purposes, we must take into account that the $\mathrm{C} / \mathrm{P}$ values found for the Bajo de la campana tusk could have been affected by overestimated carbonate content because the $\mathrm{C} / \mathrm{P}$ ratio is a measure of the total content of the carbonate ions present in the sample, which includes not only the carbonate ions incorporated into the apatite lattice, but also the calcium carbonate crystals (calcite, aragonite), along with the rest of calcareous skeletons of microplankton that infilled the archaeological tusk; particularly, throughout ivory tubules, fissures and cracks. The high $\mathrm{Ca} / \mathrm{P}$ values obtained by FESEM-EDX, especially in the ivory-cementum junction, together with the identification of aragonite as a major component of these materials, should support that the authigenic minerals which infilled the tusk could enhance the $\mathrm{C} / \mathrm{P}$ values obtained for the Bajo de la campana tusk. Prior studies have demonstrated 
860

that these authigenic minerals tend to accumulate around the Haversian canals of bones during diagenesis [35].

The $v_{3} v_{1}\left(\mathrm{PO}_{4}\right)$ domain.- As seen in Table 4, the ivory and cementum in the modern tusk exhibited $\mathrm{I}_{1030} / \mathrm{I}_{1020}$ ratios of 0.35 and 0.91 , respectively. The latter came closer to that reported by Lebon et al. [95] for mature bones of modern ox $\left(\mathrm{I}_{1030} / \mathrm{I}_{1020}: 1.12\right)$. It has been evidenced that during bone and tooth maturation, which results in the progressive loss of non-stoichiometric apatitic environments, the $\mathrm{I}_{1030} / \mathrm{I}_{1020}$ ratio tends to increase $[29,88,89,90,92]$. Therefore, a comparison of the experimental values obtained herein for the modern ivory and cementum indicated that the former occurred in an earlier maturity stage, which is in good agreement with the fact that the cementum forms first during tusk growth.

The values calculated for the Bajo de la campana cementum (CAI: 1.17, CAO: 1.31) fell within the range of values previously reported for fossil bones (1.12-2.31)[95], whereas the $I_{1030} / I_{1020}$ ratio for ivory was lower (DA: 0.38 ), which evidences the lower ivory crystallinity. The greater crystallinity of cementum in archaeological tusk, which referred to its counterpart in the modern tusk, was also evidenced by comparing their $\mathrm{I}_{1030} / \mathrm{I}_{1020}$ ratio values [95]. The higher fluorine content found in the cementum could help increase the crystallinity of this outer layer.

The $\mathrm{HPO}_{4}{ }^{2-}$ content values obtained in the modern tusk (DM: 0.34 and CM: 0.25 ) provided a measure of the contribution of the non-stoichiometric apatitic environments that contained $\mathrm{HPO}_{4}{ }^{2-}$ to the bioapatite nanocrystals structure. They informed about the level of maturity achieved by each tusk part [95]. These values, particularly that for ivory, fell within the range of that reported for modern ox bones $\left(\mathrm{HPO}_{4}{ }^{2-}\right.$ content: 0.32$)$ [95]. The lower cementum value confirmed the more advanced level of maturation achieved by this outer layer.

The $\mathrm{HPO}_{4}{ }^{2-}$ content values obtained in the archaeological tusk (DA: 0.33, CAI: 0.31 and CAO: 0.20) were lower than their counterparts in the modern tusk. The higher value obtained for the CAI sublayer in cementum was associated with the greater contribution 
892

893

894

895

896

897

898

899

900

901

902

903

904

905

906

907

908

909

910

911

912

913

914

915

916

917

918

919

920

921

922

923

924

of the apatitic micrograins, which occurred inside the alveolar apatitic bulk which, according to their higher $\mathrm{Ca} / \mathrm{P}$ value (Table 3), should be less stoichiometric.

Several authors have suggested that diagenetic processes, influence acid phosphate content, which was progressively removed to result in fewer non-apatitic environments associated with the hydrated layer $[95,118]$. This parameter has been proposed as FTIR proxy to better characterize diagenetic alterations [95]. Accordingly, the Bajo de la campana tusk should be located on the boundary between an in vivo specimen and a slightly altered fossil, as a $\mathrm{HPO}_{4}{ }^{2-}$ content of 0.30 establishes [95].

The $v_{4}\left(\mathrm{PO}_{4}{ }^{3-}\right)$ domain.- The IRSF values found in the modern tusk (DM: 2.28 and CM: 2.78) were slightly lower than those reported by Godfrey et al. [28] for modern ivory (2.83-2.84). The higher IRSF values found in the cementum layer indicated the greater crystallinity of the bioapatite crystals that formed this outer layer in the modern specimen, as already evidenced by the high value for the $\mathrm{I}_{1030} / \mathrm{I}_{1020}$ ratios in this layer.

The values obtained in the archaeological tusk (DA: 3.22, CAI: 3.34 and CAO: 3.46) were also higher than those for the modern tusk, and the cementum had the highest IRSF values. The Bajo de la campana samples exhibited slightly lower IRSF values than those reported by Godfrey et al. [28] for waterlogged tusks (ivory: 3.77, outer cementum: 3.62), but reached the threshold (3.2) established by Lebon et al [95] between in vivo and slightly altered fossil bone.

The $\left.\mathrm{R}\left(\mathrm{HPO}_{4}{ }^{2-}\right)_{\mathrm{na}} / \mathrm{R}_{\left(\mathrm{HPO}_{4}\right.}{ }^{2-}\right)_{\mathrm{a}}$ ratio obtained for the modern tusk (DM: 1.84, CM: 0.53) attested the prevalence of the $\mathrm{HPO}_{4}{ }^{2-}$ ions located on the hydrated layer in ivory, which was in agreement with its lower maturity level. A similar trend was noted between the samples of the archaeological series, which had lower ratios than the modern series of samples. Thus the highest $\mathrm{R}\left(\mathrm{HPO}_{4}{ }^{2-}\right)_{\mathrm{na}} / \mathrm{R}_{(}\left(\mathrm{HPO}_{4}{ }^{2-}\right)_{\mathrm{a}}$ ratio was found in the ivory (1.01), whereas the cementum gave lower values of 0.43 for the inner sublayer and 0.39 for the outer sublayer.

Correlations between indices.- a) modern tusk. As tusk age remains unknown owing to its particular provenance, no consideration can be made on the maturation level of the 
925 bioapatite as an age/time-dependent property, and only the comparison made between

926 ivory and cementum structure and composition is discussed. As expected, the 927 cementum, firstly formed in the tusk, had a higher maturation level, as indicated by the 928 higher IRSF and $\mathrm{I}_{1030} / \mathrm{I}_{1020}$ ratio values found in it (Fig. 11a). These provide a measure 929 of the greater crystallinity and maturity of the bioapatite on this outer layer [91,93], 930 together with the $\mathrm{CI}$. This trend correlates well with the higher $\mathrm{Ca} / \mathrm{P}$ ratio (Fig. $11 \mathrm{~b}$ ) 931 found in the cementum. A satisfactory anti-correlation was also found between $\mathrm{HPO}_{4}{ }^{2-}$ 932 content and the IRSF and $\mathrm{I}_{1030} / \mathrm{I}_{1020}$ ratio (Fig. 11a,c). A satisfactory correlation between 933 presence of the non-apatitic hydrated layer and crystallinity is evidenced in the modern 934 tusk by the inverse correspondence found between the values for the $\mathrm{R}\left(\mathrm{HPO}_{4}{ }^{2-}\right.$

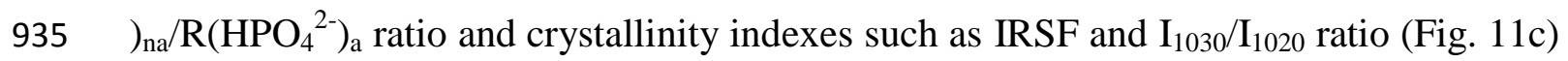
936 [91-93].

937

938 b) Archaeological tusk.- The CI, $\mathrm{I}_{1030} / \mathrm{I}_{1020}$ ratio and IRSF values, all of which are 939 crystallinity-related parameters, exhibited a similar trend for the archaeological samples 940 (Fig. 11a and Supplementary Electronic Material). The lowest CI, $\mathrm{I}_{1030} / \mathrm{I}_{1020}$ ratio and 941 IRSF values were found in the ivory, which attested its lower degree of crystallinity. An 942 inverse correlation was found between the CI, IRSF and the $\mathrm{I}_{1030} / \mathrm{I}_{1020}$ ratio vs $\mathrm{Ca} / \mathrm{P}$ and 943 C/P index (Fig. 11b and Supplementary Electronic Material), which coincides with 944 other studies $[31,35,56,84,99,119,120]$. This anti-correlation between indices is 945 consistent with reduced crystallinity due to the replacement of phosphate ions with 946 carbonate ones, which results in non-stoichiometric lattices. Nevertheless, the diagrams 947 depicted in Fig. 11b show a certain divergence in the behaviour of sample CAI from the 948 inner cementum. Deviation from the expected value for this sample was associated with 949 the location of this sublayer in direct contact with the ivory-cementum fissures junction, 950 which favours deposition of authigenic minerals, colonisation by microorganisms (as 951 evidenced by abundant framboidal pyrites) and ion-exchange of species (as also 952 evidenced by abundant and highly altered disaggregated apatitic grains that infilled 953 alveoli). Thus the average $\mathrm{Ca} / \mathrm{P}$ value for this sublayer, listed in Table 2, should be 954 affected by the notable contribution of the rounded apatitic carbonate-enriched grains 955 and, eventually, by the presence of inclusions of authigenic minerals, whereas the 956 alveolar apatitic bulk, with a $\mathrm{Ca} / \mathrm{P}$ value nearer to the stoichiometric value of 1.67 , 957 contributed to the average $\mathrm{Ca} / \mathrm{P}$ ratio to a lesser extent. It must be noted that the better 
correlation between the $\mathrm{Ca} / \mathrm{P}$ molar ratio and the IRSF, CI and the $\mathrm{I}_{1030} / \mathrm{I}_{1020}$ ratio was found if the $\mathrm{Ca} / \mathrm{P}$ ratio values calculated for the apatitic bulk listed in Table 3 were used (Fig. 11b) instead of the average values listed in Table 2.

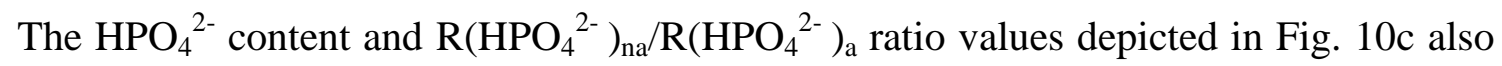
well intercorrelated, and correlated with the IRSF, CI and the $\mathrm{I}_{1030} / \mathrm{I}_{1020}$ ratio in the archaeological series (see Supplementary Electronic Material). The higher values of both indices found in the ivory (Fig. 11c) attested that most non-apatitic $\mathrm{HPO}_{4}{ }^{2-}$ was located on the surface hydrated layer, which is consistent with the lesser crystallinity and with the higher $\mathrm{P}$ content of this tusk part [95].

c) Modern tusk vs. archaeological tusk.- In all cases, the $\mathrm{Ca} / \mathrm{P}, \mathrm{C} / \mathrm{P}, \mathrm{CI}, \mathrm{I}_{1030} / \mathrm{I}_{1020}$ ratio and IRSF for the archaeological tusk were higher than those for the modern tusk (Table 4, Fig. 11a,b and Supplementary Electronic Material), which evidenced that diagenetic processes had taken place in the former. Nevertheless, and according to Lebon et al. [95], the obtained results suggested that the $\mathrm{I}_{1030} / \mathrm{I}_{1020}$ ratio and IRSF obtained in the $v_{1} v_{3} \mathrm{PO}_{4}$ and the $v_{4} \mathrm{PO}_{4}$ domains, respectively, represent different aspects of the alteration processes. Indeed, the IRSF values were more sensitive to the differences associated with the specific alteration processes that affected the specimens in the marine environment, whereas the $\mathrm{I}_{1030} / \mathrm{I}_{1020}$ ratio related more to the apatitic lattice structure in the different tusk parts (Fig. 11a).

$\mathrm{HPO}_{4}{ }^{2-}$ content exhibited the expected anti-correlation with the $\mathrm{CI}, \mathrm{I}_{1030} / \mathrm{I}_{1020}$ ratio and IRSF (see Supplementary Electronic Material), whereas the $\mathrm{HPO}_{4}{ }^{2-}$ content and CI values were well-fitted, no linear relationship was found for the $\mathrm{I}_{1030} / \mathrm{I}_{1020}$ ratio $v s$. $\mathrm{HPO}_{4}{ }^{2-}$ content or IRSF vs. $\mathrm{HPO}_{4}{ }^{2-}$ content when both samples series were considered conjointly.

No straightforward correlation was found between $\mathrm{HPO}_{4}{ }^{2-}$ content and the $\mathrm{R}\left(\mathrm{HPO}_{4}{ }^{2-}\right.$ )$_{\mathrm{na}} / \mathrm{R}_{(}\left(\mathrm{HPO}_{4}{ }^{2-}\right)_{\mathrm{a}}$ ratio for the two samples series from the modern and archaeological tusks. Yet the diagram in Fig. 11c attested that the $\mathrm{R}\left(\mathrm{HPO}_{4}{ }^{2-}\right)_{\mathrm{na}} / \mathrm{R}\left(\mathrm{HPO}_{4}{ }^{2-}\right)_{\mathrm{a}}$ ratio was able to discriminate between the ivory and the cementum, irrespectively of sample provenance, which suggests that the formation of the hydrated layer in the antemortem 
991 phase was not strongly influenced by postdepositional processes in this marine

992

993

994

995

996

997

998

999

1000

1001

1002

1003

1004

1005

1006

1007

1008

1009

1010

1011

1012

1013

1014

1015

1016

1017

1018

1019

1020

1021

1022

1023 environment.

\subsection{Characterisation of organic matter}

Two analytical techniques were implemented herein to characterise the organic matter present in the tusk. FTIR spectroscopy enabled an estimate of the organic matter loss in the different tusk layers, as well as an identification of the conformational changes associated with the structure of collagenous molecules. GC-MS provided an amino acid profile of the proteinaceous matter and identified the lipids present in the tusk.

\section{FTIR spectroscopy}

The notable decrease in the amide bands, observed by comparing the IR spectra from the modern and archaeological tusks (Figs. 9 and 10), attested the significant loss of organic matter undergone by the archaeological specimen. The PM/P values for the modern tusk shown in Table 5 (DM: 0.18 and CM: 0.23$)$ were lower than that $(0.62)$ reported by Godfrey et al [28]. This difference can be attributed to the taxonomical diversity of the specimens analysed in both studies. A comparison of the PM/P values calculated for the archaeological samples (0.015-0.054) and the modern ones confirmed the notable loss of proteinaceous matter undergone by the Bajo de la campana tusk due to waterlogged conditions. The PM/P values also indicated that this process occurred prevalently in the ivory, and also in the cementum, but to a lesser extent, and also that the outer cementum sublayer was where the organic matter seemed to be better preserved. This higher value found in the outer sublayer could be attributed to differences in the diagenetic pathways associated with environmental conditions on the microscale on both sublayers (vide infra).

An examination of the features in the amide I region of the IR spectra obtained in the modern tusk samples after applying the FSD process provided interesting information. The individual bands that made up the amide I band strongly overlapped for both the modern tusk samples, which suggests abundant diversification of functionalities in 
1024

1025

1026

1027

1028

1029

1030

1031

1032

1033

1034

1035

1036

1037

1038

1039

1040

1041

1042

1043

1044

1045

1046

1047

1048

1049

1050

1051

1052

1053

1054

1055

1056

proteinaceous molecules (Fig. 12a,b). Amide I band was dominated by the $\beta$-sheet (maximum) at $1637 \mathrm{~cm}^{-1}$, which is in good agreement with previous studies on dried proteins (note that samples were air-dried prior to FTIR-ATR spectra acquisition). The secondary maxima at $1647-48$ and $1656 \mathrm{~cm}^{-1}$ ascribed to the random coil and $\alpha$-helix structures, and three shoulders within the $1660-1700 \mathrm{~cm}^{-1}$ range ascribed to turns, were observed in both samples. The triple-helix (the shoulder at $1660 \mathrm{~cm}^{-1}$ ) was characteristic of collagenous material [106,121]. High helical conformation values have also been reported in membrane proteins of some microorganisms, which describe the phenomenon of cell adhesion to solid mineral surfaces [122]. Attachment occurs after cells have been "conditioned" by the adsorption of the extracellular polymeric substances, such as polysaccharides, proteins, lipids or nucleic acids. In the tusk samples, part of the notable contribution of this conformation can be attributed to the conformational structure adopted by the protein to adhere to the hydroxylapatite mineral $[123,124]$. Figure 13a-c depicts the amide I bands for the ivory and the two cementum sublayers in the archaeological tusk. The individual bands associated with the diverse functionalities assigned to each conformation are well resolved in the archaeological samples. The maximum ascribed to the $\beta$-sheet redshifted to $1633-34 \mathrm{~cm}^{-1}$. The maxima associated with the helical and random coil conformations also redshifted to 1645 and $1651 \mathrm{~cm}^{-1}$. The redshifts observed for the individual bands associated with the $\beta$-sheet, helical and random coil conformations are indicative of the transformation of collagen proteins into gelatin $[106,121]$. The shoulder ascribed to the triple-helix appeared at the expected value of $1660 \mathrm{~cm}^{-1}$. An increased number of shoulders were recognised in the turn domain between $1660-1700 \mathrm{~cm}^{-1}$.

Table 5 shows the percentage area contribution calculated for the components of amide I band in the IR spectra for the modern and archaeological tusk samples by applying FSD-CF. This process enabled the identification and quantification of the contribution of the individual band ascribed to various secondary structures, in particular the triple helical conformation, which is characteristic of collagen. Several considerations can be made: a) amide I band obtained by FTIR was a mixture of total organic matter, including collagenous and non-collagenous proteins. According to the literature, collagen content in bones is around $85-90 \%$ of the total protein in bone $[2,125]$, accompanied by approx. $15 \%$ of other non-collagenous proteins, including osteocalcin, 
haemoglobin, albumin, etc. All these proteins contribute to the amide I band profile in the IR spectra of the series of analysed samples. Therefore, distinct values of the percent area contribution of the triple helix (secondary structure characteristic of collagen) found in the ivory (12\%) and the cementum (17\%) of the modern tusk could be indicative of different protein compositions, with slightly more collagen in the cementum. A slightly higher proportion of the triple helix conformation was also observed in the archaeological cementum (DA: 10, CAI and CAO: 11); b) the comparison made between the values of the helical conformation and, in particular the triple-helix, found in the modern and archaeological tusk samples provided an estimate of loss of collagen and/or its degradation in the different tusk parts in the depositional context. Thus the evident depletion of helical conformations in both the ivory and cementum (DM: 28\%, DA: 21\%, CM: 32\%, CAI and CAO: 22\%) (with the corresponding increase in other conformations, especially random coil and turns) suggests that this protein notably degraded in the archaeological tusk; c) in line with the prior statement, the random coil in all the archaeological samples notably increased. Increase of the percentage area contribution of turns is also observed accompanied of an increase of the number of individual bands. These conformational changes are associated with an opening and unfolding of the protein chain, which may be ascribed to the transformation of the collagen protein into more soluble biodegradable gelatin [106,121]. Collagen gelatinisation has been described as a diagenetic trajectory of bioapatitic materials which involves hydrolysis of the molecule, fragmentation and the formation of more soluble peptides and free amino acids, which can be leached from the tusk [2]. This change should result in a selective loss of collagenous matter and is consistent with the notable drop in the PM/P ratios in the archaeological samples; d) similar values of the percent area contribution of helical conformations found in the ivory and cementum of the archaeological tusk (DM: 21(10)\%, CAI and CAO: $22(11) \%)$ suggest that the collagenous proteins in these layers achieved a similar helical characteristic, irrespectively of the larger or smaller amount of remaining proteinaceous matter $\left(\mathrm{PM} / \mathrm{P}_{\mathrm{DA}}: 0.015, \mathrm{PM} / \mathrm{P}_{\mathrm{CAI}}: 0.024, \mathrm{PM} / \mathrm{P}_{\mathrm{CAO}}: 0.054\right)$; e) the reduced percentage area contribution of the intermolecular $\beta$-sheet conformation observed for archaeological samples is also indicative of a lowering number of cross-links between protein molecules, which disaggregates the fibrous structure, and concomitantly favours the progress of protein molecules degradation [2]. 
1091 Correlations between indices.- Figure 11d shows the diagram PM/P vs. IRSF in which an anti-correlation is recognised between the crystallinity of the bioapatitic material and the organic matter content previously stated in other studies $[55,56,84]$. The reported data also indicated that organic matter content was higher in the cementum in both the modern and archaeological tusks. As expected, PM/P index in the archaeological tusk also showed anti-correlation with other indices such as $\mathrm{CI}, \mathrm{I}_{1030} / \mathrm{I}_{1020}$ ratio, or $\mathrm{C} / \mathrm{P}$ ratio (see Supplementary Electronic Material).

Gas chromatography-mass spectrometry

Figure 14 shows the chromatograms of the N(O,S)ethoxycarbonyl (EOC) ethyl esters of the amino acids found in the modern and archaeological samples under study. Table 6 provides the amino acid profile found in the ivory and cementum samples of the modern and archaeological tusks. The data shown in the table were obtained by applying a row scaling process to the individual amino acid peak area values identified in the chromatogram. The CM sample results were not included given the poor quality chromatogram obtained in this layer, which we attributed to the difficulty of mechanically separating the amount needed of this thin layer without contaminating the sample with ivory. The data shown in Table 6 were obtained by applying a row scaling process to the individual values of the amino acid peak area identified in the chromatogram. The amino acid profile for the modern ivory remained close to the range of values for the modern pure collagen reported in the literature [54], with glycine making up about one third of the total amino acid content, and alanine, proline and hydroxyproline together made up another third. Note that the organic matter in the tusk included both collagenous and non-collagenous matters. Therefore, some deviation should be expected of the experimental values obtained from the values reported for collagen.

Changes in the amino acid profile caused by diagenetic processes were recognised by comparing the values found in the archaeological samples to the modern ivory. The diagenetic processes resulted in a notable increase in the relative content of glycine and, to a lesser extent, in that of alanine, valine, leucine and isoleucine, and the 
corresponding reduction in the content of hydroxyproline, proline, phenylalanine and aspartic acid. Complete loss of tyrosine, histidine, lysine, glutamic acid and threonine was also observed.

Interestingly, previous studies in the literature on the diagenetic alteration of organic matter in bones have reported diverse results. DeNiro and Weiner [54] and Masters [62] found that when protein from buried bones and dentin degraded over time in skeletal materials, the non-collagenous matter, composed mostly of acidic polypeptides, was preferentially retained by charge interactions with the mineral phase so that the amino acid profile was modified by depleting glycine, alanine and proline in parallel to the increase in aspartic and glutamic acid. In agreement with the changes observed in the Bajo de la campana tusk, Ho [61] and Harbeck and Grupe [53] carried out studies on archaeological bones and chemical degradation experiments by simulating natural diagenetic alteration, respectively, and found a noticeable increase in glycine and alanine, accompanied by reduced hydroxyproline and proline. Ho [61] attributed this behaviour to the sound stability of glycine-rich polypeptides that resulted from collagen degradation. Loss of selective amino acids of an acid type, such as aspartic and glutamic acid, which was also observed in the Bajo de la campana tusk, was justified by Harbeck and Grupe [53] given the tendency of both the acid-type hydrophilic amino acids and the degraded polypeptides that contained most acid residues to solubilise in water. This scenario in the marine environment of Bajo de la campana should be notably favoured. Thermally unstable amino acids, such as threonine and serine, either sharply lowered or were absent in fossils, bones or teeth [126]. Selective loss of amino acids, such as tyrosine, lysine and histidine, has also been described in proteinaceous materials used as binding media that were attached to inorganic pigments [127].

GC-MS also enables the qualitative study of the lipids present in tusks, as summarised in Table 7. Figure 15 shows the chromatograms of the ethyl derivatives of fatty acids and other lipids present in the chloroformic extract of the studied samples series. Weak chromatographic signals for the ethyl derivatives of palmitic, stearic and oleic longchain fatty acids were found in all the samples. Glyceryl monopalmitate and monooleate and cholesteryl oleate were also identified in the archaeological and modern ivory samples. The high proportion of monounsaturated oleic (C18:1) acid to palmitic (C16:0) 
and stearic (C18:0) saturated fatty acids in the archaeological samples suggests that the oxidative degradation of the lipids that remained in the tusk was minimal, and probably due to the slightly anoxic underwater environment at the Bajo de la campana site. Cholesterol and related degradation products in ancient buried bones has also been identified [65,67]. These studies suggest that the diagenetic history of the lipids contained in the bone strongly depends on burial environment conditions. In waterlogged deposits, microbial reduction under anaerobic conditions results in the formation of reduced compounds [67], whereas oxidizing conditions prevails and the oxidation of cholesterol and lipids occurs in well-drained or dry sites [65]. Cholesteryl fatty acyl esters have also been reported in association with the mineral phase of fresh bone [69] and ancient buried bone [67]. These studies have demonstrated that such compounds were endogenous to bone at the time of death and subsequent burial. Their presence in bone has been associated with blood, which could have precipitated at the time of specimen death. Absence of cholesterol in both modern and archaeological ivory from Bajo de la campana suggests that this biomaterial has a low lipid content. Recognition of cholesteryl oleate in the archaeological ivory indicated that this compound has been well preserved thanks to its higher hydrophobicity, which would have restricted its migration in seawater and surrounding sediments.

\subsection{Diagenetic sequences at the Bajo de la campana site}

a) Influence of the marine environment in diagenetic trajectories and tusk conservation conditions

The analyses performed on the archaeological tusk section indicated several processes that have played an important role in the diagenetic sequence that the tusk followed. The particular waterlogged preservation conditions of this tusk must first be noted as it was: (i) buried in a seabed that consisted mainly in finely particulated calcium carbonate with noticeable amounts of gypsum, quartz and plagioclase; (ii) accessible to various microplankton species and other marine colonisation organisms; (iii) surrounded by metallic artifacts, also transported in the shipwreck; (iv) saturated by seawater at $\mathrm{pH} 8$, which also contained, to some extent, heavy metals and other ions as a result of mining and associated activities (refining, smelting, etc.) in the coastal region [116]. This environment favours a number of primary processes that result in other concomitant 
diagenetic reactions and mechanisms. The determinant factor of influence is obviously muddy seawater, which mechanically erodes the tusk surface and permeates it by generating cracks and fissures. Once seawater is inside the tusk, invasive microorganisms start to act and, in parallel, chemical mechanisms are initiated. As a result of the former, organic matter loss starts and porosity increases, which favours not only the further entry of water with a simultaneous ion exchange (leaching and uptake), but also more organic matter loss [2]. In parallel, pyrite framboids can be formed by the reduction of dissolved sulphate, which is abundant in Bajo de la campana sediments, and by the mediation of sulphate-reducing bacteria under slight anoxic conditions [79] or without the mediation of microorganisms [110,113-115]. These grains (see Fig. 8-a) would obstruct most alveoli, so the transport of materials throughout the tusk would diminish.

Biological activity involves the consumption of organic matter used as nourishment and an energy source by most microorganisms. This metabolic activity can result in the partial fragmentation of protein molecules with the release of different sized amino acids and polypeptides by enzymatic hydrolysis. The finding of several microplankton species infilling ivory (see Fig. 5b) supports these probable diagenetic pathways that involve biological organisms. Nevertheless, mineralised bone collagen has been considered insusceptible to enzymatic degradation [2]. Therefore, loss of hydrolysed peptide fragments via non-enzymatic hydrolysis must be considered a highly probable mechanism for collagen decay and loss at Bajo de la campana. Irrespectively of the hydrolysis of proteins taking place by enzymatic or chemical mechanisms, this process is followed by lixiviation via gelatinisation, as evidenced by the recognition of characteristic gelatin features in amide I band in tusk samples.

Hydrophobic properties have been a determinant factor in the selective survival of the organic compounds in ivory. The performed analyses have evidenced that the remaining organic matter was composed of a few weakly soluble lipids, such as long-chain fatty acids, monoacylglycerols, cholesteryl oleate and polypeptide rich in hydrophobic residues, such as glycine or alanine. These are hydrophobic molecules that can better resist degradation in the studied underwater environment. Moreover, the slightly anoxic 
conditions at the Bajo de la campana site favoured unsaturated oleic acid preservation which, under oxic conditions, would readily degrade.

Other chemical processes associated with an underwater environment also played a key role in Bajo de la campana tusk degradation. $\mathrm{Mg}$, an ion with good solubility in water, was leached. In parallel, the uptake of a number of elements took place. The heavy metals that derived from the surrounding artifacts and the pollutants present in seawater were present at a trace level. $\mathrm{Al}, \mathrm{Si}, \mathrm{Cl}$ and $\mathrm{F}$ were found at low concentration. Prior studies carried out by Reiche et al. on bones (4000 BC) from the Neolithic site of Bercy in Paris [3,79] have evidenced that a correlation between the fluorine content and preservation state of collagen can be established in burial environments. As mentioned above, organic matter loss resulted in increased porosity, which allowed ivory-seawater interactions and promoted the uptake of exogenous species $[79,95]$. It has also been reported that loss of collagenous matter in burial environments is often accompanied by increased microbial activity [128]. The latter, along with chemical hydrolysis and dissolution processes, also contributed to increased bone porosity and promoted the incorporation fluorine into the bioapatite structure. Our results indicate that fluorine enrichment took place in the waterlogged tusk concomitantly to proteinaceous matter loss, which agrees with these former studies on buried bones and tusks. Yet in agreement with previous studies by Godfrey et al. [28] on waterlogged tusks, collagen retention was enhanced on the outer cementum layer (PM/P: 0.024-0.054), where the highest fluorine content for Bajo de la campana tusk was reported. Therefore, the obtained results suggested that in marine environments, both mechanisms of fluorine uptake and preferential collagen loss showed no such straightforward correlation as they seemed to show in burial environments. Among the factors that could have contributed to better preserve the organic matter on the cementum layer at the Bajo de la campana site, we observed that the apatitic and pyrite micrograins obstructed alveoli and could prevent organic matter from leaving the cementum tusk (Fig. 8). In contrast, the higher ivory porosity due to the tubules that acted as a broad pattern of channels that connected this inner layer with the marine environment should facilitate organic matter loss (see Fig. 5, 6). The role played by $\mathrm{Fe}^{2+}$ ions as microbial inhibitors could have also contributed to reduce microorganism activity, hence the open porosity noted in the cementum [28]. As previously shown, this ion was present mainly in the cementum, 
where it mostly precipitated as pyrite framboids. Presence of other heavy metals to enrich the small granules preferentially deposited on cementum surfaces could have played a similar inhibitory role. The alkaline conditions found in seawater could have also contributed to inhibit bioapatite demineralisation, considered a prerequisite for microbial attack [28].

It has been reported that once the organic matrix breaks down, bone crystallites undergo simultaneous dissolution and growth similarly to Ostwald ripening [129], where large crystals grow at the expense of smaller crystallites. This has been supported by the strong relationship between IRSF and organic content reported elsewhere [55]. No direct evidence was found that this phenomenon took place at Bajo de la campana. A study by TEM conducted to characterise the morphological and compositional properties of nanocrystals in different tusk layers, which could provide data on this, is currently underway. Nevertheless, the notably low organic matter content, along with the high IRSF, CI and $\mathrm{I}_{1030} / \mathrm{I}_{1020}$ ratio values found in the archaeological samples, could be indicative of not only a high degree of antemortem maturity of their apatitic lattices, but also of some recrystallisation process. Recognition of these transformations was complicated by other processes which occur on the microscale, and prevalently on external cementum surfaces, which resulted in certain bioapatite structure disaggregation on the microscale. It is difficult to establish the origin of such changes, although they could be due to a combination of microorganisms activity and chemical reactions favoured by underwater conditions. Nevertheless, the different composition exhibited by both the apatitic bulk and the microsized rounded grains was indicative of at least two different diagenetic pathways on the cementum layer. The former could have undergone recrystallisation processes and involved the partial transformation of apatite in fluorapatite which, apart from the higher degree of maturation of the bioapatite on the cementum layer undergoing antemortem, could justify a closer composition to that of the ideal hydroxylapatite (see the $\mathrm{Ca} / \mathrm{P}$ values in Tables 2 and 3). Conversely, the small apatitic grains formed on the both external cementum layer surfaces exhibited the typical composition of the non-stoichiometric apatites enriched in carbonates (type B), and also in Si. Substitution of silicate ions for phosphate ions in hydroxylapatite has been reported to enhance the formation of a poorly crystalline apatite surface layer [112]. The latter was also applicable to ivory and indicated a poorer 
crystallised bioapatite as the direct consequence of greater accessibility to water, which therefore promoted ion-exchange and organic matter loss.

\section{b) Implications for the intervention treatment of the tusk collection}

From a conservation point of view, several aspects must be taken into account to plan future preservation conditions. It should first be noted that under waterlogged conditions, water acts as a weak consolidant that fills the internal voids of the porous solid structure to confer mechanical strength. Consequently, the tusk excavation task must be carried out by avoiding the fast evacuation of infilling water to prevent the object from collapsing. Reducing the amount of common ions and foreign species present in seawater is recommendable as they can contribute to the degradation processes identified and described above. Therefore, the gradual replacement of seawater that infilled the tusk with deionised water seemed the most suitable treatment. In this way, the proper balance between the minimal disturbance of the delicate compositional equilibrium achieved by the tusk immersed in seawater over centuries and the maximum delay in the progress of processes that deteriorated the tusk must be struck. Nevertheless, water immersion is an inappropriate preservation system for permanent exhibition purposes. So other preservation methods, such as consolidation with acrylic or PVAc water emulsions or polyethyleneglycol [75] after removing water, have been proposed, but have not proven that successful. In particular, the latter has been demonstrated as inappropriate because, under environmental exhibition conditions of high relative humidity, iron impurities result in the oxidation of reduced sulphur forms, such as pyrite and the formation of iron acid salts, which degrade organic matter [130]. More recently, consolidation via plastination has been proposed as an alternative to these methods. Plastination is a tissue preservation technique, developed by von Hagens in the 1970s [73,74], which consists in replacing water and lipids in biological tissues with curable polymers of a silicone type. More recently this procedure has been applied by Godfrey et al. [75] to waterlogged tusks with satisfactory results. The infilling of the tusk structure by weakly reactive silicone molecules simultaneously confers mechanical strength and lowers the risk of oxidative reactions. Nevertheless, the risk of reactivity associated with remains of tin-containing catalysts used in the industrial silicone synthesis persists [131], which means that assessing the posttreatment stability of archaeological materials is necessary. The evaluation experiments 
carried out in several sections of the tusk from the Bajo de la campana site suggested that ivory maintains a suitable degree of physico-chemical stability in the short/mid term [132].

Another important conservation premise is related to preserving visual tusk appearance. Presence of micrograined pyrite on the tusk surface was firstly responsible for the orange-brown colour that characterised its current visual appearance. Suppression of this material via mechanical or chemical treatment without damaging the remaining organic matter and apatitic structure was not possible. Therefore, suitable tusk preservation required the chemical stabilisation of pyrite to prevent possible oxidation processes resulting in the formation of iron oxyhydroxydes via iron sulphates and sulphuric acid as intermediates [83]. A higher volume of these neoformed compounds could distort and damage the apatitic lattice. As previously described, plastination treatment, in which the water that contained reactive oxygen was replaced with a more inert silicone polymer, could notably contribute to the stabilisation of pyrites and other reactive compounds that remained in the tusk.

\section{Conclusions}

The study conducted out on a waterlogged tusk found at the submarine archaeological Bajo de la campana site using a multi-technique approach has shed new light on the understanding of diagenetic processes that take place on the structure and composition of both inorganic and organic components of this biomaterial and evidenced how ivory alteration phenomena strongly depend on the site's specific physico-chemical conditions.

The depositional marine environment where the tusk has been preserved for centuries has determined substantial transportation of water to the tusk, and has concomitantly promoted organic matter loss and the consequent increase in fissures, cracks and microporosity. This scenario has favoured high mobility ion leaching, such as $\mathrm{Mg}^{2+}$, the uptake of exogenous chemical species linked to the seawater and seabed composition, as well as infiltration of authigenic minerals, such as calcite/aragonite, feldspars, plagioclase, quartz or skeletal remains of marine microplankton, trapped preferentially 
in the ivory given the presence of tubules that increment porosity. Uptake of exogenous elements (F, Cl, Si, Al, S, Na, Fe, Cu, Sr, Pb, Sn, Ag, V, Ni, Cd and Zn) has prevalently taken place in the external tusk region. In particular, uptake of $\mathrm{S}$ and $\mathrm{Fe}$ has been associated with the microbiological/chemical neoformation of pyrite framboids, which has attested the slightly anoxic character of the Bajo de la campana environment. Uptake of $\mathrm{F}$ has been linked to other diagenetic factors and has correlated with the increased crystallinity of the bioapatite, associated with re-crystallization processes and/or organic matter loss. Nevertheless, the higher F content in the cementum layer where organic matter is better preserved, contrarily to what occurs under burial conditions, is indicative of the complexity of uptake mechanisms.

Compositional and structural changes in the bioapatite of both the ivory and cementum layers have been characterised by combination of several structural and chemical parameters, which have been compared with a modern tusk. The obtained results indicate an increase in the degree of crystallinity and a drop in the $\mathrm{HPO}_{4}{ }^{2-}$ content, has taken place in the archaeological tusk. The greater accessibility of water throughout tubules in the ivory has favoured organic matter loss. A lower degree of increased crystallinity and higher $\mathrm{HPO}_{4}{ }^{2-}$ content have been associated with the hydrated layer exhibited by the bioapatite nanocryistals in this layer. A comparison of the obtained results with the available values of these parameters in other studies has been made, which has enabled to place the alteration state of the tusk in a more general context, which extends to other environments and a broader time scale. Within this more general frame, the values reported for the parameters of crystal growth (given by IRSF among other crystallinity indices), and the elimination of the non- apatitic environments associated mainly with the hydrated layer (given by $\mathrm{HPO}_{4}{ }^{2-}$ content and the $\mathrm{R}\left(\mathrm{HPO}_{4}{ }^{2-}\right.$ ) ratio), situate the Bajo de la campana tusk on the boundary between in vivo biomaterial (bone/tooth/ivory) and slightly altered fossil biomaterial [95].

As regards the preservation state of organic matter, two aspects must be emphasised. Irrespectively of hydrolysis taking place via a chemical or enzymatic mechanism, the remaining organic matter and peptide fragments exhibited selective enrichment in glycine and other low water-soluble residues, as well as depletion in the more soluble acid-type amino acids. This firstly suggests that the hydrophobicity of the remaining 
organic matter in this waterlogged environment has been essential for its survival. Secondly, the recognition of collagenous matter gelatinisation as a mechanism of degradation indicates the decisive role of the marine environment in promoting this structural change in the protein molecules, which should be followed by their solubilisation and elimination from the tusk, and has also been a factor to proteinaceous matter behaviour. Characterisation of lipids in waterlogged ivory has been done for the first time. Presence of lipid materials, such as long-chain fatty acids, monoacilglycerols and cholesteryl oleate in the tusk, supports the assumption made that the hydrophobicity of materials has prevented solubilisation and leaching.

The identification of large amounts of pyrite framboids and the high oleic acid/palmitic acid ratio obtained in the archaeological tusk suggest that oxidative degradation processes were minimal and confirm the slightly anoxic conditions of the underwater Bajo de la campana site environment.

The results obtained herein have been essential for establishing a suitable preservation and exhibition programme for the Bajo de la campana tusk collection. Most attention should be paid to the presence of pyrite that infilled ivory. Under oxic conditions, such as those which occurred when ivory came into contact with the atmosphere in the exhibition room, these microcrystals could start oxidative processes, which could result in severe bioapatite lattice distortions. To avoid that, plastination treatment is an alternative that simultaneously consolidates ivory and prevents oxidation processes due to the low reactivity of the silicone polymers that infill voids and tubules. Thus it can be concluded that this study has helped improve the conservation and management strategies of waterlogged ivory. Further knowledge of diagenesis processes and the environmental conditions of this archaeological material before its recovery would assist future decision-making and planning.

\section{Acknowledgements}

The authors wish to thank CITES España and Dirección General de Bienes Culturales y Enseñanzas Artísticas, de la Consejería de Educación, Cultura y Universidades de la Comunidad Autónoma de la Región de Murcia, Museo Nacional de Arqueología 
1419 Subacuática. Financial support is gratefully acknowledged from Spanish "I+D+I

1420 MINECO" projects CTQ2011-28079-CO3-01 and 02 and CTQ2014-53736-C3-1-P 1421 supported by ERDEF funds. The authors also wish to thank Mr. Manuel Planes and Dr. 1422 José Luis Moya, technical supervisors of the Electron Microscopy Service of the 1423 Universitat Politècnica de València.

\section{References}

[1] R.E.M. Hedges, Bone diagenesis: an overview of processes, Archaeometry 44 1428 (2002) 319-328.

[2] M.J. Collins, C.M. Nielsen-Marsh, J. Hiller, C.I. Smith and J.P. Roberts, The survival of organic matter in bone: a review, Archaeometry 44 (2002) 383-394. [3] I. Reiche, L. Favre-Quattropani, T. Calligaro, J. Salomon, H.Bocherens, L. Charlet, M. Menu, Trace element composition of archaeological bones and postmortem alteration in the burial environment, Nucl. Inst. Methods Phys. Res. B 150 (1999) 656662.

[4] T. Tütken, T.W. Vennemann, H.-U. Pfretzschner, Nd and $\mathrm{Sr}$ isotope compositions in modern and fossil bones -Proxies for vertebrate provenance and taphonomy, Geochim. Cosmochim. Acta 75 (2011) 5951-5970. [5] A.A.-M. Gaschen, M. Döbeli, A. Markwitz, B. Barry, S. Ulrich-Bochsler, U. Krähenbühl Restrictions on fluorine depth profiling for exposure age dating in archaeological bones, J. Archaeol. Sci. 35 (2008) 535-552. [6] K. Müller, I. Reiche, Differentiation of archaeological ivory and bone materials by micro-PIXE/PIGE with emphasis on two Upper Palaeolithic key sites: Abri Pataud and Isturitz, France, J. Archaeol. Sci. 38 (2011) 3234-3243.

1444 [7] H.G.M. Edwards, N.F. Nik Hassan, N. Arya, Evaluation of Raman spectroscopy and application of chemometric methods for the differentiation of modern ivory specimens

1446 I: elephant and mammalian species, J. Raman Spectrosc. 37 (2006) 353-360.

1447 [8] H.G.M. Edwards, R.H. Brody, N.F. Nik Hassan, D.W. Farwell, S.O’Connor, 1448 Identification of archaeological ivories using FT-Raman spectroscopy, Anal. Chim. Acta 559 (2006) 64-72.

1450 [9] F. Nocete, J.M. Vargas, T.X. Schuhmacher, A. Banerjee, W. Dindorf, The ivory 1451 workshop of Valencina de la Concepción (Seville, Spain) and the identification of ivory 
1452 from Asian elephant on the Iberian Peninsula in the first half of the 3rd millennium BC, 1453 J. Archaeol. Sci. 40 (2013) 1579-1592.

1454 [10] G. Molin, A.G. Drusini, D. Pasqual, F. Martignago, G. Scarazzati, Microchemical and Crystallographic Analysis of Human Bones from Nasca, Peru. A Possible Method of Direct Dating of Archaeological Skeletal Material, Int. J. Osteoarchaeol. 8 (1998) $1457 \quad 38-44$.

1458 [11] C. Gelvin-Reymiller, J.D. Reuther, B.A. Potter, P.M. Bowers, Technical aspects of 1459 a worked proboscidean tusk from Inmachuk River, Seward Peninsula, Alaska, J. 1460 Archaeol. Sci.33 (2006) 1088-1094.

1461 [12] C. Heckel, K. Müller, R.White, H. Floss, N.J. Conard, I. Reiche, Micro1462 PIXE/PIGE analysis of Palaeolithic mammoth ivory: Potential chemical markers of 1463 provenance and relative dating, Palaeogeog. Palaeoclimatol. Palaeoecol. 416 (2014) 1464 133-141.

1465 [13] C. Kottler, M. Döbeli, U. Krähenbühl, M. Nussbaumer, Exposure age dating by 1466 fluorine diffusion, Nucl. Inst. Meth. B, 188 (2002) 61-66.

1467 [14] C. Corti, L. Rampazzi, C. Ravedoni, B. Giussani, On the use of trace elements in 1468 ancient necropolis studies: Overviewand ICP-MS application to the case study of Valdaro site, Italy, Microchem.1 J. 110 (2013) 614-623. [15] M. Tomassetti, F. Marini, L. Campanella, A. Coppa, Study of modern or ancient collagen and human fossil bones from an archaeological site of middle Nile by thermal analysis and chemometrics, Microchem. J. 108 (2013) 7-13. [16] J.E. Laffoon, R. Valcárcel Rojas, C.L. Hofman, Oxygen and carbon isotope analysis of human dental enamel from the caribbean: implications for investigating individual origins, Archaeometry 55, 4 (2013) 742-765 [17] C.N. Trueman, A.K. Behrensmeyer, R. Potts, N. Tuross, High-resolution records of location and stratigraphic provenance from the rare earth element composition of fossil bones, Geochim. Cosmochim. Acta 70 (2006) 4343-4355.

[18] R.C.A. Rottlander, Variation in the chemical composition of bone as an indicator of climatic change, J. Archaeol. Sci. 3 (1976) 83-88. [19] D.J. Ortner, N. Tuross, A.I. Stix, New approaches to the study of disease in archaeological New World populations, Hum. Biol. 64 (1992) 337-360. [20] G.J.R. Maat, Bone preservation, decay and its related conditions in ancient human bones from Kuwait, Int. J. Osteoarchaeol. 3 (1993) 77-86. 
1485 [21] Y. Dauphin, C. Kowalski, C. Denys, Assemblage date and bone and teeth

1486

1487

1488

1489

1490

1491

1492

1493

1494

1495

1496

1497

1498

1499

1500

1501

1502

1503

1504

1505

1506

1507

1508

1509

1510

1511

1512

1513

1514

1515

1516 modifications as an aid to paleoenvironmental interpretations of the open-air Pleistocene site of Tighenif (Algeria), Quaternary Res., 42 (1994) 340-349.

[22] M. Balasse, H. Bocherens, A. Marioth, Intra-bone variability of collagen and apatite isotopic composition used as evidence of change of diet, J. Archaeol. Sci. 26 (999) 593-598.

[23] R. Djingova, B. Zlateva, I. Kuleff, On the possibilities of inductively coupled plasma mass spectrometry for analysis of archaeological bones for reconstruction of paleodiet, Talanta 63 (2004) 785-789.

[24] J.B. Lambert, S.V. Simpson, J.E. Buikstra D. Hanson, Electron microprobe analysis of elemental distribution in excavated human femurs, Am. J. Phys. Anthropol. 62 (1983) 409-423.

[25] K.B. Byrne, D.C. Parris, Reconstruction of the diet of the Middle Woodland Amerindian population at Abbott Farm by bone-trace element analysis. Am. J. Phys. Anthropol. 74 (1987) 373-384.

[26] J.B. Lambert, S.V. Simpson, S.G. Weiner, J.E. Buikstra, Induced metal ion exchange in excavated human bone. J. Archaeol. Sci. 12 (1985) 85-92.

[27] N.S. Baer, Chemical Aspects of the Conservation of Archaeological Materials in: Advances in Chemistry 171, American Chemical Society, New York: USA (2009) pp 25-32.

[28] I.M. Godfrey, E.L. Ghisalberti, E.W. Beng, L.T. Byrne, G.W. Richardson, The Analysis of Ivory from a Marine Environment, Stud. Conserv. 47 (2002) 29-45.

[29] A. Grunenwald, C. Keyser, A.M. Sauterau, E. Crubézy, B. Ludes,C. Drouet, Anal. Bioanal. Chem. 406 (2014) 4691-4704.

[30] C.A.M. France, D.B. Thomas, C.R. Doney, O. Madden, FT-Raman spectroscopy as a method for screening collagen diagenesis in bone, J. Archaeol. Sci. 42 (2014) 346355 .

[31] L.E., Wright, H.P. Schwarcz, Infrared and isotopic evidence for diagenesis of bone apatite at Dos Pilas, Guatemala: palaeodietary implications, J. Archaeol. Sci. 23 (1996) 933-944.

[32] M.L. Carvalho A.F. Marques, Diagenesis evaluation in Middle Ages human bones using EDXRF, X-Ray Spectrom. 37 (2008) 32-36. 
1517 [33] S.W. Keenan, A.S. Engel, A. Roy, G.L. Bovenkamp-Langlois, Evaluating the 1518 consequences of diagenesis and fossilization on bioapatite lattice structure and 1519 composition, Chemical Geology 413 (2015) 18-27.

1520 [34] G. Dal Sasso, L. Maritan, D. Usai, I. Angelini, G. Artioli, Bone diagenesis at the 1521 micro-scale: Bone alteration patterns during multiple burial phases at Al Khiday 1522 (Khartoum, Sudan) between the Early Holocene and the II century AD, Paleogeog. 1523 Paleoclimatol. Paleoecol. 416 (2014) 30-42.

1524 [35] M. Lebon, K Müller, L. Bellot-Gurlet, C. Paris, I. Reche, Application des micro1525 spectrométries infrarouge et Raman à l'étude des processus diagénéticques altérant les 1526 ossements paléollithiques, Archeosciences 35 (2011) 179-190.

1527

1528

[36] G. Arnaud, S. Arnaud, A. Ascenzi, E. Bonucci, G. Graziani, On the problem of the 1529 preservation of human bone in sea-water, J. Hum. Evol. 7 (1978) 409-420.

1530 [37] L.S. Bell, A. Elkerton, Uniquemarine taphonomy in human skeletalmaterial recovered fromthe medieval warship Mary Rose, Int. J. Osteoarchaeol. 18 (2008) 5231532 535 .

1533

[38] L.S. Bell, A. Boyde, S.J. Jones, Diagenetic alteration to teeth in situ illustrated by 1534 backscattered electron imaging, Scanning 13 (1991) 173-183.

1535 [39] T.A. Elliot, G.W. Grime, Examining the diagenetic alteration of human bone 1536 material from a range of archaeological burial sites using nuclearmicroscopy, Nucl. Inst. Methods Phys. Res. B77 (1993) 537-547.

1538 [40] A. Virág, Histogenesis of the Unique Morphology of Proboscidean Ivory, J. 1539 Morphol. 273 (2012) 1406-1423.

1540 [41] M. Locke, Structure of Ivory, J. Morphol. 269 (2008) 423-450.

1541 [42] X.W. Su, F.Z. Cui, Hierarchical structure of ivory: from nanometer to centimeter, Mat. Sci. Eng. C, 7 (1999) 19-29.

1543 [43] B.F. McEwen, M.J. Song, W.J. Landis, Quantitative determination of the mineral 1544 distribution in different collagen zones of calcifying tendon using high voltage electron 1545 microscopic tomography, J. Comput. Assist. Microsc. 3 (1992) 201-208.

1546 [44] F.Z. Cui, H.B. Wen, H.B. Zhang, H.D. Li, D.C. Liu, Anistropic indentation 1547 morphology and hardness of natural ivory, Mat. Sci. Eng. C 2 (1994) 87-91. 
1548

1549

1550

1551

1552

1553

1554

1555

1556

1557

1558

1559

1560

1561

1562

1563

1564

1565

1566

1567

1568

1569

1570

1571

1572

1573

1574

1575

1576

1577

1578

1579

[45] E.J. Raubenheimer, J. Dauth, M.J. Dreyer, P.D. Smith, M.L. Turner, Structure and composition of ivory of the African elephant (Loxodonta africana). S. Afr. J. Sci. 86 (1990) 192-193.

[46] D. Large, K. Müller, I. Reiche, Approche analytique pour l'étude des ivores archéologiques. Les defences d'élephant du site de Jinsha (1200-650 BC, Sichuan, Chine), Archeosciences 35 (2011) 167-177.

[47] N.S. Baer, N. Indictor, Chemical Investigations of Ancient Near Eastern Archaeological Ivory Artifacts, in: Advances in Chemistry 138, American Chemical Society. (2009) 236-246.

[48] N.S. Baer, T. Jochsberger, N. Indictor, Chemical Investigations on Ancient Near Eastern Archaeological Ivory Artifacts. Fluorine and Nitrogen Composition in: Advances in Chemistry 171, American Chemical Society, (2009) 139-149.

[49] M. Albéric, A. Gourrier, K. Müller, I. Zizak, W. Wagermaier, P. Fratzl, I. Reiche, Early diagenesis of elephant tusk in marine environment, Paleogeog. Paleoclimatol. Paleoecol. 416 (2014) 120-132.

[50] M. Albéric, A. Gourrier, K. Müller, I. Zizak, W. Wagermaier, P. Fratzl, I. Reiche, Studying the chemical and structural heterogeneities of elephant tusks induced by diagenetic processes in seawater using combined micro-PIXE/RBS and microSAXS/WAXS profiling, $7^{\text {th }}$ International Bone Diagenesis Meeting Lyon, (2013) 16.

[51] S. Tripati, I. Godfrey, Studies on elephant tusks and hippopotamus teeth collected from the early 17th century Portuguese shipwreck off Goa, west coast of India: evidence of maritime trade between Goa, Portugal and African countries, Curr. Sci. 92-3 (2007) 332-339.

[52] T. Tütken, T.W. Vennemann, Fossil bones and teeth: Preservation or alteration of biogenic composition? Paleogeog. Paleoclimatol. Paleoecol. 310 (2011) 1-8 and references therein.

[53] M. Harbeck, G. Grupe, Experimental chemical degradation compared to natural, diagenetic alteration of collagen: implications for collagen quality indicators for stable isotope analysis, Archaeol. Anthropol. Sci. 1 (2009) 43-57.

[54] M.J. DeNiro, S. Weiner, Chemical, enzymatic and spectroscopic characterization of "collagen" and other organic fractions from prehistoric bones, Geochim. Cosmochim. Acta 52 (1988) 2197-2206. 
1580

1581

1582

1583

1584

1585

1586

1587

1588

1589

1590

1591

1592

1593

1594

1595

1596

1597

1598

1599

1600

1601

1602

1603

1604

1605

1606

1607

1608

1609

1610

[55] C.N.G. Trueman, A.K. Behrensmeyer, N. Tuross, S. Weiner, Mineralogical and compositional changes in bones exposed on soil surfaces in Amboseli National Park, Kenya: diagenetic mechanisms and the role of sediment pore fluids, J. Archaeol. Sci. 31 (2004) 721-739.

[56] C.N. Trueman, K. Privat, J. Field, Why do crystallinity values fail to predict the extent of diagenetic alteration of bone mineral? Paleogeog. Paleoclimatol. Paleoecol. 266 (2008) 160-167.

[57] C. Sosa, E. Vispe, C. Nuñez, M. Baeta, Y. Casalod, M. Bolea, R.E.M. Hedges, B. Martinez-Jarreta, Association between ancient bone preservation and DNA yield: a multidisciplinary approach, Am. J. Anthropol 151 (2013) 102-109.

[58] M.M.W. Ulrich, W.R.K. Perizonius, C.F. Spoor, P. Sandberg, C. Vermeer, Extraction of osteocalcin from fossil bones and teeth, Biochm. Biophys. Res. Com. 149 (1987) 712-719.

[59] T.H. Schmidt-Schultz, M. Schultz, Bone Protects Proteins Over Thousands of Years: Extraction, Analysis, and Interpretation of Extracellular Matrix Proteins in Archeological Skeletal Remains, Am. J. Phys. Anthropol. 123 (2004) 30-39.

[60] T.H. Schmidt-Schultz, M. Schultz, Well Preserved Non-collagenous Extracellular Matrix Proteins in Ancient Human Bone and Teeth, Int. J. Osteoarchaeol. 17 (2007) 9199.

[61] T-Y. Ho, The amino acid composition of bone and tooth proteins in Late Pleistocene mammals, Proc. N.A.S 54 (1965) 26-31.

[62] P.M. Masters, Preferential preservation of noncollagenous protein during bone diagenesis: Implications for chronometric and stable isotopic measurements, Geochim. Cosmochim. Acta 51 (1987) 3209-3214.

[63] H. Ochiai, M. Akiyawa, Well-Preserved Collagen from a Late Pleistocene Elephant Ivory in Mechanisms and Phylogeny of Mineralization in Biological Systems $(\mathrm{H}$. Nakahara ed.) Springer, Tokyo (1991) chapter 4.25.

[64] M. Buckley, C. Wadsworth, Proteome degradation in ancient bone: Diagenesis and phylogenetic potential, Paleogeog. Paleoclimatol. Paleoecol. 416 (2014) 69-79.

[65] R.P. Evershed, R.C. Connoly, Post-Mortem Transformations of Sterols in Bog Body Tissues, J. Archaeol. Sci. 21 (1994) 577-583. 
1611 [66] A. C. Colonese, T. Farrell, A. Lucquin, D. Firth, S. Charlton, H.K. Robson, M.

1612 Alexander, O.E. Craig, Archaeological bone lipids as palaeodietary markers, Rapid 1613 Commun. Mass Spectrom. 29 (2015) 611-618.

1614 [67] R.P. Evershed, G. Turner-Walker, R.E.M. Edges, N. Tuross, A. Leyden, 1615 Preliminary Results for the Analysis of Lipids in Ancient Bone, J. Archaeol. Sci. 22 1616 (1995) 277-290.

1617 [68] R.P. Evershed, R. E.M. Hedges, N. Tuross, Preliminary Results for the Analysis of 1618 Lipids in Ancient Bone, J. Archaeol. Sci. 22 (1995) 277-290.

1619 [69] I.M. Saphiro, The lipids of skeletal and dental tissues: their role in mineralization. 1620 In: I. Zipkin (ed), Biological Mineralisation, Wiley: New York, USA (1973).

1621 [70] A. Boaks, D. Siwek, F. Mortazavi, The temporal degradation of bone collagen: A 1622 histochemical approach, Forensic Sci. Int. 240 (2014) 104-110

1623 [71] R.C. Dobberstein, M.J. Collins, O.E. Craig, G. Taylor, K.E.H. Penkman, S. Ritz1624 Timme, Archaeological collagen: Why worry about collagen diagenesis? Archaeol. 1625 Anthropol. Sci. 1 (2009) 31-42.

1626 [72] M.J. Collins, M.S. Riley, A.M. Child, G. Turner-Walker, A Basic Mathematical 1627 Simulation of the Chemical Degradation of Ancient Collagen, J. Archaeol. Sci. 22 1628 (1995) 175-183.

1629 [73] R.W. Henry, Silicone plastination of biological tissue: room-temperature technique 1630 North Carolina technique and products. J. Int. Soc. Plastination, 22 (2007) 26-30.

1631 [74] G. Von Hagens, K. Tiedemann, W. Kriz, The current potential of plastination, 1632 Anat. Embryol. 175 (1987) 411-421.

1633 [75] I. Godfrey, K. Kasi, S. Lussier (dec.), C. Wayne Smith, Conservation of 1634 waterlogged elephant tusks, in: K. Straetkvern, E. Williams (eds.) Proceedings of the 1635 11th ICOM Working Group on Wet Organic Archaeological Materials Conference, 1636 Greenville. 2011, Greenville, (2012) 633-646.

1637 [76] Geological Map of Murcia Community (Spain) 1638 http://www.igme.es/internet/cartografia/cartografia/regional.asp?mapa=murcia200) 1639 12th-01-2015.

1640 [77] F.J. Millero, R. Feistel, D.G. Wright, T.J. McDougall, The composition of standard 1641 seawater and the definition of the reference-composition salinity scale, Deep-Sea Res. I 1642 (2008). 50-72.

1643 [78] http://www.puertos.es (22th-07-2015). 
1644

1645

1646

1647

1648

1649

1650

1651

1652

1653

1654

1655

1656

1657

1658

1659

1660

1661

1662

1663

1664

1665

1666

1667

1668

1669

1670

1671

1672

1673

1674

1675

1676

[79] I. Reiche, L. Favre-Quattropani, C. Vignaud, H. Bocherens, L. Charlet, M. Menu, A multi-analytical study of bone diagenesis: the Neolithic site of Bercy (Paris, France). Measurement Science and Technology 14 (2003) 1608-1619.

[80] D. Rickard, M.A.A. Schoonen, G.W. Luther III, Chemistry of iron sulphides in sedimentary environments. In: M.A. Vairavamurthy, M.A.A. Schoonen, (eds.), Geochemical Transformation of Sedimentary Sulfur, American Chemical Society Symposium Series, 612 (1995) pp. 168-193.

[81] M.P. Álvarez-Iglesias, B. Rubio, Early diagenesis of organic-matter-rich sediments in a ría environment: Organic matter sources, pyrites morphology and limitation of pyritization at depth Estuarine, Coast. Shelf Sci. 100 (2012) 113-123.

[82] M. Polzer, The Bajo de la campana shipwreck and colonial trade in Phoenician Spain. In: Catalogue of the exhibition Assyria to Iberia at the Dawn of the Classical Age, Metropolitan Museum of Art de New York, (2014) p.231.

[83] M.I. Herráez Martín, N. Morán Luengo, T. Antelo, M. Bueso, J.V. Navarro Gascón, N. Valentín, J. A. Herráez, G. Enríquez de Salamanca, A. Gabaldón, C. Vega, M. D. Gayo, T. Gil, Intervenciones de conservación-restauración sobre los marfiles del pecio fenicio del Bajo de la Campana (Cartagena, Murcia) Informes y trabajos del Ministerio de Educación, Cultura y Deporte 10 (2014) 129-148.

[84] A. Pearson, H. Bocherens, F. parís, V. Zeitoun, M. Gérard Early Diagenetic Evolution of Bone Phosphat: A X-ray Diffractometry Analysis, J Archaeol. Sci. 22 (1995) 211-221.

[85] H.I. Hollund, F. Ariese, R. Fernandes, M.M.E. Jans, H. Kars, Testing an alternative high-throughput tool for investigating bone diagenesis: FTIR in attenuated total reflection (ATR) mode, Archaeometry 55, 3 (2013) 507-532.

[86] A. Boskey, N. Pleshko Camacho, FT-IR imaging of native and tissue-engineered bone and cartilage, Biomaterials 28 (2007) 2465-2478

[87] Z. Lu, H. Wang, J. Zeng, J. Liu, Dynamic crystal-growth process observed during hydrothermal coarsening of nanocrystalline hydroxyfluorapatite. J. Cryst. Growth 311 (2009) 4791-4798.

[88] C. Rey, M. Shimizu, B. Collins, M.J. Glimcher, Resolution-enhanced Fourier transform infrared spectroscopy study of the environment of phosphate ions in the early deposits of a solid phase of calcium-phosphate in bone and enamel, and their evolution with age. I: Investigations in the $v_{4} \mathrm{PO}_{4}$ domain. Calcif. Tissue Int. 46 (1990) 384-394. 
[89] C. Rey, M. Shimizu, B. Collins, M.J. Glimcher, Resolution-enhanced Fourier transform infrared spectroscopy study of the environment of phosphate ion in the early deposits of a solid phase of calcium phosphate in bone and enamel and their evolution with age: 2 . Investigations in the $v_{3} \mathrm{PO}_{4}$ domain. Calcif. Tissue Int. 49 (1991) 383-388. [90] S.J. Gadaleta, E.P. Paschalis, F. Betts, P. Sherman, R. Mendelsohn, A.L. Boskey, 1682 Fourier Transform Infrared Spectroscopy on the Solution-Mediated Conversion of Amorphous Calcium Phosphate to Hydroxyapatite: New Correlations Between X-Ray Diffraction and Infrared Data, Calcif. Tissue Int 58 (1996) 9-16. [91] E.P. Paschalis, E. DiCarlo, F. Betts, P. Sherman, R. Mendelsohn, A.L. Boskey, FTIR Microspectroscopic Analysis of Human Osteonal Bone, Calcif. Tissue Int 59 (1996) 480-487.

1688 [92] N. Vandecandelaere, C. Rey, C. Drouet, Biomimetic apatite-based biomaerials: on the critical impact of synthesis and post-synthesis parameters, J. Mater. Sci: Mater. Med. 23 (2012) 2593-2606.

1691 [93] D. Eichert, M. Salomé, M. Banu, J. Susini, C. Rey, Preliminary characterization of 1692 calcium chemical environment in apatitic and non-apatitic calcium phosphates of 1693 biological interest by X-ray absorption spectroscopy, Spectrochim. Acta B 60 (2005.) 850-858.

1695 [94] C. Rey, C. Combes, C. Drouet, H. Sfihi, A. Barroug, Physico-chemical properties 1696 of nanocrystalline apatites: implications for biominerals and biomaterials, Mat. Sci. Eng. C 27 (2007) 198-205.

1698 [95] M. Lebon, I. Reiche, J.-J. Bahain, C. Chadefaux, A.-M. Moigne, F. Fröhlich, F. 1699 Sémah, H.P. Schwarcz, C. Falguères, New parameters for the characterization of diagenetic alterations and heat-induced changes of fossil bone mineral using Fourier transform infrared spectrometry J. Archaeol. Sci. 37 (2010) 2265-2276.

1702 [96] A. Grunenwald, C. Keyser, A.M. Sautereau, E. Crubézy, B. Ludes, C. Drouet, 1703 Revisting carbonate quantification in apatite (bio)minerals: a validated FTIR methodology, J. Archaeol. Sci. 49 (2014) 134-141. [97] K. Müller, C. Chadefaux, N. Thomas, I. Reiche, Microbial attack of archaeological bones versus high concentrations of heavy metals in the burial environment. A case study of animal bones from a mediaeval copper workshop in Paris, Paleogeog. 
[98] E. Goormaghtigh, R. Gasper, A. Bénard, A. Goldsztein, V. Raussens, Protein secondary structure content in solution, films and tissues: Redundancy and complementarity of the information content in circular dichroism transmission and ATR FTIR spectra, Biochim Biophys. Acta 1794 (2009) 1332-1343. reflectance infrared Fourier transform spectroscopy (DRIFTS) for the identification of potential diagenesis and crystallinity changes in teeth, Microchem. J. 76 (2004) 141149.

[100] S. Weiner, O. Bar-Yosef, States of preservation of bones from prehistoric sites in the Near East: a survey, J Archaeol. Sci. 17 (1990) 187-196.

[101] A. Shemesh, Crystallinity and diagenesis of sedimentary apatites. Geochim. Cosmochim. Acta 54 (1990) 2433-2438.

1721 [102] J.D. Termine, A.S. Posner, Infrared analysis of rat bone: age dependency of amorphous and crystalline mineral fractions, Science 153 (1966) 1523-1525. [103] D.M. Byler, H. Susi, Examination of the Secondary Structure of Proteins by Deconvolved FTIR Spectra, Biopolymers 25 (1986) 469-487.

[104] H. Susi, D.M. Byler, Resolution-enhanced Fourier transform infrared spectroscopy of enzymes, Methods. Enzymol. 130 (1986) 290-311. [105] J.T. Pelton, L.R. McLean, Spectroscopic Methods for Analysis of Protein Secondary Structure, Anal. Biochem. 277 (2000) 167-176. [106] K.J. Payne, A. Veis, Fourier Transform IR Spectroscopy of Collagen and Gelatin Solutions: Deconvolution of the Amide I band for Conformational Studies, Biopolymers 27 (1988) 1749-1760. [107] D.A. Prystupa, A.M. Donald, Infrared study of gelatin conformations in the gel and sol states. Polym. Gels Networks, 4 (1996) 87-110. [108] M.T. Doménech-Carbó, M.J. Casas-Catalán, A. Doménech-Carbó, R. MateoCastro, J.V. Gimeno-Adelantado, y F. Bosch-Reig, Analytical study of canvas painting collection from the Basilica de la Virgen de los Desamparados using SEM/EDX, FT-IR, GC and electrochemical techniques, Fresenius' J. Anal. Chem. 369 (2001) 571-575. [109] M. Buendia Ortuño, M. T. Doménech Carbó, T. Pasies-Oviedo, La conservación del marfil de procedencia subacuática. Las defensas de elefante del yacimiento Bajo de la campana (Murcia) in: Proceedings of EMERGE2014 Congress, Universitat Politècnica de Valencia, Valencia: Spain (2014) 249-260. 
1742

1743

1744

1745

1746

1747

1748

1749

1750

1751

1752

1753

1754

1755

1756

1757

1758

1759

1760

1761

1762

1763

1764

1765

1766

1767

1768

1769

1770

1771

1772

1773

1774

[110] I.B. Butler, D. Rickard, Framboidal pyrite formation via the oxidation of iron (II) monosulfide by hydrogen sulphide, Geochim. Cosmochim. Acta 64 (2000) 2665-2672.

[111] J.F. Hubert, P.T. Panish, D.J. Chure, K.S. Prostak, Chemistry, microstructure, petrology, and diagenetic model of Jurassic dinosaur bones, Dinosaur National Monument, Utah. J. Sediment. Res. 66 (1996) 531-547.

[112] D.M. Ibrahim1, A.A. Mostafa, S.I. Korowash, Chemical characterization of some substituted Hydroxyapatites, Chem. Central J. 5 (2011) 74.

[113] D. Rickard, Kinetics of pyrite formation by the $\mathrm{H}_{2} \mathrm{~S}$ oxidation of iron (II) monosulfide in aqueous solutions between 25 and $125^{\circ} \mathrm{C}$ : The rate equation, Geochim. Cosmochim. Acta, 61(1997) 115 - 134.

[114] D. Rickard, Kinetics and mechanism of pyrite formation at low temperatures, Amer. J. Sci. 275 (1975) 636-652.

[115] M. Yücel, S.K. Konovalov, T.S. Moore, C.P. Janzen, G.W. Luther III, Sulfur speciation in the upper Black Sea sediments, Chem. Geol. 269 (2010) 364-375.

[116] H.M. Conesa, F.J. Jiménez-Cárceles, The Mar Menor lagoon (SE Spain): A singular natural ecosystem threatened by human activities, Mar. Pollut. Bull. 54 (2007) 839-849.

[117] M. Vignoles, G. Bonel, D.W. Holcomb, R.A. Young, Influence of preparation conditions of type Bcarbonated hydroxyapatite and on localization of carbonate ions, Calcif. Tissue Int. 43 (1988) 33-40.

[118] S. Cazalbou, D. Eichert, C. Drouet, C. Combes, C. Rey, Minéralisations biologiques à base de phosphates de calcium. C. R. Palevol. 3 (2004) 563-572.

[119] J.C. Hiller, M.J. Collins, A.T. Chamberlain, T.J. Wess, Small-angle X-ray scattering: a high-throughput technique for investigating archaeological bone preservation. J. Archaeol. Sci. 31 (2004) 1349-1359.

[120] J.C. Hiller, T.J. Wess, The use of small-angle X-ray scaterring to study archaeological and experimentally altered bone, J. Archaeol. Sci. 33 (2006) 560-572.

[121] J.H. Muyonga, C.G.B. Cole, K.G. Duodu, Fourier transform infrared (FTIR) spectroscopic study of acid soluble collagen and gelatin from skins and bones of young and adult Nile perch (Lates niloticus), Food Chem. 86 (2004) 325-332.

[122] M. Cagnasso, V. Boero M.A. Franchini, J. Chorover, ATR-FTIR studies of phospholipid vesicle interactions with $\alpha-\mathrm{FeOOH}$ and $\alpha-\mathrm{Fe}_{2} \mathrm{O}_{3}$ surfaces, Colloid Surf. B: Biointerfaces 76 (2010) 456-467. 
1775 [123] A. Omoike, J. Chorover, K.D. Kwon, J.D. Kubicki, Adhesion of Bacteria 1776 Exopolymers to $\alpha-\mathrm{FeOOH}$ : Inner-Sphere Complexation of Phosphodiester Groups, 1777 Langmuir 20 (2004) 11108-11114.

1778 [124] S.J. Parikh, J. Chorover, ATR-FTIR Spectroscopy Reveals Bond Formation 1779 During Bacterial Adhesion to Iron Oxide, Langmuir 22 (2006) 8492-8500.

1780 [125] J.D. Termine, The tissue-specific proteins of the bone matrix, in: The Chemistry 1781 and Biology of Mineralized Tissues (W.T. Butlesr ed.) Ebsco-Media Inc., Birmingham, 1782 USA (1984) 94-97.

1783 [126] P.H. Abelson, Paleobiochemistry and Organic Geochemistry, Prog Chem. Org. 1784 Nat. Prod. 17 (1959) 379-403.

1785 [127] A. Karpowicz, Ageing and deterioration of proteinaceous media, Stud. Conserv. $178626(1981) 153-160$.

1787 [128] H. Bocherens, A. Tresset, F. Wiedemann, F. Giligny, F. Lafage, Y. Lanchon, A. 1788 Mariotti, Diagenetic evolution of mammal bones in two French Neolithic sites, Bull. 1789 Soc. Géol. France 168 (1997) 555-564.

1790 [129] T. Werz, M. Baumann, U. Wolfram, C.E. Krill III, Particle tracking during 1791 Ostwald ripening using time-resolved laboratory X-ray microtomography, Mater. 1792 Charact. 90 (2014) 185-195.

1793 [130] M. Sandström, Y. Fors, I. Persson, The Vasa's new battle: Sulphur, acid and iron, 1794 Vasa Studies 19, The Swedish National Maritime Museums, Stockholm (2003).

1795 [131] P. Chaynes, A.F. Mingotaud, Analysis of commercial plastination agents, Surg. 1796 Radiol. Anat. 26 (2004) 235-238.

1797 [132] M. Buendia-Ortuño, La conservación del marfil de procedencia subacuática: las 1798 defensas de elefante del Bajo de la campana (San Javier, Murcia) del Museo Nacional 1799 de Arqueología Subacuática, PhD Thesis, 2016. 
Figure 1.- Map of the archaeological area Polígono submarino de Cabo de Palos, which includes the archaeological sites of Punta de Algas, Bajo de la campana, Bajo de Dentro, Los Esculls, Escolletes 1, Escolletes 2 and Playa de las Amoladeras.

Figure 2.- A) View of archaeological tusk fragment Inv. No. SJBC_11_2471. B) View of the transverse section of the archaeological tusk fragment used in the present study.

Figure 3.- Photograph of the transverse section of the tusk retrieved from the wreck obtained by stereoscopic microscopy (specular episcopic illumination). A) A Schreger pattern can be seen in the ivory region. The sampling point for ivory (DA) and the black-greyish microcrystalline matter that filled the ivory-cementum junction (DCJ). B) Sampling points on the cementum layer: inner cementum (CAI) and outer cementum

Figure 4.-A) The IR absorption spectrum of sample CAO in the $1800-500 \mathrm{~cm}^{-1}$. B) Detail of the curve fitting process carried out on the $v_{3} v_{1}\left(\mathrm{PO}_{4}\right)$, the original spectrum, the resultant spectrum and the underlying bands obtained. C) Detail of the curve fitting process carried out on the $v_{4} \mathrm{PO}_{4}{ }^{3-}$ band, the original spectrum, the resultant spectrum and the underlying bands. D) Detail of the $v_{4}\left(\mathrm{PO}_{4}\right)$ band. Heights of the IR bands at 565 and $605 \mathrm{~cm}^{-1}$ that corresponded to the $v_{4}\left(\mathrm{PO}_{4}\right)$ and the height in the valley used to calculate the IRSF.

Figure 5.- A) Photograph (50X, XPL) of the cross section of a sample excised in the outer ivory part in the transverse section of the tusk from the wreck: D (ivory); DI (ivory with pyrite inclusions); DD (orange-died ivory). B) Secondary electron image of the outer orange-brown ivory layer with skeletal remains of marine microorganisms deposited in the mineral biopatite. C) Backscattered electron image of an area of the ivory layer died black with the pyrite microcrystals included in the mineral biopatite. 
1836 Figure 6.- Secondary electron image from: A) the ivory from the modern tusk. B) the 1837 ivory from the archaeological tusk. C) Detail of the ivory from the modern tusk. D)

1838

1839

1840

1841

1842

1843

1844

1845

1846

1847

1848

1849

1850

1851

1852

1853

1854

1855

1856

1857

1858

1859

1860

1861

1862

1863

1864

1865

1866

1867

Figure 7.- A) Secondary electron image of the outer cementum surface from the modern tusk. B) Secondary electron image of the outer cementum surface from the archaeological tusk. C) Secondary electron image of the inner cementum surface that came into contact with the cementum-ivory junction from the archaeological tusk. D) Backscattered electron image of the framboidal pyrite aggregates on the inner cementum layer from the archaeological tusk.

Figure 8.- Secondary electron image that shows details of the alveolar morphology of the bioapatite on the inner surface of the cementum layer of the Bajo de la campana tusk. Both a) small apatitic grains and b) pyrite framboids and small apatitic grains can be seen inside the alveoli.

Figure 9.- The IR absorption spectra of ivory (DM) and cementum (CM) from the modern tusk.

Figure 10.- The IR absorption spectra of outer cementum (CAO), inner cementum (CAI), ivory (DA) and materials deposited in the ivory-cementum junction (DCJ) of the archaeological tusk.

Figure 11.- Diagrams showing the correlation among: A) the $\mathrm{I}_{1030} / \mathrm{I}_{1020}$ ratio vs. IRSF; B) $\mathrm{Ca} / \mathrm{P}$ vs. IRSF; C) $\mathrm{HPO}_{4}{ }^{2-}$ content $v s$. the $\left(\mathrm{R}\left(\mathrm{HPO}_{4}{ }^{2-}\right)_{\mathrm{na}}\right) /\left(\mathrm{R}\left(\mathrm{HPO}_{4}{ }^{2-}\right)_{\mathrm{a}}\right)$ ratio; D) PM/P vs. IRSF.

Figure 12.- The Amide I curve fitted band and underlying bands that resulted from the curve fitting process for: a) the ivory of the modern tusk (DM); b) the cementum of the modern tusk (CM). ( $\beta$-1) intermolecular $\beta$-sheet, $(\beta-2)$ intramolecular $\beta$-sheet, (rc) random coil, $(\alpha)$ helical, $(\alpha \mathrm{t})$ triple-helical and $(\mathrm{t})$ turns. 
1868 Figure 13.- The Amide I curve fitted band and the underlying bands that resulted from 1869 the curve fitting process for: a) the ivory of the archaeological tusk (DA); b) the inner 1870 cementum of the archaeological tusk (CAI); c) the outer cementum of the archaeological 1871 tusk (CAO). ( $\beta$-1) intermolecular $\beta$-sheet, $(\beta-2)$ intramolecular $\beta$-sheet, (rc) random 1872 coil, $(\alpha)$ helical, $(\alpha \mathrm{t})$ triple-helical and $(\mathrm{t})$ turns.

1874 Figure 14.- Chromatograms of the $\mathrm{N}(\mathrm{O}, \mathrm{S})$ ethoxycarbonyl (EOC) ethyl esters of the 1875 amino acids found in the proteinaceous matter extracted from the modern tusk (ivory, 1876 DM (a)) and the archaeological tusk (ivory, DA (b) and cementum CA (c)). Alanine 1877 (Ala), Glycine (Gly), Valine (Val), Leucine (Leu), Isoleucine (Ileu), Proline (Pro), 1878 Aspartic a. (Asp), Hydroxyproline (OHPro), Methionine (Meth), Glutamic a. (Glu), 1879 Phenylalanine (Phe), Lysine (Lys), Histidine (His), Tyrosine (Tyr).

Figure 15.- Chromatograms of the ethyl esters of fatty acids, glyceryl and cholestyl esters found in the lipid matter extracted from the modern tusk (ivory, DM (a)) and the archaeological tusk (ivory, DA (b) and cementum CA (c)). Palmitic a. (Pal), Oleic a.

1885 Cholestyl oleate (ChOle). 


\section{Table captions}

Table 1.- Elemental composition of the sediment on the bed of the Bay of Bajo de la campana by FESEM-EDX, expressed as a weight percentage (wt\%). The major anions identified by spectrophotometry and expressed as a weight percentage (wt $\%$ ), the characteristic IR absorption bands of the minerals identified by FTIR and the minerals with the characteristic $d$-spacing values obtained by the diffractogram.

Table 2.- Elemental composition of the major and minor elements detected in the modern and wreck tusk samples and in the materials deposited in the ivory-cementum junction expressed as a weight percentage (wt\%). Mean values were obtained from three semiquantitative measurements taken from sample areas at $c a .50-100 \mu \mathrm{m}^{2}$ and standard deviation values (SD). Some elements were detected in the spot analysis (s.a.) in individual grains. A number of elements were below the limit of detection (-) in the sample when both the area and spot measurements were taken. The listed $\mathrm{Ca} / \mathrm{P}$ ratios are expressed as a molar ratio.

Table 3.- Elemental composition of the major and minor elements detected by the spot analysis performed on the inner and outer cementum surfaces with an alveolar morphology and the small rounded apatitic grains deposited in alveoli expressed as a weight percentage $(\mathrm{wt} \%)$. The points at which the spot analyses were performed are indicated with arrows in Fig. 8a,b. The calculated molar ratio $\mathrm{Ca} / \mathrm{P}$ for all the spot analyses performed is also shown. (-) Elements were below the limit of detection.

Table 4.- Values of the diagenetic indices used to characterise the structure of the different tusk parts: $\mathrm{Ca} / \mathrm{P}, \mathrm{CI}$, IRSF, $\mathrm{C} / \mathrm{P}$ ratio; carbonate weight percentage $\left(\mathrm{wt}_{\mathrm{t}} \mathrm{CO}_{3}\right)$, $\mathrm{I}_{1030} / \mathrm{I}_{1020}$ ratio, $\mathrm{HPO}_{4}{ }^{2-}$ content and $\left.\mathrm{R}\left(\mathrm{HPO}_{4}{ }^{2-}\right)_{\mathrm{na}}\right) /\left(\mathrm{R}\left(\mathrm{HPO}_{4}{ }^{2-}\right)_{\mathrm{a}}\right.$ ratio.

Table 5.- The percentage area contribution of the components of the amide I band in the IR spectra for the archaeological and modern tusk samples. The protein (amide I) /phosphate $v_{3} v_{1}\left(\mathrm{PO}_{4}\right)$ band area ratio $(\mathrm{PM} / \mathrm{P})$. 
1919 Table 6.- Amino acid content of the proteinaceous organic matter contained in the 1920 archaeological and modern tusks. Main $\mathrm{m} / \mathrm{z}$ values of compounds and fragment ions 1921 found in the MS of each derivative of the amino acid (base peak in bold).

1922

1923 Table 7.- The lipid compounds found in the archaeological and modern tusk samples by 1924 GC-MS. The characteristic m/z values of the identified compounds are also listed. Main $1925 \mathrm{~m} / \mathrm{z}$ values of compounds and fragment ions found in the MS of each lipid and ethyl 1926 ester of fatty acid (base peak in bold).

1927

1928

1929

1930

1931

1932

1933 
Figure 1
Click here to download high resolution image

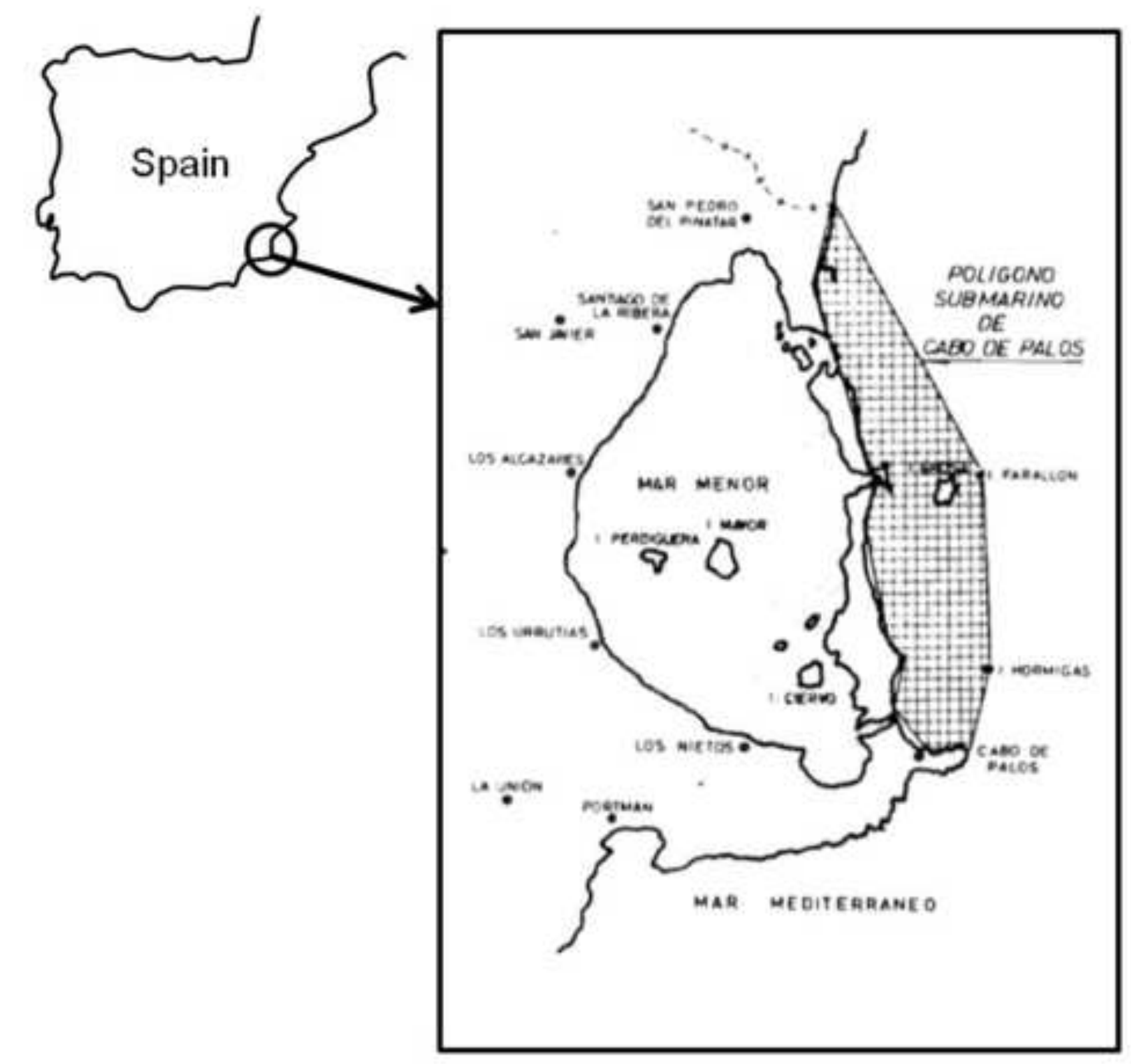


Figure 2
Click here to download high resolution image

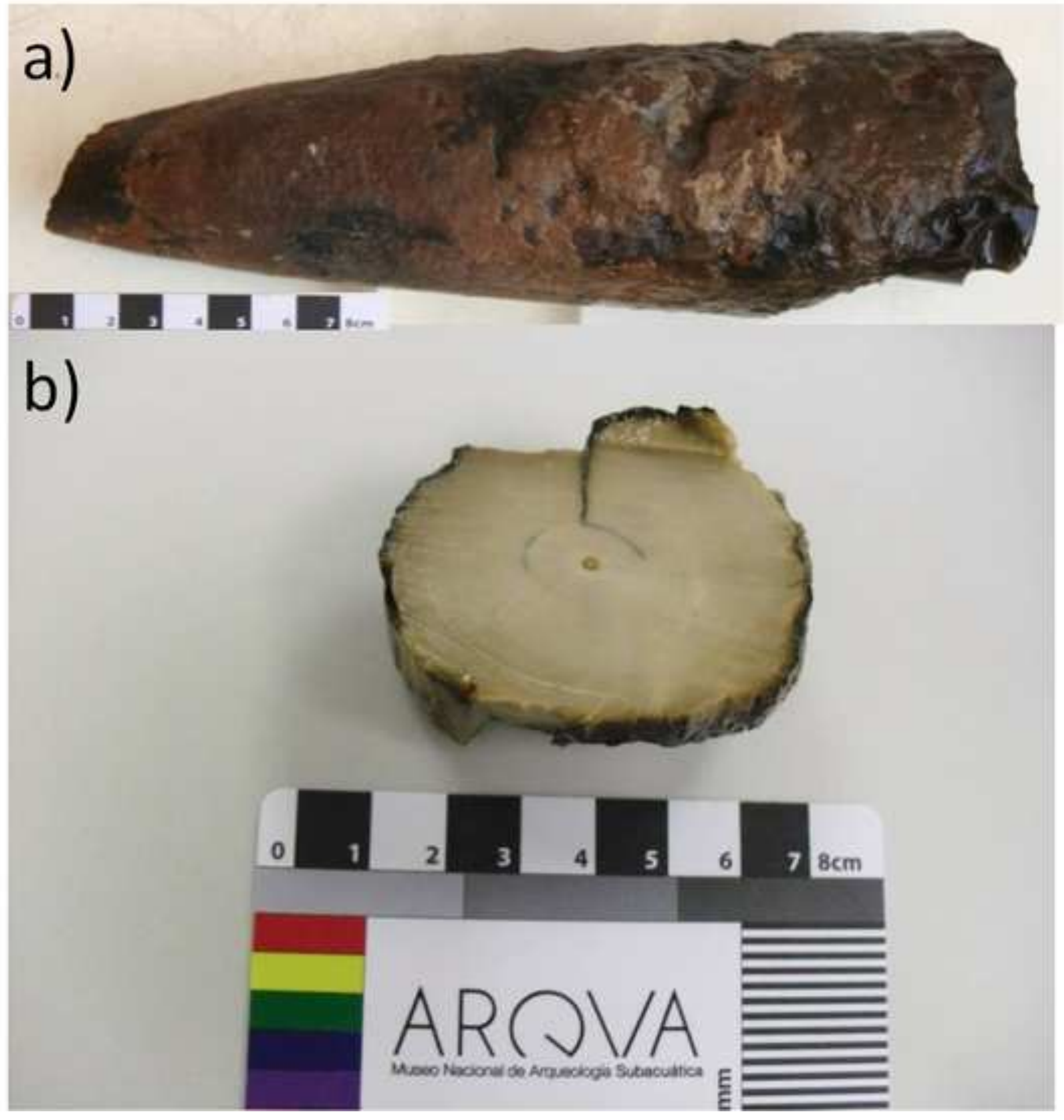


Click here to download high resolution image

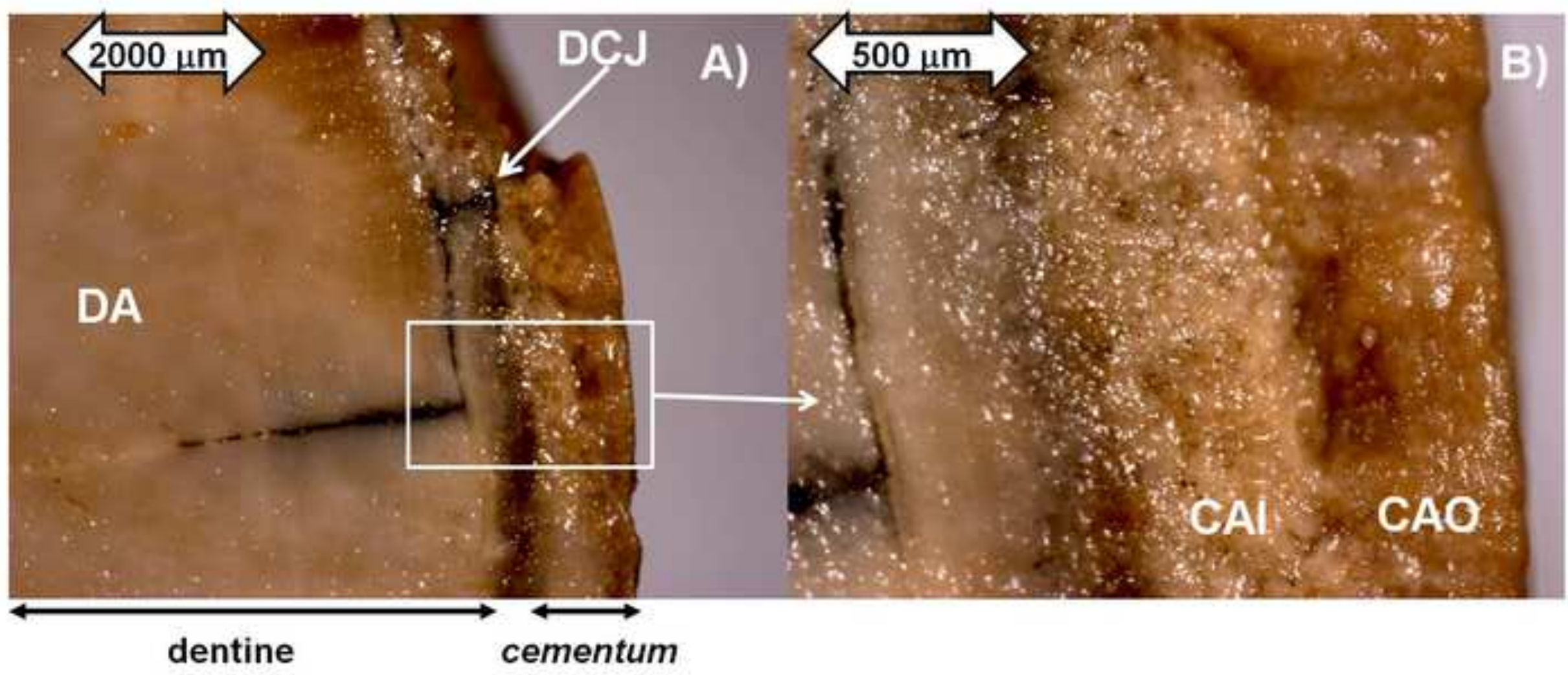


Click here to download high resolution image
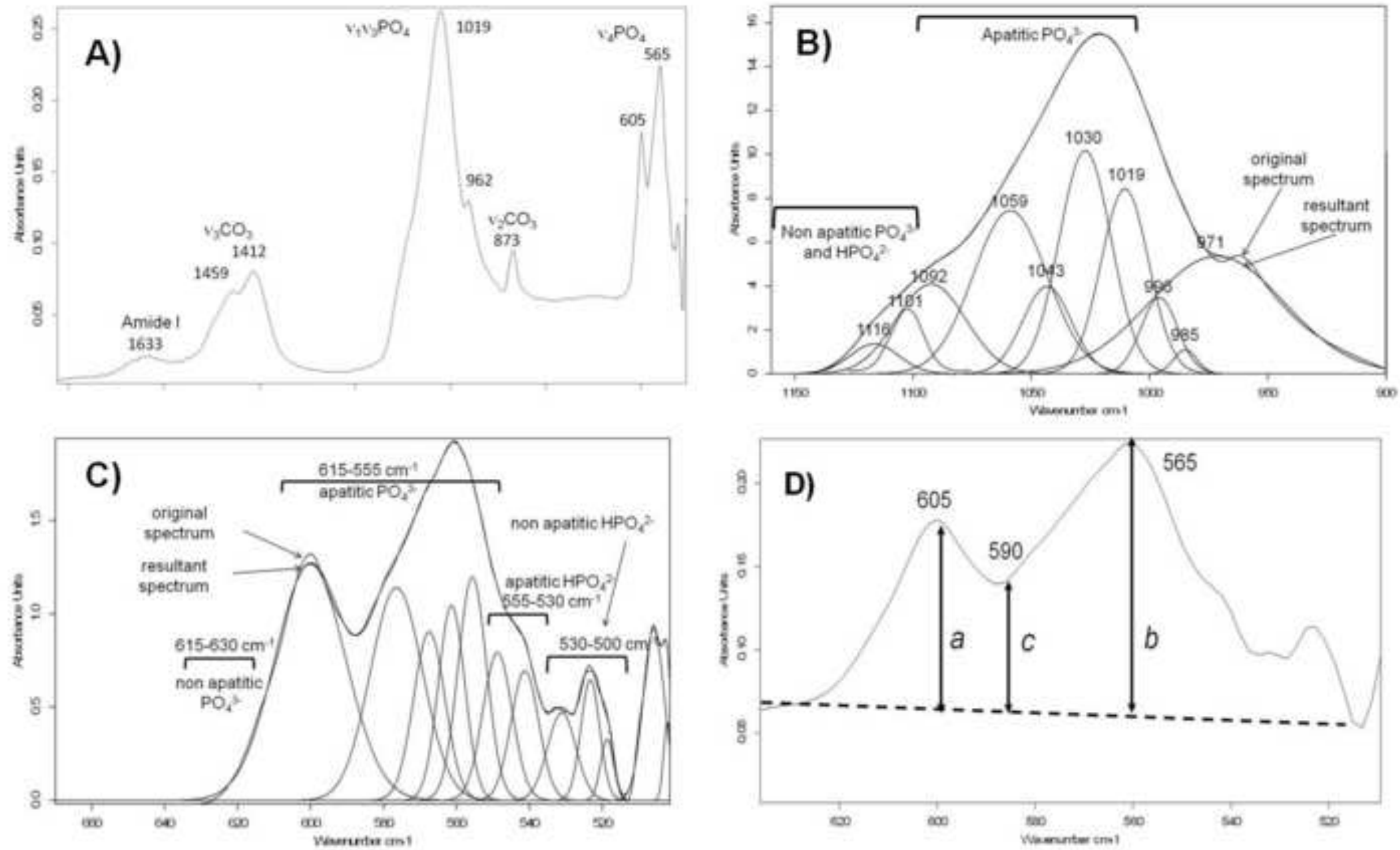
Click here to download high resolution image

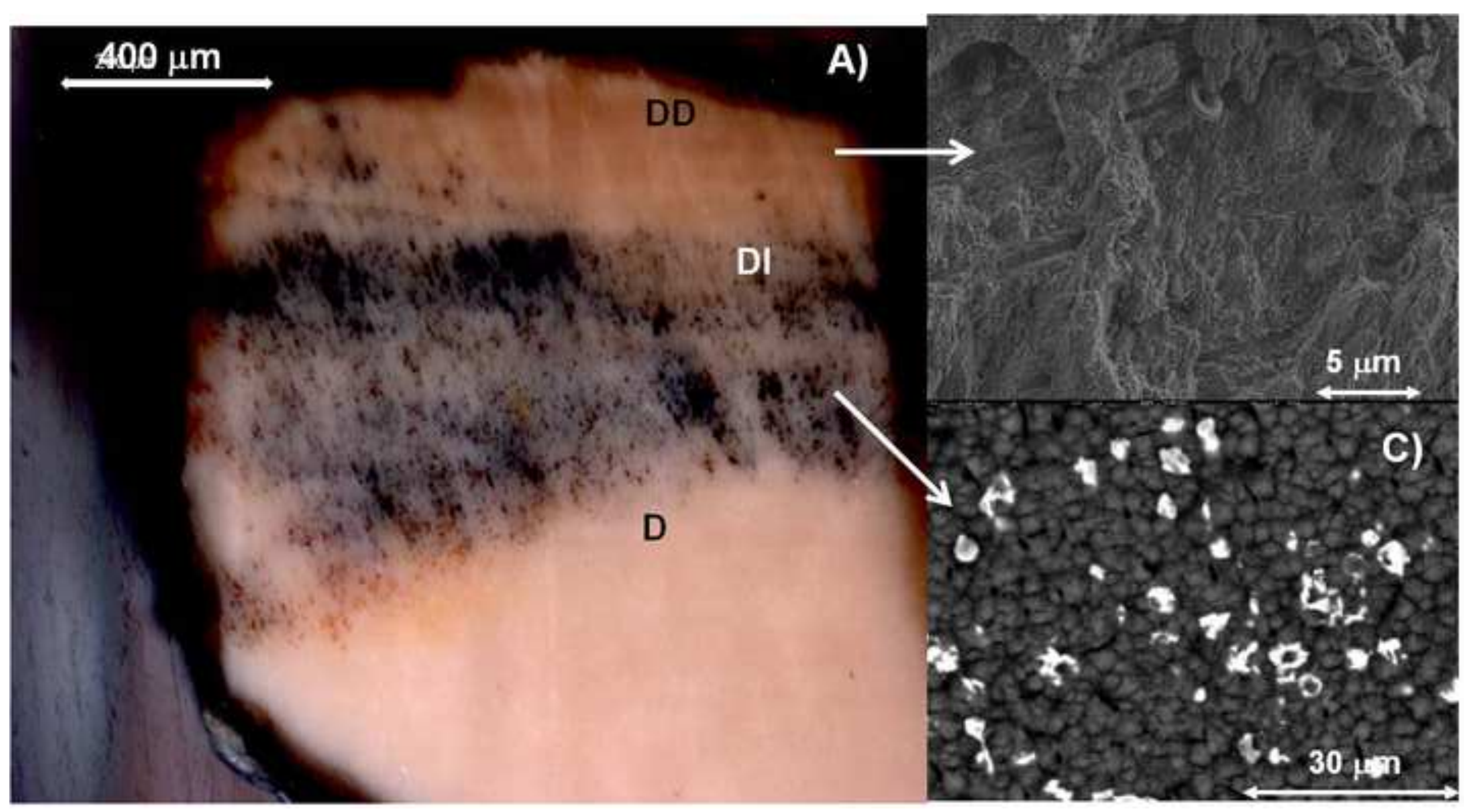

D 
Click here to download high resolution image

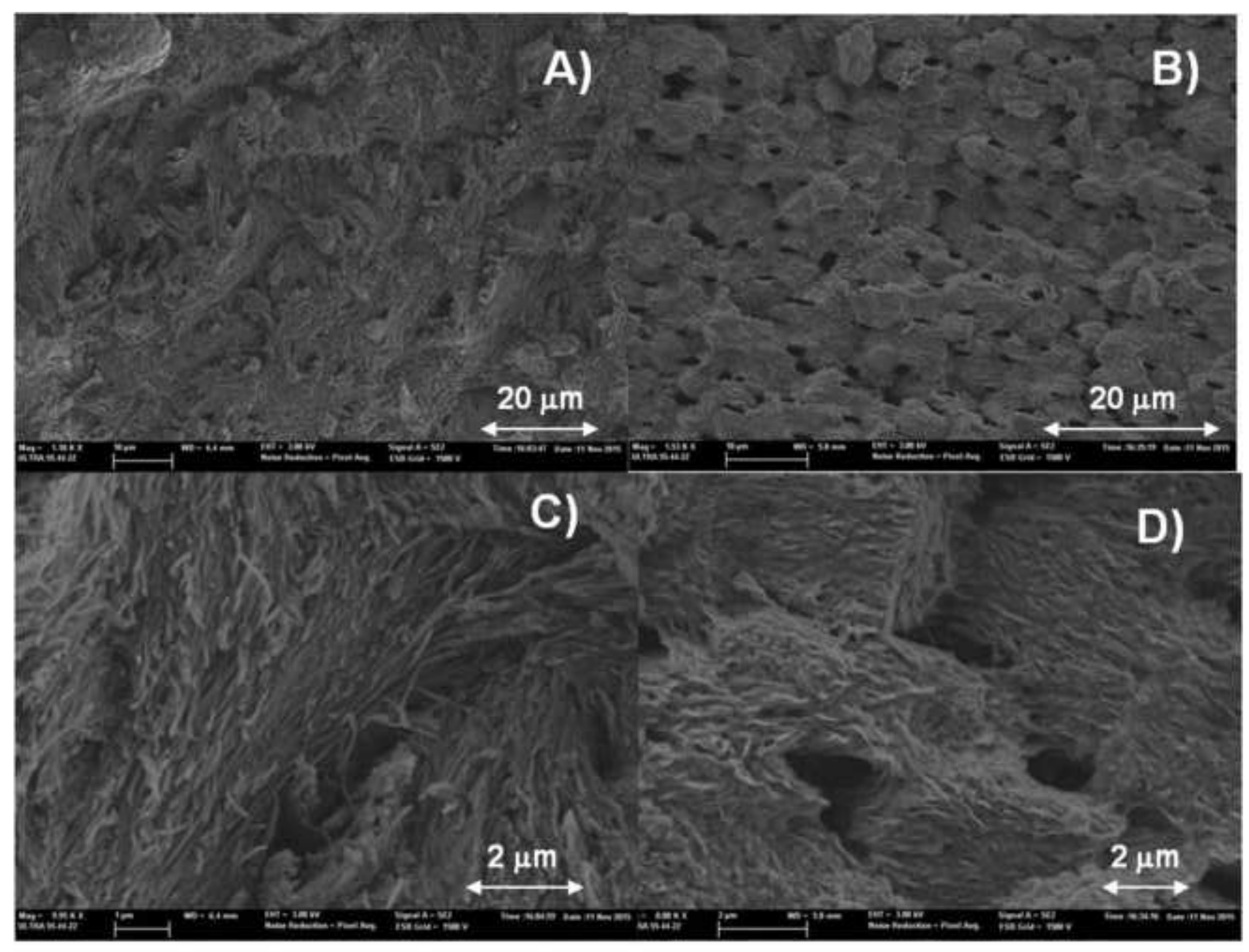




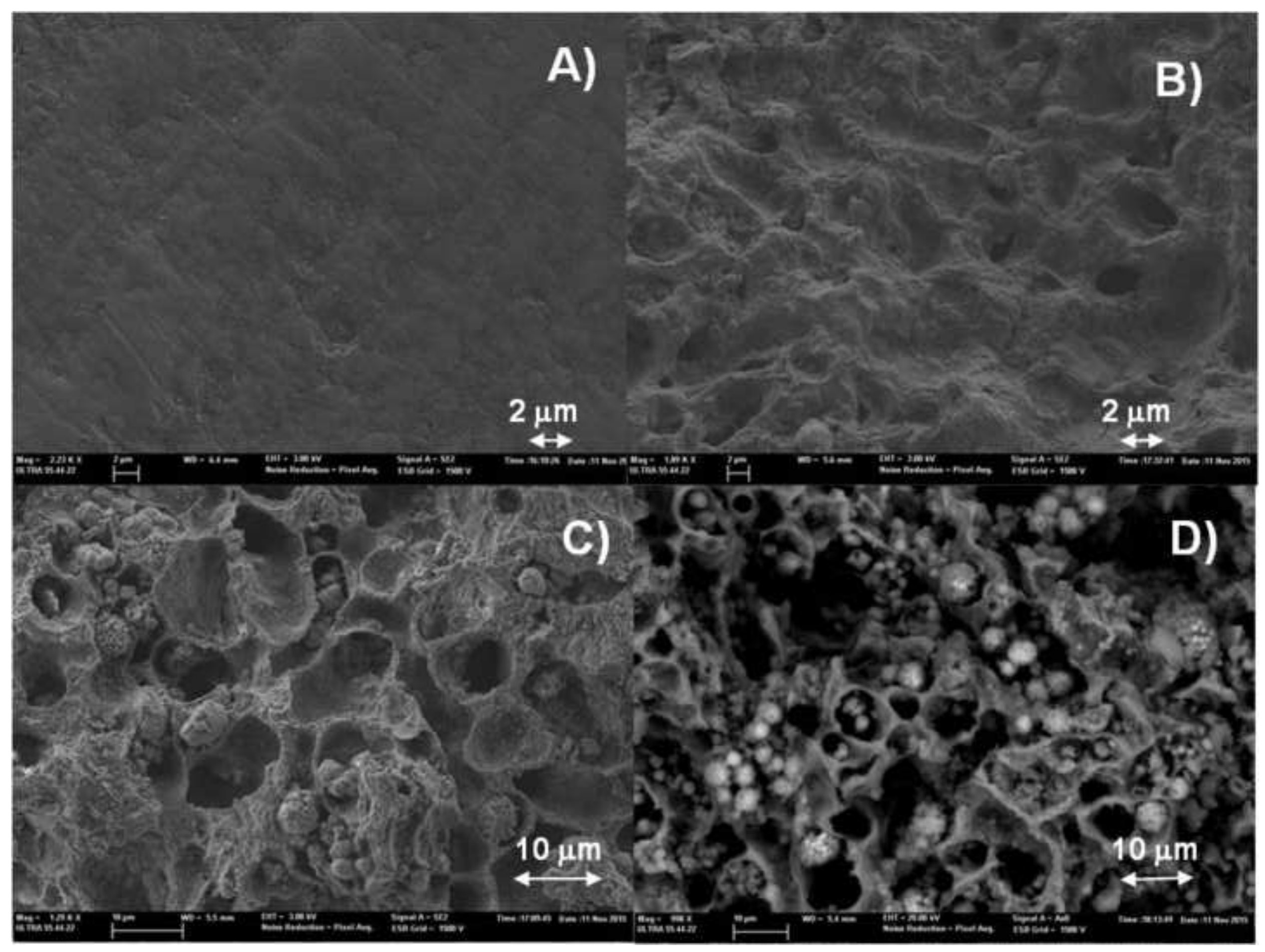

A)

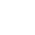

.


Click here to download high resolution image

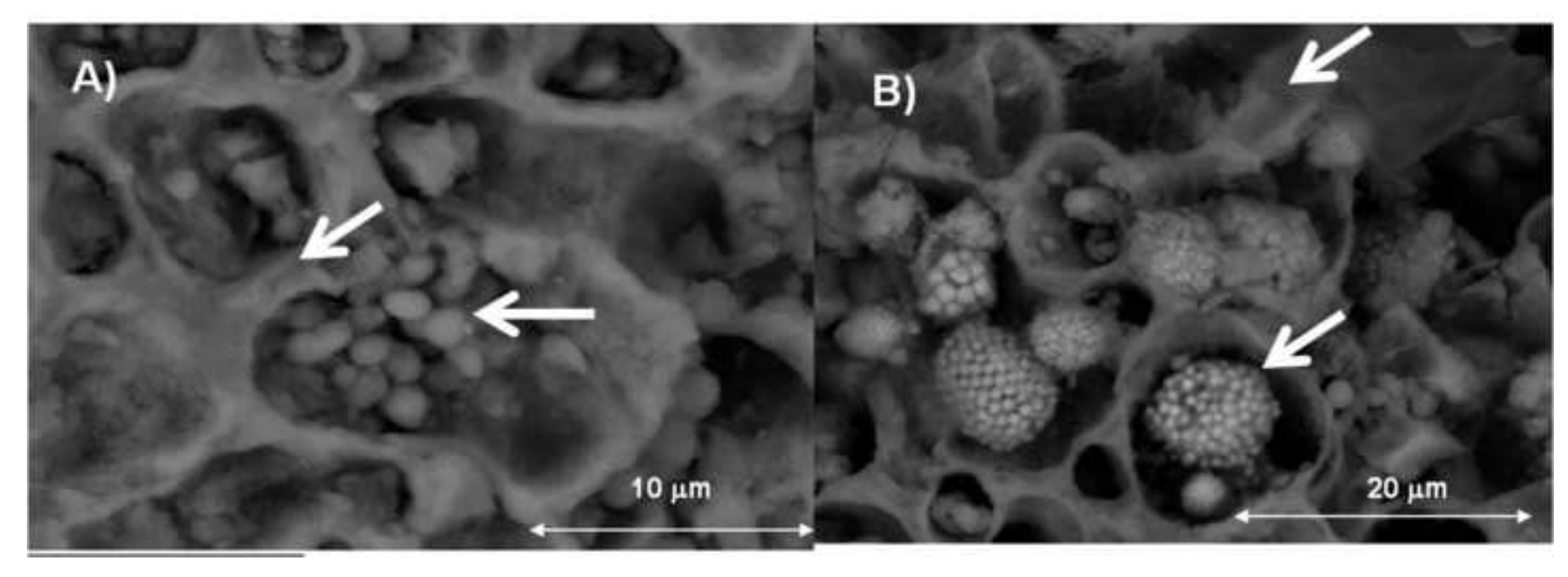




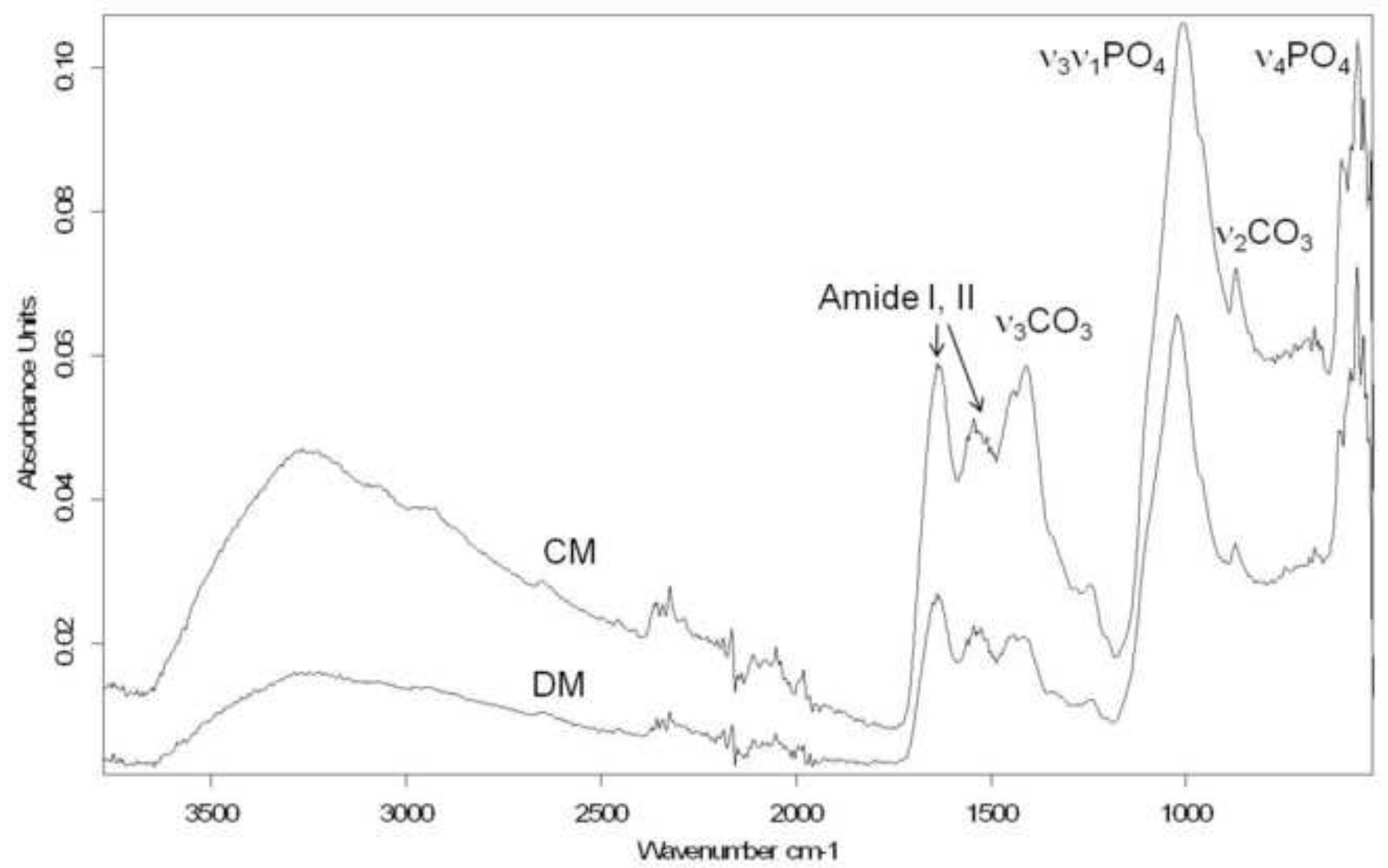


Click here to download high resolution image

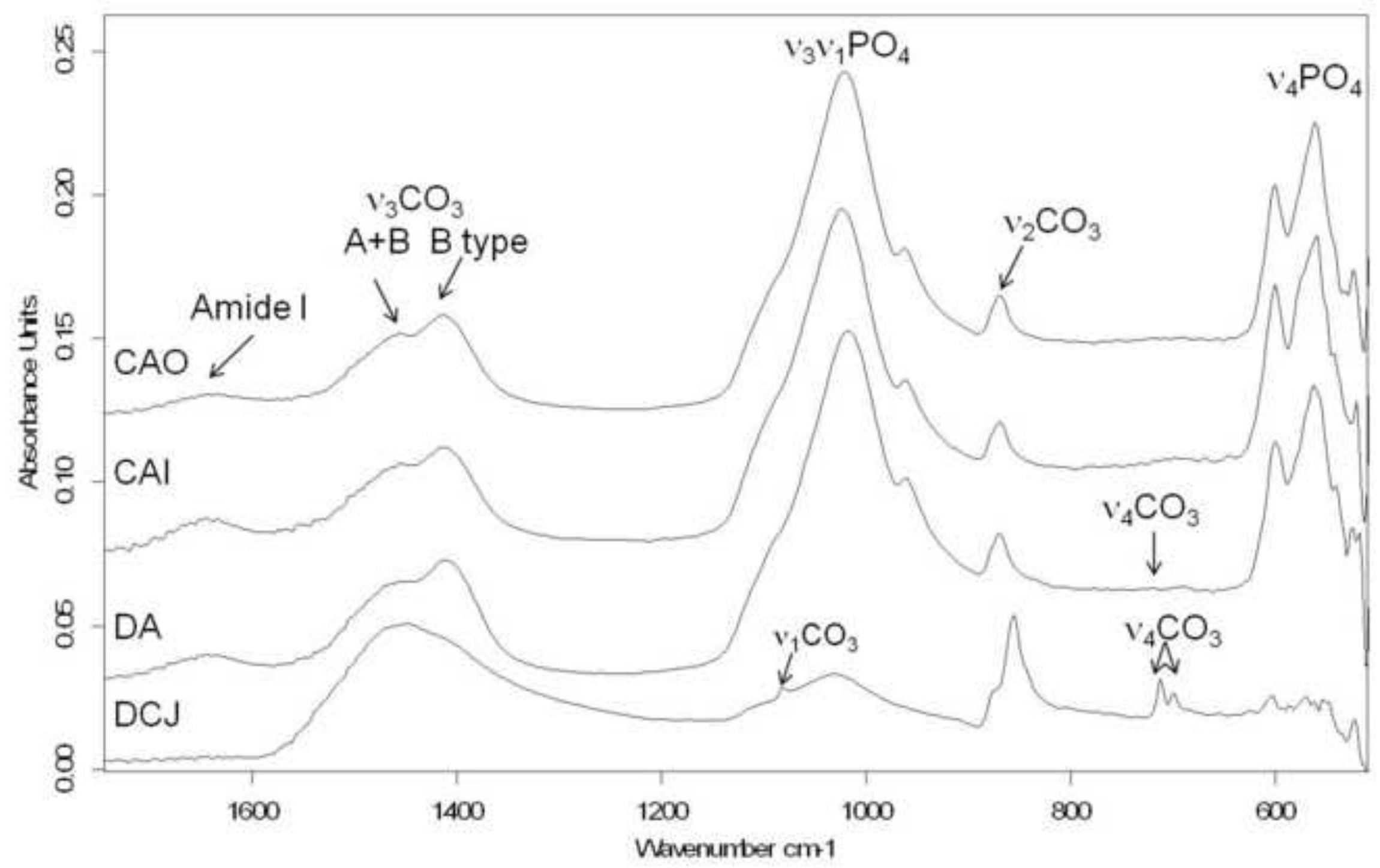



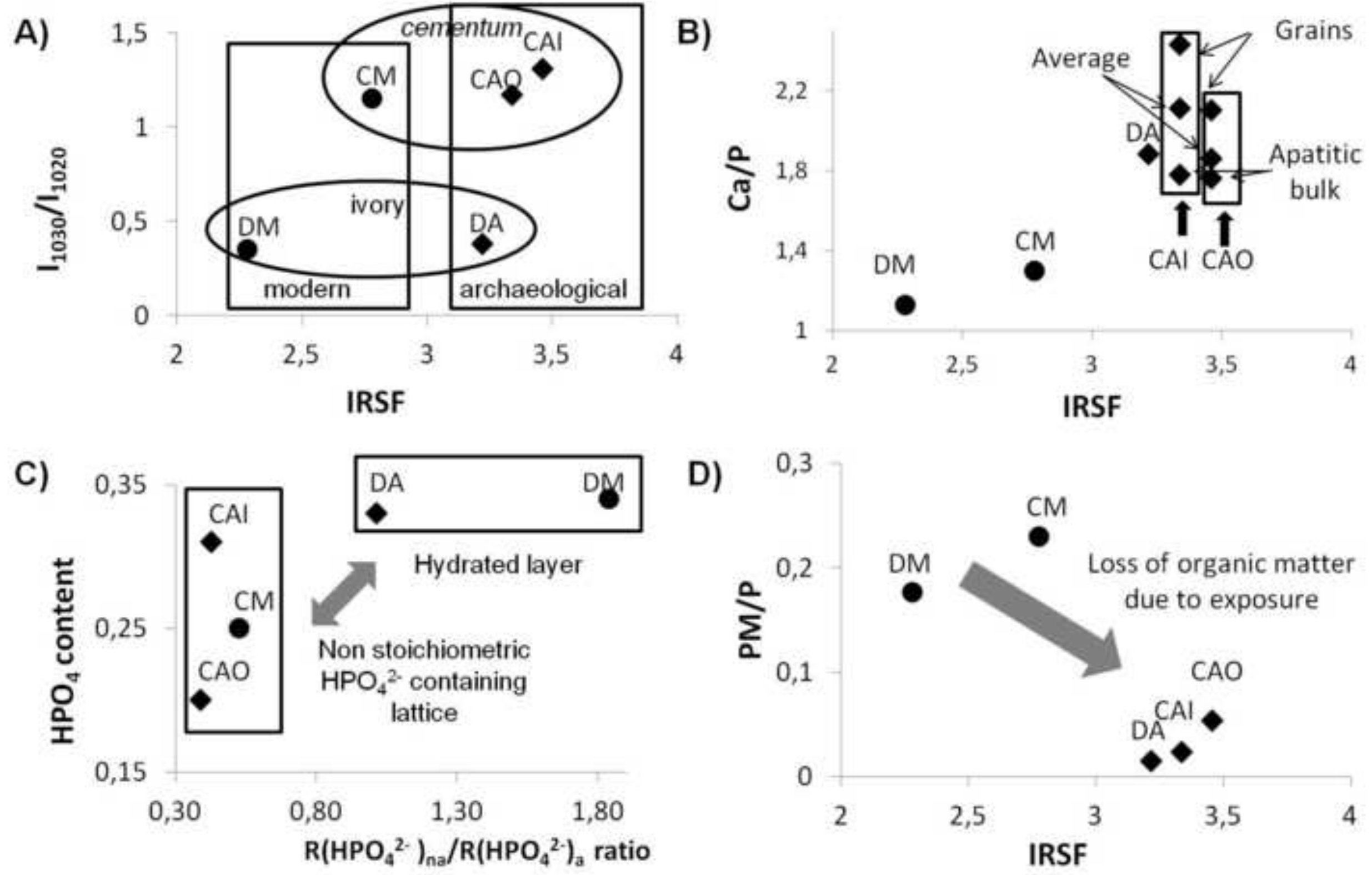

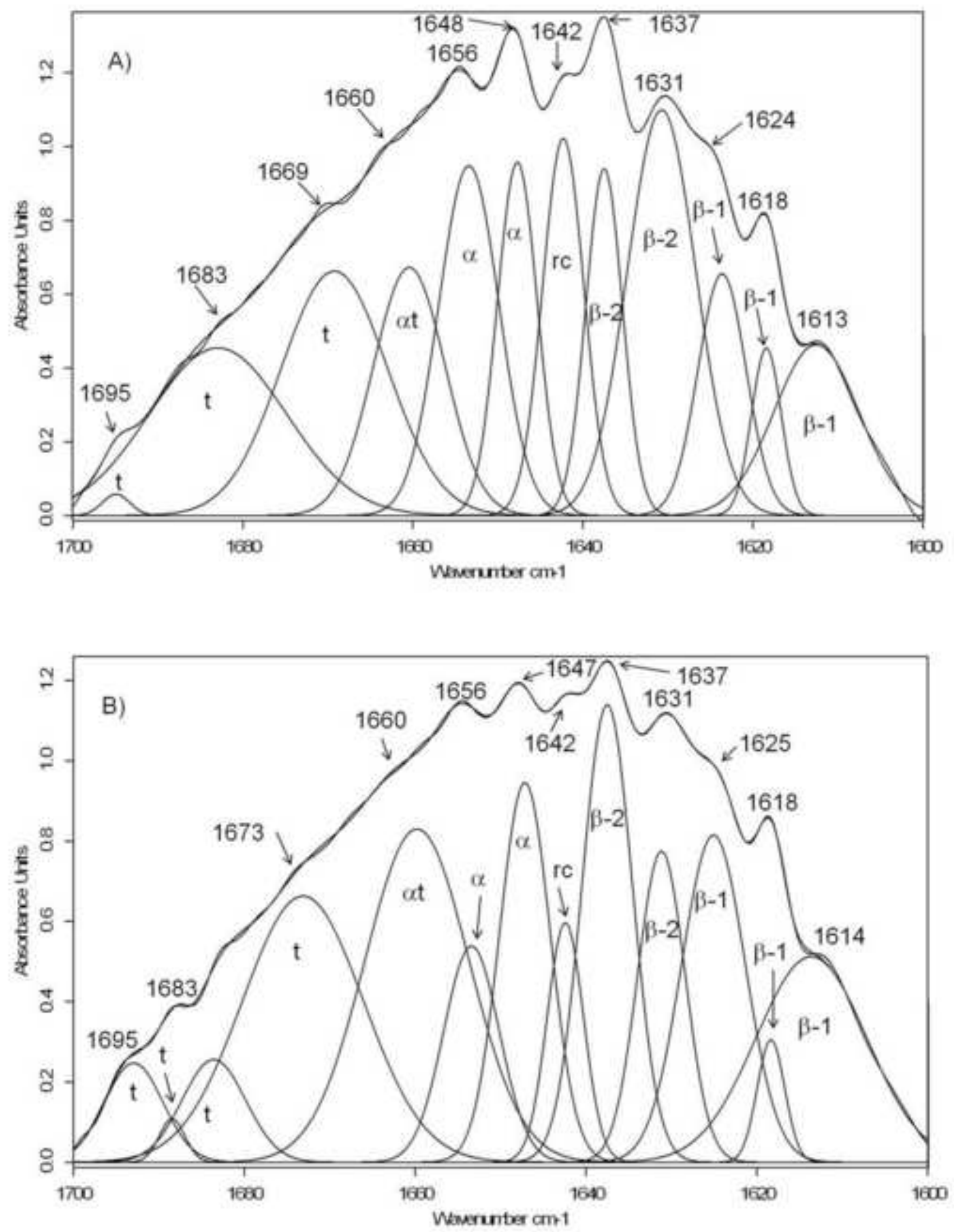

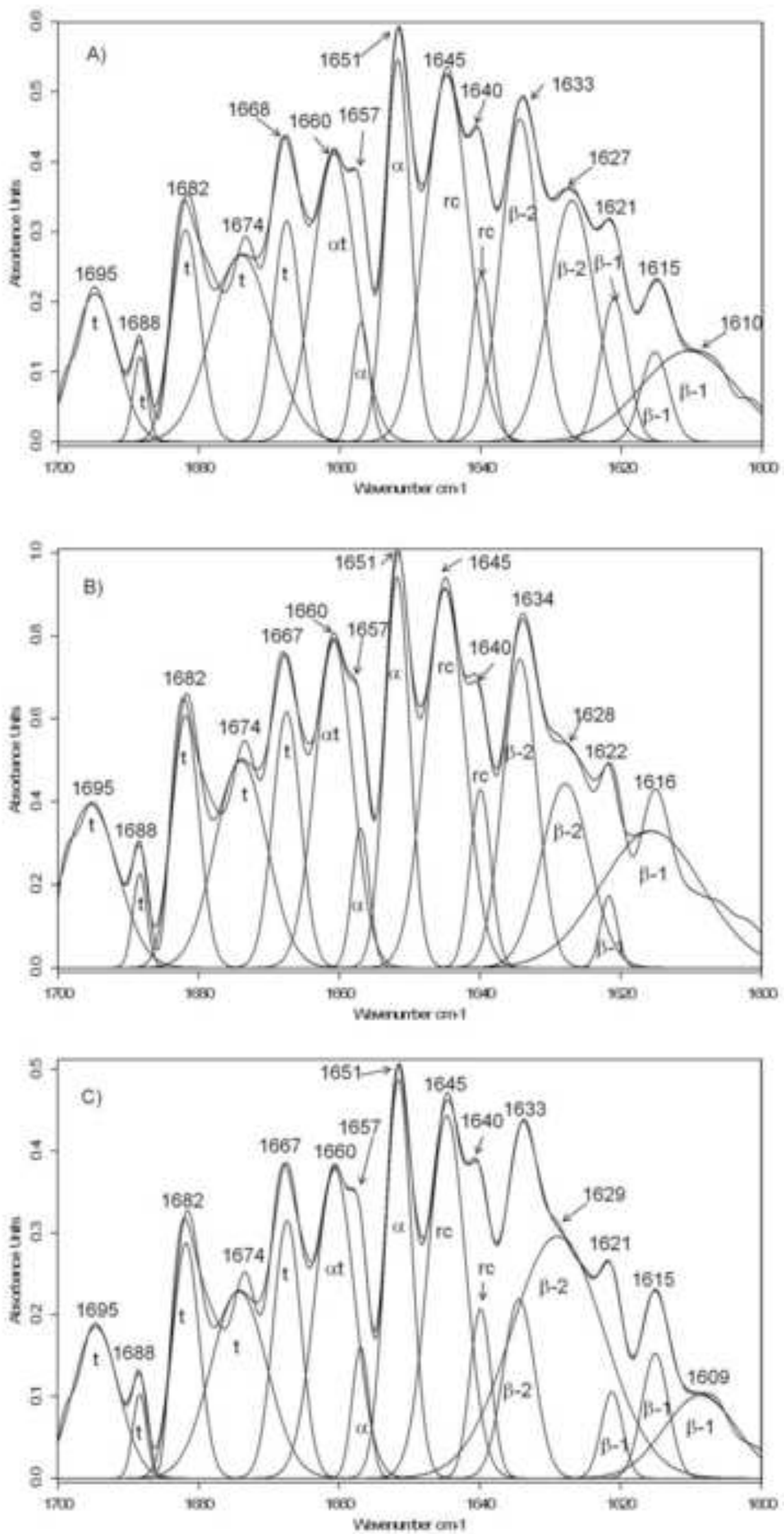


\section{Abundance}

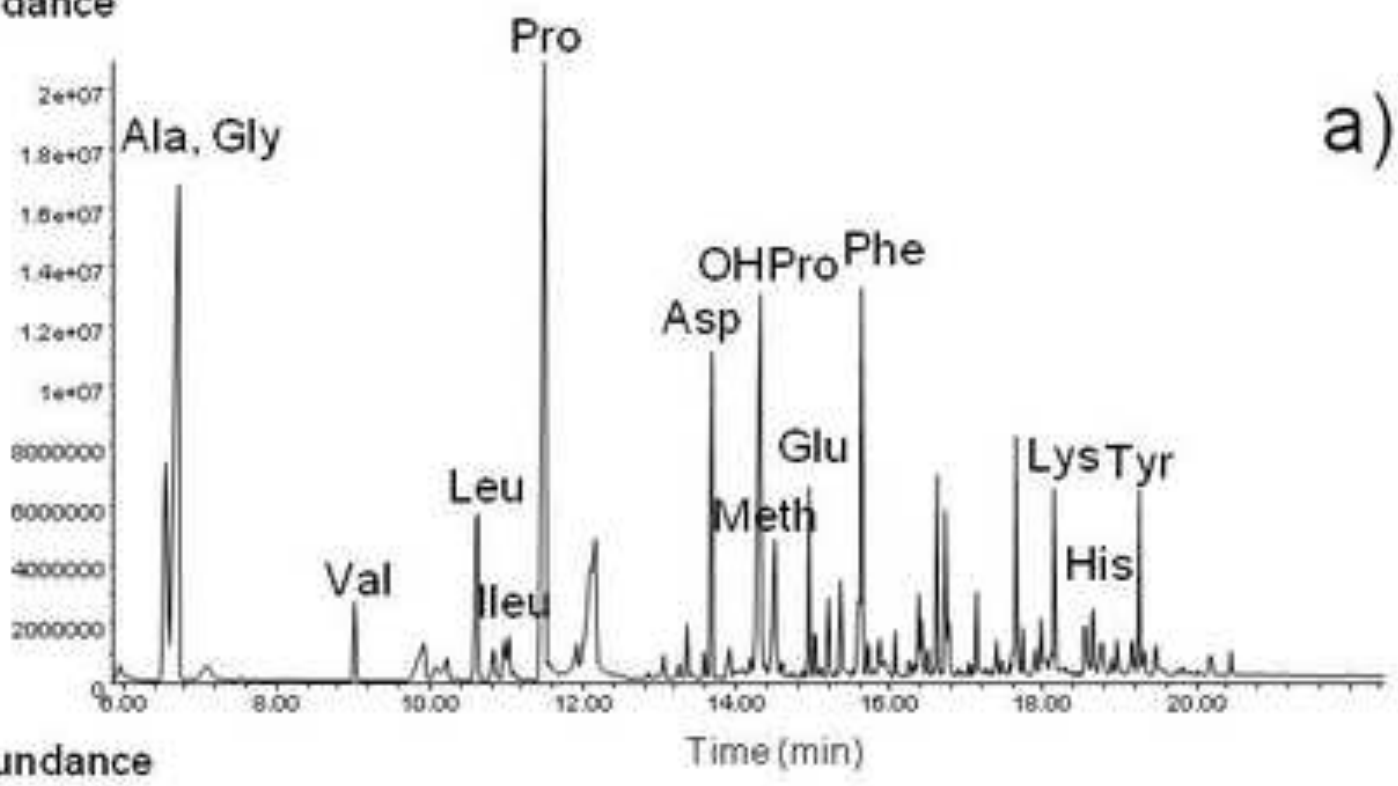

\section{Abundance}

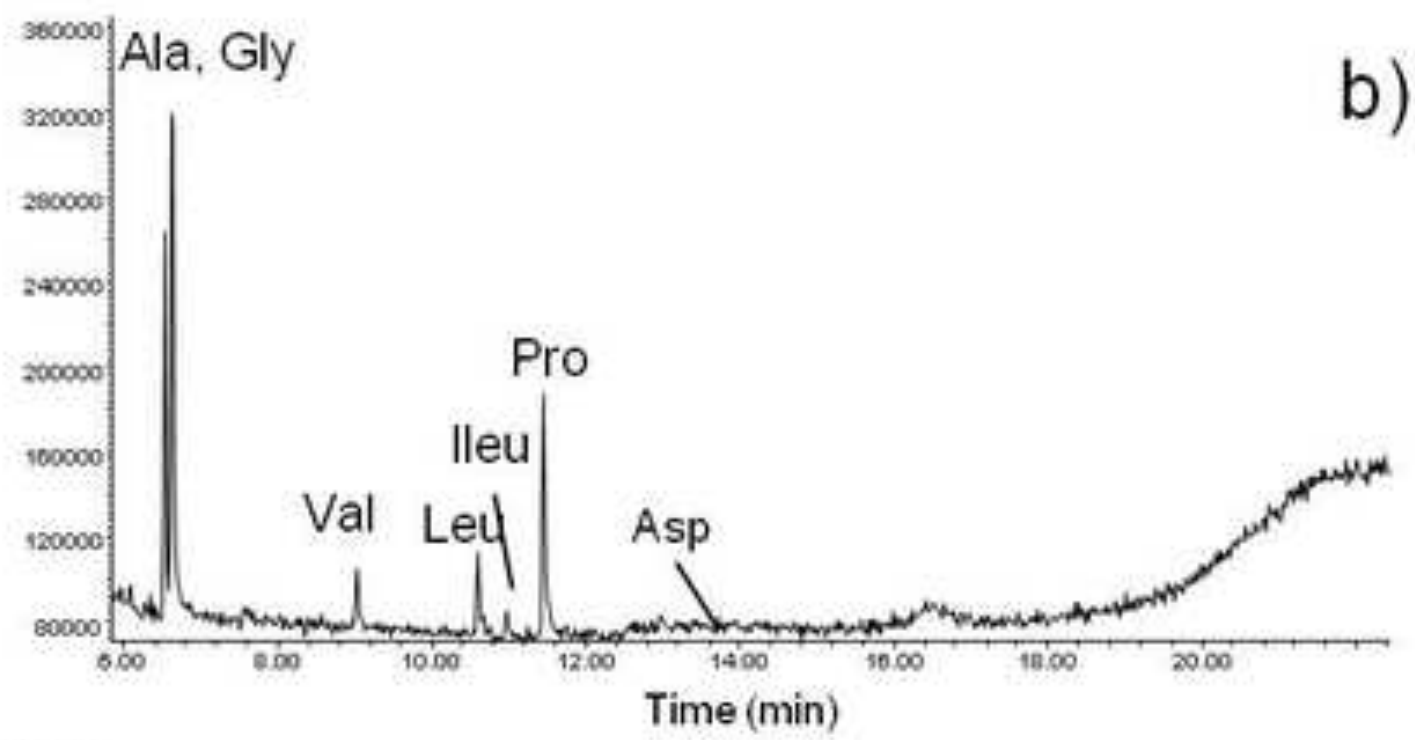

\section{Abundance}

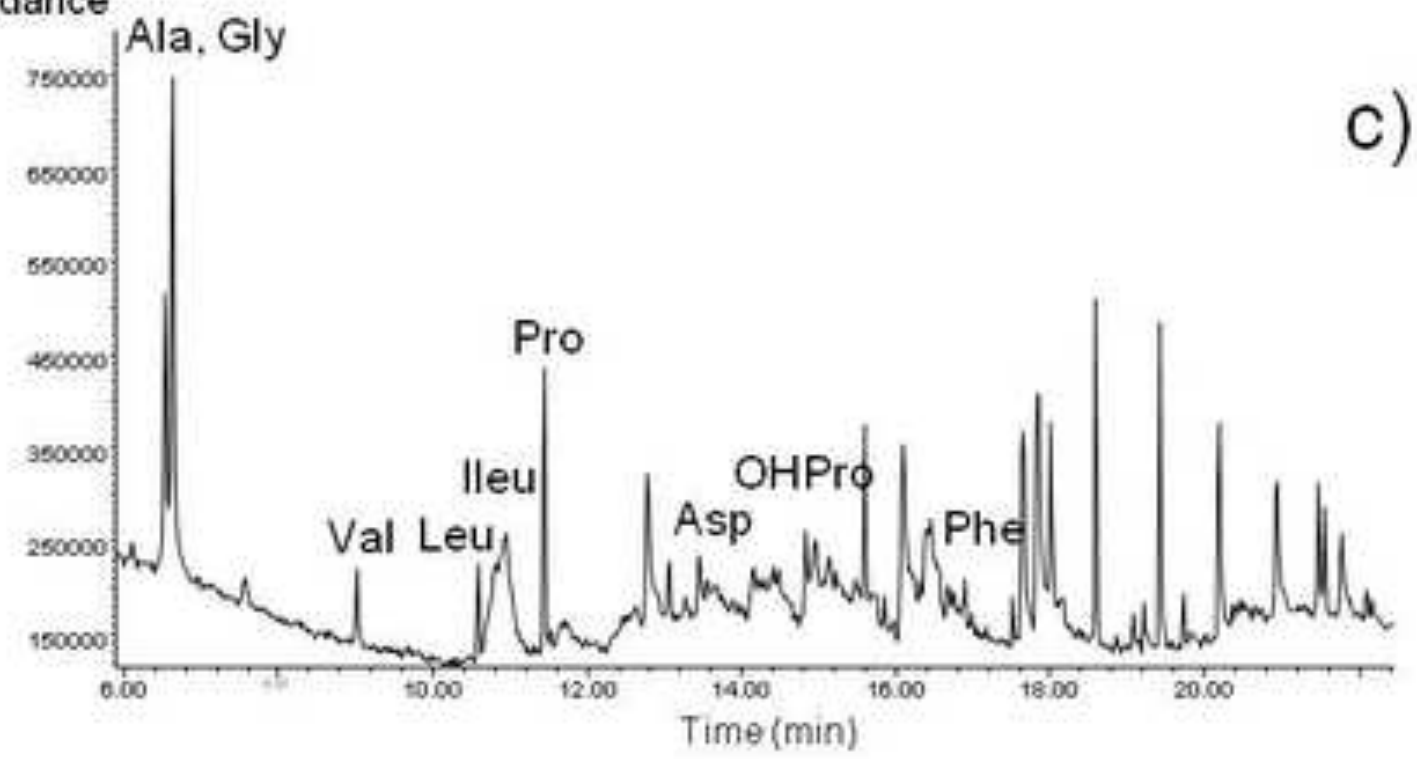


Abundance

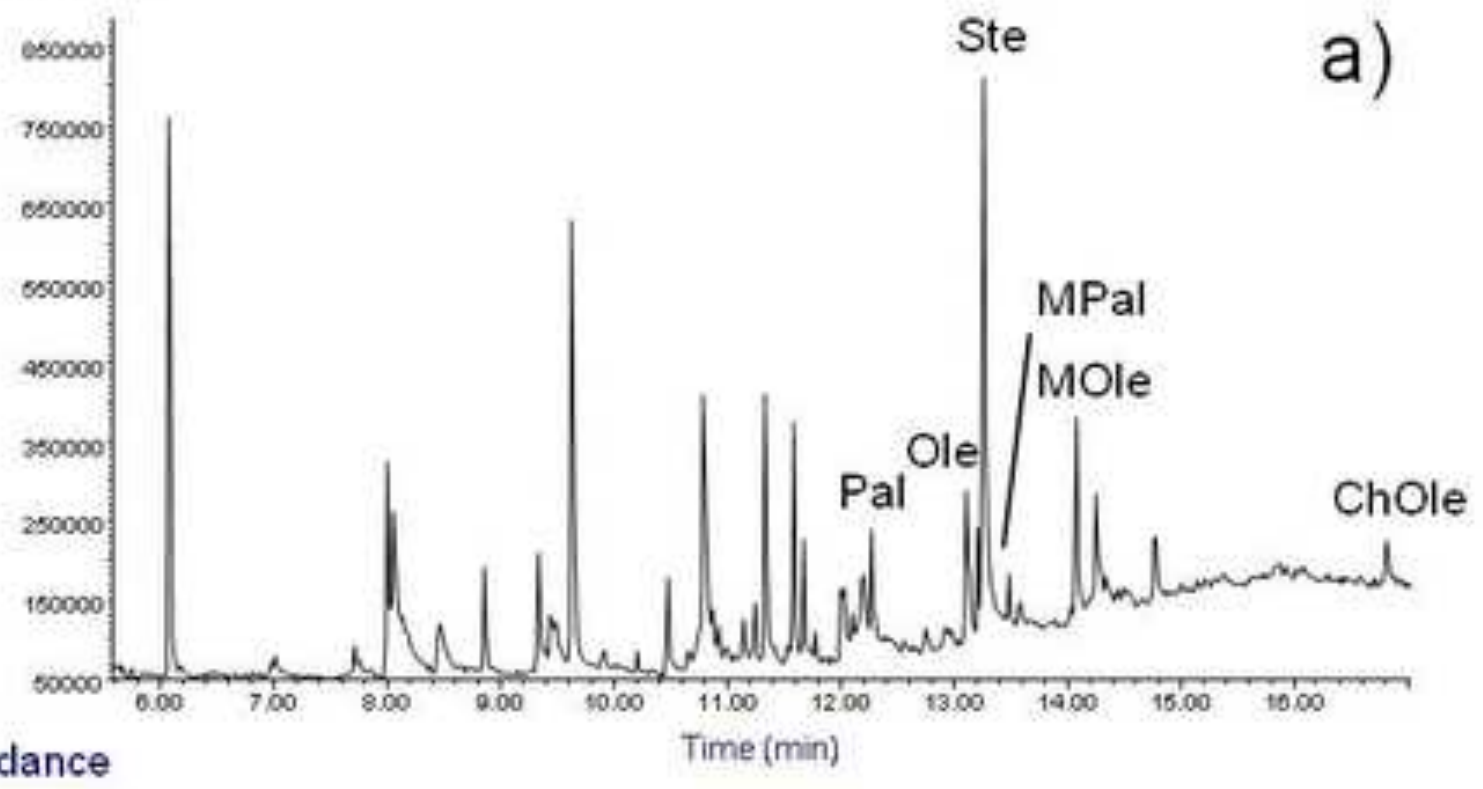

\section{Abundance}

b)

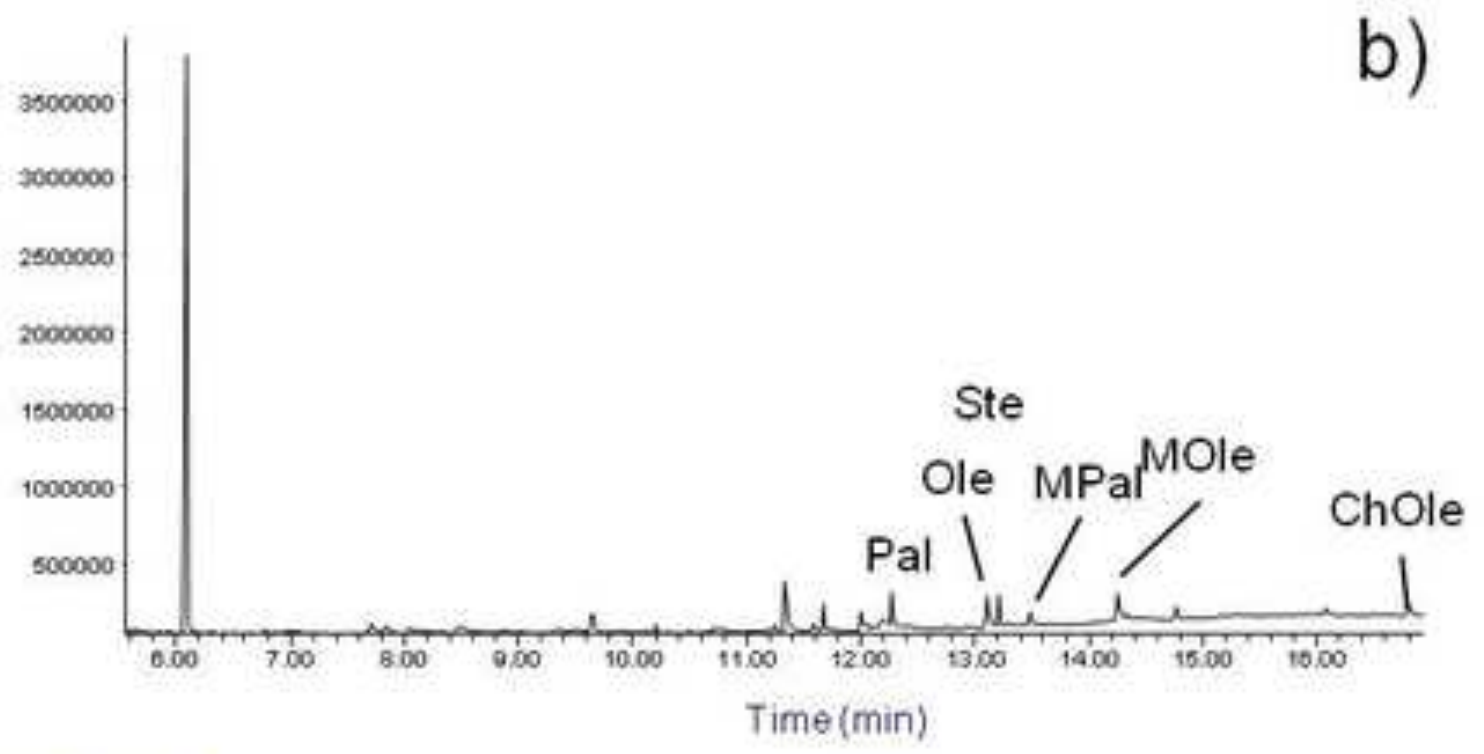

Abundance

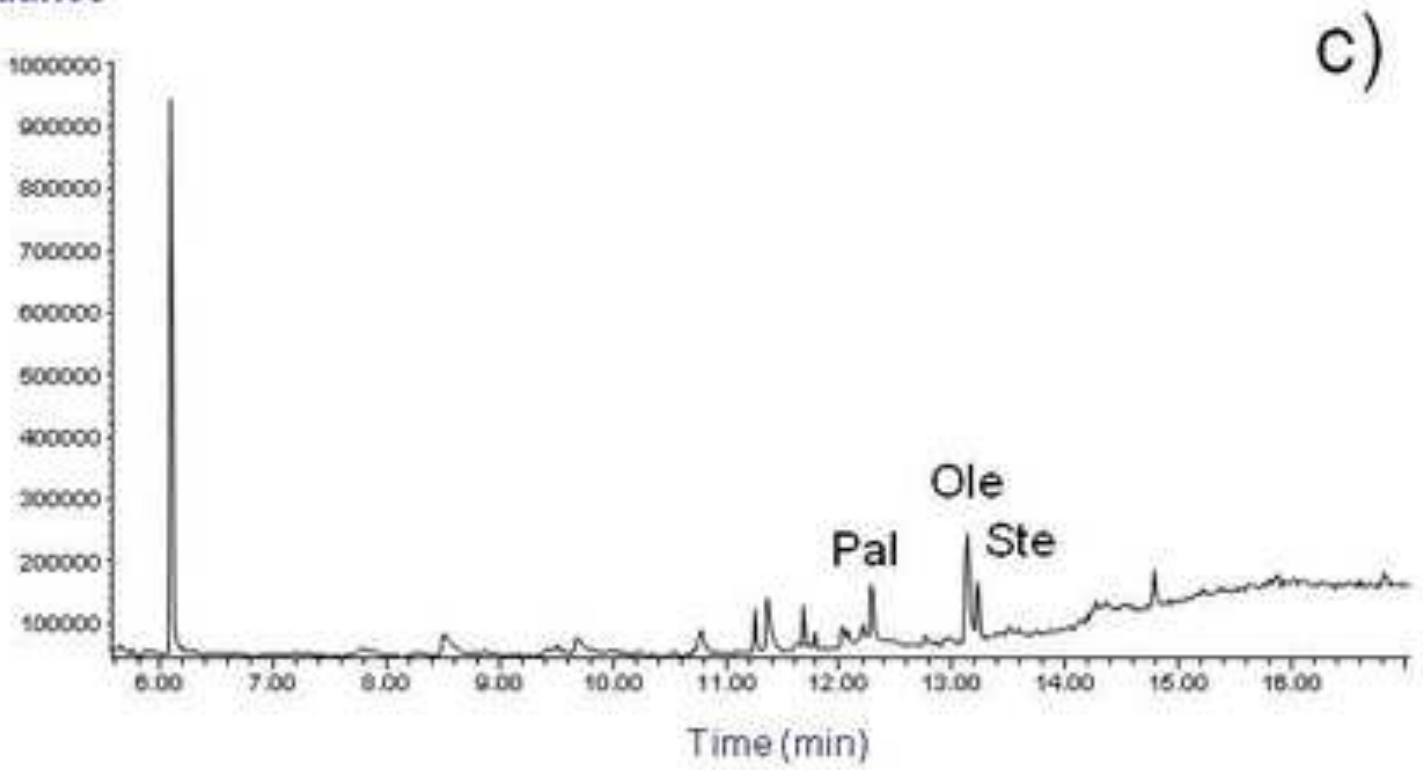


Table 1

\section{SEM-EDX}

\begin{tabular}{cc}
\hline Element & $\begin{array}{c}\text { Chemical composition } \\
(\mathbf{w t} \%)\end{array}$ \\
\hline $\mathrm{Na}$ & $0.7 \pm 0.9$ \\
$\mathrm{Mg}$ & $3.3 \pm 0.07$ \\
$\mathrm{Al}$ & $4.89 \pm 0.02$ \\
$\mathrm{Si}$ & $13.9 \pm 0.5$ \\
$\mathrm{~S}$ & $0.82 \pm 0.13$ \\
$\mathrm{Cl}$ & $1.5 \pm 0.3$ \\
$\mathrm{~K}$ & $1.91 \pm 0.14$ \\
$\mathrm{Ca}$ & $32.76 \pm 0.09$ \\
$\mathrm{Fe}$ & $2.38 \pm 0.11$ \\
\hline
\end{tabular}

Spectrophotometry

\begin{tabular}{cc}
\hline Anion & $\begin{array}{c}\text { Chemical composition } \\
(\mathbf{w t} \%)\end{array}$ \\
\hline $\mathrm{Cl}^{-}$ & $1.63 \pm 0.02$ \\
$\mathrm{SO}_{4}{ }^{2-}$ & $2.11 \pm 0.07$ \\
$\mathrm{NO}_{3}{ }^{-}$ & $<0.2$ \\
\hline
\end{tabular}

FTIR spectroscopy

\begin{tabular}{|c|c|}
\hline Compound & $\begin{array}{l}\text { Characteristic IR bands } \\
\qquad\left(\mathrm{cm}^{-1}\right)\end{array}$ \\
\hline Calcite & $1418,873,712$ \\
\hline Aragonite & $1447^{\text {sh }}, 873,857,713,700$ \\
\hline Quartz & $1082,1012,795,780$ \\
\hline Clayey and silicate minerals & $1026,918,790,750$ \\
\hline \multicolumn{2}{|l|}{ sh: shoulder } \\
\hline \multicolumn{2}{|c|}{ XRD } \\
\hline Compound & d $(\AA)$ \\
\hline Calcite & $3.03(100), 2.28(18), 2.09$ (18) \\
\hline Aragonite & $3.39(100), 3.27(52), 1.97(65)$ \\
\hline Quartz & $3.34(100), 4.26(35), 1.81(17)$ \\
\hline Gypsum & $7.56(100), 4.27(50), 3.06(55)$ \\
\hline Bassanite & $3.00(100), 2.81(85)$ \\
\hline Plagioclase & $3.18(100)$ \\
\hline
\end{tabular}


Table 2

\begin{tabular}{|c|c|c|c|c|c|c|c|c|c|c|c|c|}
\hline & \multicolumn{2}{|c|}{ DM } & \multicolumn{2}{|c|}{$\mathbf{C M}$} & \multicolumn{2}{|c|}{ DA } & \multicolumn{2}{|c|}{ CAI } & \multicolumn{2}{|c|}{ CAO } & \multicolumn{2}{|c|}{ DCJ } \\
\hline & Mean & SD & Mean & SD & Mean & SD & Mean & SD & Mean & SD & Mean & SD \\
\hline Element & & & & & & & & & & & & \\
\hline $\mathbf{F}$ & - & - & - & - & 0.6 & 0.3 & 0.8 & 0.7 & 1.4 & 0.8 & - & - \\
\hline $\mathrm{Na}$ & 0.49 & 0.07 & 0.63 & 0.08 & 0.51 & 0.07 & 0.63 & 0.08 & 0.70 & 0.07 & - & - \\
\hline Mg & 2.75 & 0.07 & 1.63 & 0.12 & 0.41 & 0.05 & 0.55 & 0.09 & 0.68 & 0.06 & - & - \\
\hline Al & - & - & 0.11 & 0.08 & - & - & 0.06 & 0.07 & 0.40 & 0.08 & - & - \\
\hline $\mathbf{S i}$ & - & - & 0.2 & 0.8 & - & - & 0.36 & 0.05 & 0.85 & 0.13 & 1.22 & 0.14 \\
\hline $\mathbf{P}$ & 13.5 & 0.9 & 14.6 & 1.3 & 14.3 & 1.5 & 10.7 & 0.9 & 11.8 & 0.8 & - & - \\
\hline $\mathbf{S}$ & - & - & 0.1 & 0.2 & 0.38 & 0.08 & 0.51 & 0.08 & 0.47 & 0.02 & 10.0 & 0.9 \\
\hline $\mathrm{Cl}$ & - & - & - & - & 0.02 & 0.06 & - & - & - & - & - & - \\
\hline $\mathbf{K}$ & 0.08 & 0.12 & 0.06 & 0.08 & s.a. & - & - & - & 0.07 & 0.09 & - & - \\
\hline $\mathbf{C a}$ & 19.7 & 0.2 & 24.5 & 1.2 & 34.5 & 1.1 & 29.1 & 0.9 & 28.2 & 0.7 & 43.8 & 1.2 \\
\hline $\mathbf{T i}$ & - & - & - & - & - & - & - & - & s.a. & - & - & - \\
\hline $\mathbf{V}$ & - & - & - & - & - & - & - & - & s.a. & - & - & - \\
\hline Mn & - & - & - & - & - & - & 0.03 & 0.04 & 0.04 & 0.04 & - & - \\
\hline $\mathbf{F e}$ & - & - & - & - & - & - & 0.57 & 0.08 & 0.69 & 0.03 & 8.8 & 0.8 \\
\hline $\mathbf{N i}$ & - & - & - & - & - & - & - & - & 0.01 & 0.02 & - & - \\
\hline $\mathbf{Z n}$ & - & - & - & - & - & - & - & - & s.a & - & - & - \\
\hline $\mathbf{C u}$ & - & - & - & - & - & - & - & - & 0.03 & 0.04 & - & - \\
\hline Ag & - & - & - & - & - & - & - & - & s.a. & - & - & - \\
\hline Cd & - & - & - & - & - & - & - & - & s.a. & - & - & - \\
\hline $\mathbf{P b}$ & - & - & - & - & - & - & - & - & s.a. & - & - & - \\
\hline $\mathrm{Sr}$ & - & - & - & - & - & - & - & - & s.a. & - & - & - \\
\hline $\begin{array}{c}\mathbf{C a} / \mathbf{P} \\
\text { Molar ratio }\end{array}$ & 1.13 & & 1.30 & & 1.86 & & 2.10 & & 1.85 & & & \\
\hline
\end{tabular}


Table 3

\begin{tabular}{|c|c|c|c|c|}
\hline & \multicolumn{2}{|c|}{ CAI } & \multicolumn{2}{c|}{ CAO } \\
\hline Element & $\begin{array}{c}\text { Apatitic alveolar } \\
\text { bulk }\end{array}$ & Rounded grain & $\begin{array}{c}\text { Apatitic } \\
\text { alveolar bulk }\end{array}$ & Rounded grain \\
\hline $\mathbf{F}$ & 0.81 & 0.92 & 1.42 & 0.93 \\
\hline $\mathbf{N a}$ & 0.64 & 0.30 & 0.76 & 0.36 \\
\hline $\mathbf{M g}$ & 0.50 & 0.41 & 0.34 & 0.31 \\
\hline $\mathbf{S i}$ & 0.01 & 0.28 & 0.30 & 0.31 \\
\hline $\mathbf{P}$ & 15.73 & 10.11 & 14.43 & 11.12 \\
\hline $\mathbf{S}$ & 0.98 & 0.57 & 0.59 & 0.47 \\
\hline $\mathbf{C a}$ & 36.28 & 31.79 & 32.78 & 30.23 \\
\hline Fe & 0.86 & - & - & - \\
\hline $\mathbf{C a} / \mathbf{P}$ molar & 1.78 & 2.43 & 1.76 & 2.10 \\
ratio & & & & \\
\hline
\end{tabular}


Table 4

\begin{tabular}{|c|c|c|c|c|c|c|c|c|}
\hline Material & $\begin{array}{c}\mathrm{Ca} / \mathrm{P} \\
\text { molar } \\
\text { ratio }\end{array}$ & CI & $\mathbf{C} / \mathbf{P}$ & $\mathrm{wt}_{\mathrm{t}} \mathrm{\textrm {CO } _ { 3 }}$ & $\mathbf{I}_{1030} / \mathbf{I}_{1020}$ & $\mathrm{HPO}_{4}{ }^{2-}$ content & IRSF & $\mathbf{R}\left(\mathrm{HPO}_{4}{ }^{2-}\right)_{\mathrm{na}} / \mathrm{R}\left(\mathrm{HPO}_{4}{ }^{2-}\right)_{\mathrm{a}}$ \\
\hline $\mathbf{D M}$ & 1.13 & 0.07 & 0.14 & 4 & 0.35 & 0.34 & 2.28 & 1.84 \\
\hline $\mathbf{C M}$ & 1.30 & n.c.* & 0.15 & 4 & 0.91 & 0.25 & 2.78 & 0.53 \\
\hline DA & 1.86 & 0.08 & 0.37 & 11 & 0.38 & 0.33 & 3.22 & 1.01 \\
\hline CAI & 2.10 & 0.22 & 0.31 & 9 & 1.17 & 0.31 & 3.34 & 0.43 \\
\hline CAO & 1.85 & 0.45 & 0.30 & 9 & 1.31 & 0.20 & 3.46 & 0.39 \\
\hline
\end{tabular}

n.d.: no calculated

* Diffractogram in this sample exhibited poor features that hindered calculation of CI. 


\section{Table 5}

\begin{tabular}{lcccccc} 
Conformation & $\begin{array}{c}\text { Wavenumber } \\
\left(\mathbf{c m}^{-1}\right)\end{array}$ & \multicolumn{5}{c}{$\begin{array}{c}\text { Sample } \\
\text { Composition (\%) }\end{array}$} \\
& & DM & CM & DA & CAI & CAO \\
\hline $\boldsymbol{\beta}$-sheet intermolecular & $1600-1625$ & 16 & 23 & 13 & 10 & 12 \\
$\boldsymbol{\beta}$-sheet intramolecular & $1625-1637$ & 21 & 18 & 21 & 25 & 17 \\
Random coil & $1637-1645$ & 8 & 4 & 17 & 15 & 17 \\
$\boldsymbol{\alpha}$-helix (triple helical) & $1645-1660$ & $28(12)$ & $32(17)$ & $21(10)$ & $22(11)$ & $22(11)$ \\
Turns & $1660-1700$ & 26 & 22 & 28 & 28 & 31 \\
\hline PM/P & & 0.180 & 0.230 & 0.015 & 0.024 & 0.054 \\
\hline
\end{tabular}


Table 6

\begin{tabular}{|c|c|c|c|c|c|}
\hline Amino Acid & $\begin{array}{c}\mathbf{t}_{\text {ret }} \\
(\mathbf{m i n})\end{array}$ & DM & DA & CA & $\begin{array}{c}\text { Fragment ion } \\
(\mathrm{m} / \mathrm{z})\end{array}$ \\
\hline Alanine & 6.56 & 7.59 & 23.60 & 19.56 & $29,44,116$ \\
\hline Glycine & 6.73 & 20.66 & 41.52 & 38.65 & $29,30, \mathbf{1 0 2}$ \\
\hline Valine & 9.02 & 1.57 & 5.63 & 5.04 & $72,116,144$ \\
\hline Piroglutamic a. & 10.08 & 1.47 & n.d. & n.d. & $28,41,84$ \\
\hline Leucine & 10.62 & 4.27 & 1.04 & 5.43 & $102, \mathbf{1 5 8}, 159$ \\
\hline Isoleucine & 10.96 & 1.07 & 6.35 & 7.48 & $102,129, \mathbf{1 5 8}$ \\
\hline Proline & 11.49 & 28.17 & 20.85 & 15.40 & $70,98, \mathbf{1 4 2}$ \\
\hline Aspartic a. & 13.68 & 5.88 & 0.58 & 0.41 & $116,142, \mathbf{1 8 8}$ \\
\hline Hydroxyproline & 14.31 & 11.06 & n.d. & 7.64 & 68, 96, 158 \\
\hline Methionine & 14.50 & 3.65 & n.d. & n.d. & $61,129, \mathbf{1 7 5}$ \\
\hline Glutamic a. & 14.94 & 2.40 & n.d. & n.d. & $84,128, \mathbf{2 0 2}$ \\
\hline Phenylalanine & 15.62 & 5.77 & 0.42 & 0.39 & 91, 176, 192 \\
\hline Lysine & 18.13 & 2.68 & n.d. & n.d. & $84,128, \mathbf{1 5 6}$ \\
\hline Histidine & 18.53 & 1.34 & n.d. & n.d. & $81, \mathbf{2 3 8}, 254$ \\
\hline Tyrosine & 19.24 & 2.40 & n.d. & n.d. & $\mathbf{1 0 7}, 192,264$ \\
\hline
\end{tabular}


Tabla 7

\begin{tabular}{|c|c|c|c|c|c|}
\hline Compound & $\begin{array}{c}\mathbf{t}_{\text {ret }} \\
(\mathbf{m i n})\end{array}$ & DM & DA & $\mathbf{C A}$ & $\begin{array}{c}\text { Fragment ion } \\
\qquad(\mathrm{m} / \mathrm{z})\end{array}$ \\
\hline Palmitic a. & 12,27 & $\sqrt{ }$ & $\sqrt{ }$ & $\sqrt{ }$ & $43,55,88, \mathbf{1 0 1}, 284$ \\
\hline Oleic a. & 13,13 & $\sqrt{ }$ & $\sqrt{ }$ & $\sqrt{ }$ & $41,55, \mathbf{6 9}, 88,264,310$ \\
\hline Stearic a. & 13,21 & $\sqrt{ }$ & $\sqrt{ }$ & $\sqrt{ }$ & $43,57,88, \mathbf{1 0 1}, 312$ \\
\hline Glyceryl monopalmitate & 13,48 & $\sqrt{ }$ & $\sqrt{ }$ & - & $28,43,98, \mathbf{2 3 9}$ \\
\hline Glyceryl monooleate & 14,25 & $\sqrt{ }$ & $\sqrt{ }$ & - & $43, \mathbf{5 5}, 98,264$ \\
\hline Cholestyl oleate & 16,81 & $\sqrt{ }$ & $\sqrt{ }$ & - & $147,247,281,353,368$ \\
\hline
\end{tabular}




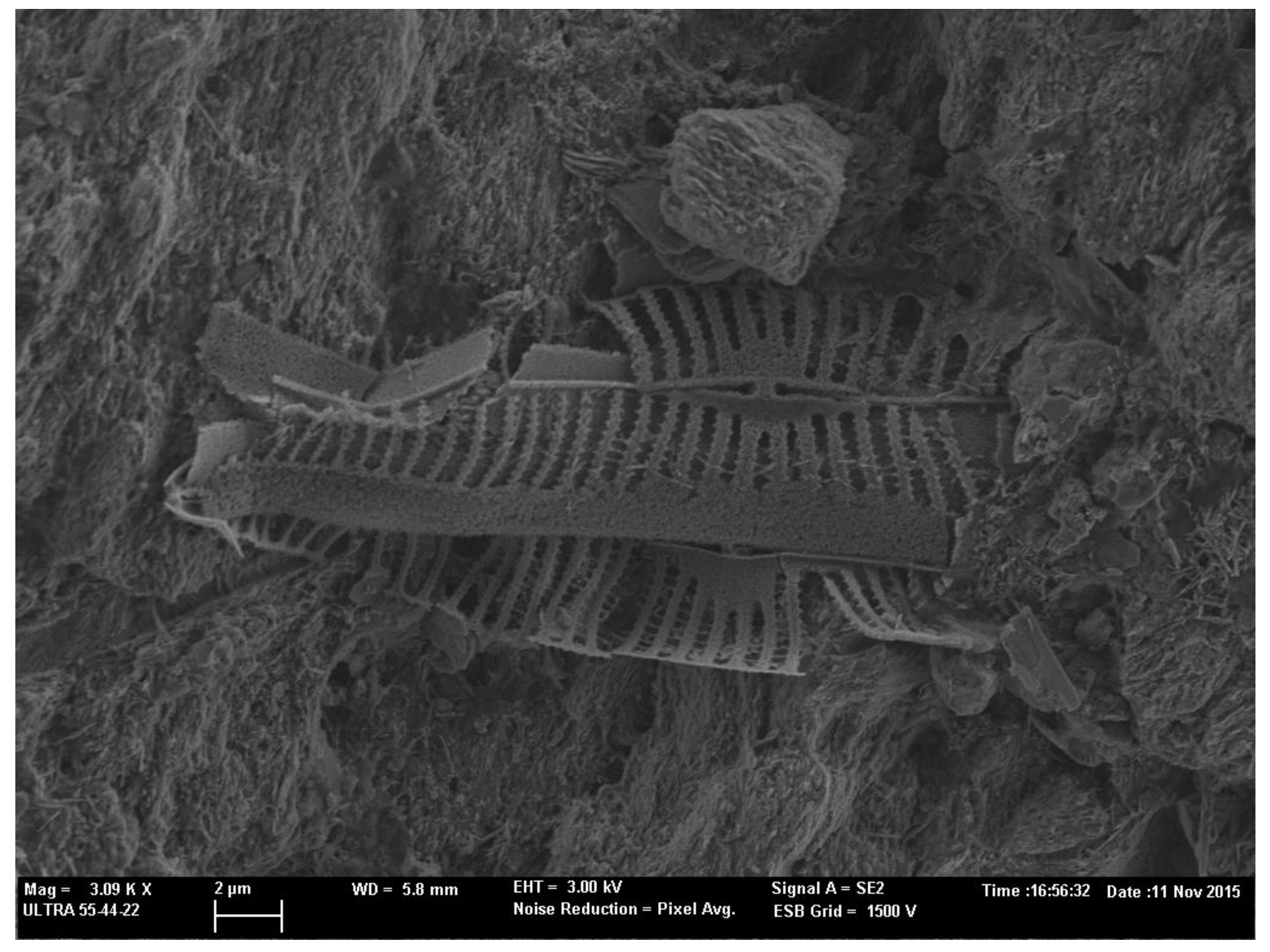

Figure 1S.- Secondary electron image of a diatomea of the navicula type found in the outer part of the ivory close to the dentine-cementum junction. 


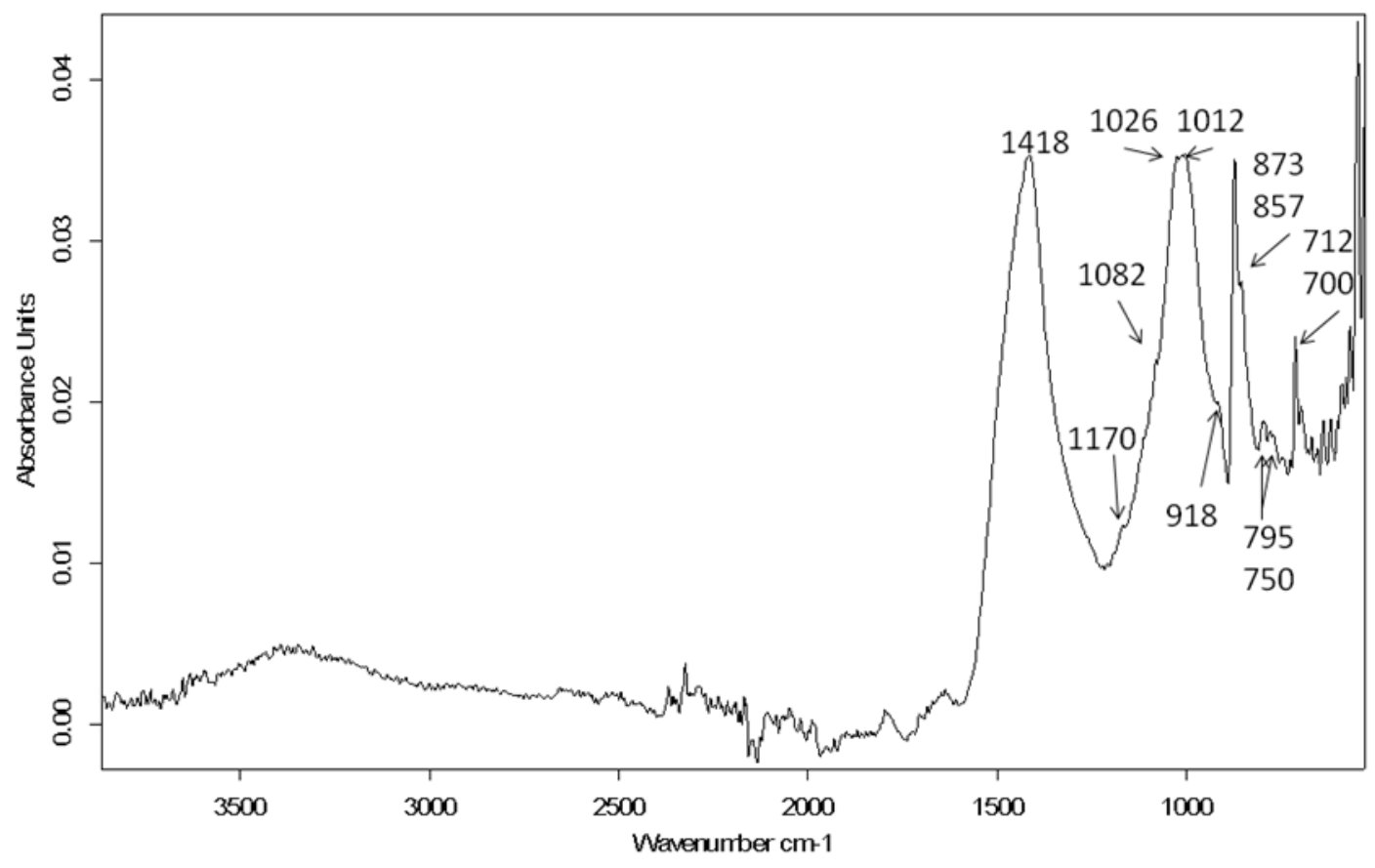

Figure 2S.- IR spectrum of material deposited in the pulp cavity. 


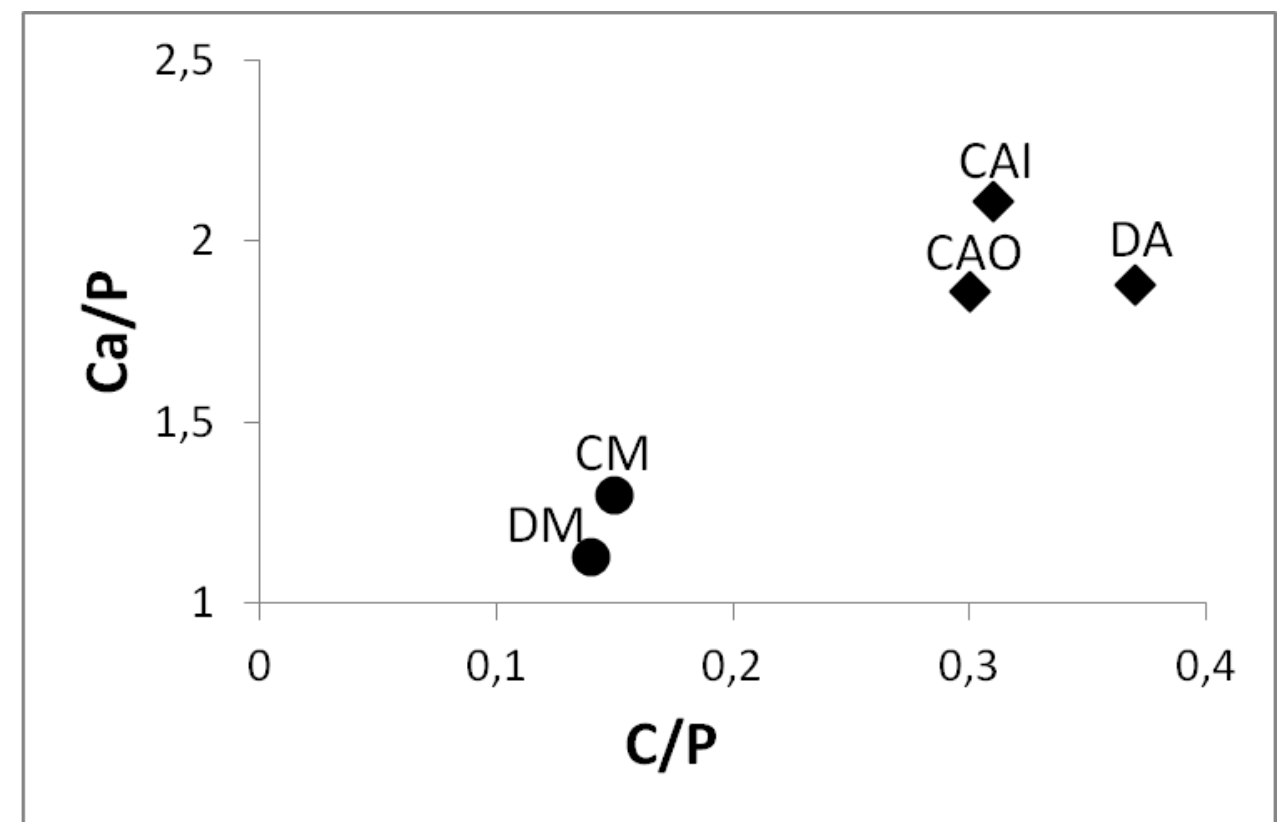

Figure 3S.- Diagram $\mathrm{Ca} / \mathrm{P}$ vs $\mathrm{C} / \mathrm{P}$. 

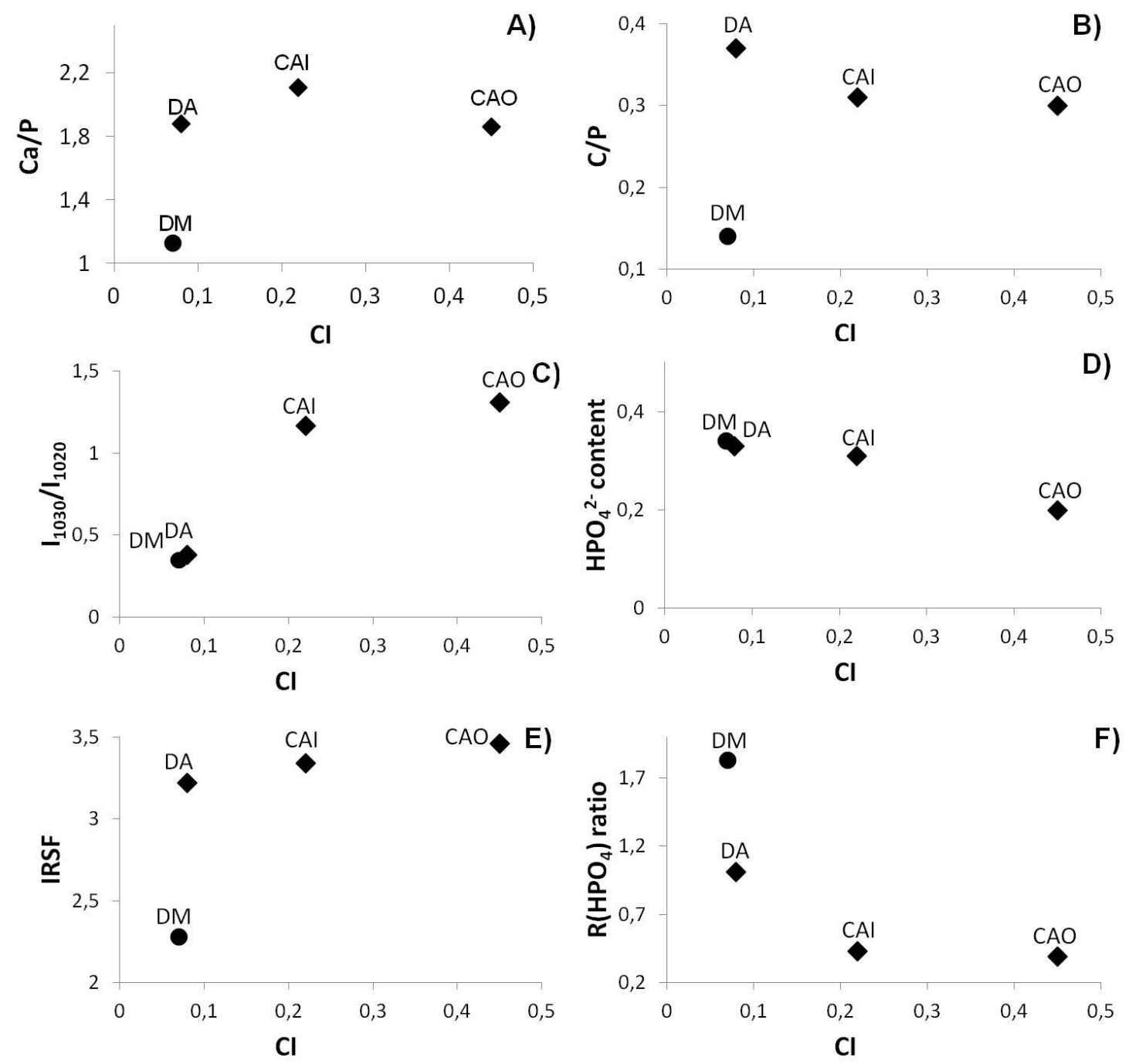

Figure 4S.- Diagrams: a) Ca/P vs CI, b) $\mathrm{C} / \mathrm{P} v s \mathrm{CI}$, c) $\mathrm{I}_{1030} / \mathrm{I}_{1020} v s \mathrm{CI}$, d) $\mathrm{HPO}_{4}{ }^{2-}$ content vs $\mathrm{CI}$, e) IRSF vs $\mathrm{CI}$ and f) $\mathrm{R}\left(\mathrm{PO}_{4}\right)$ ratio vs $\mathrm{CI}$. 

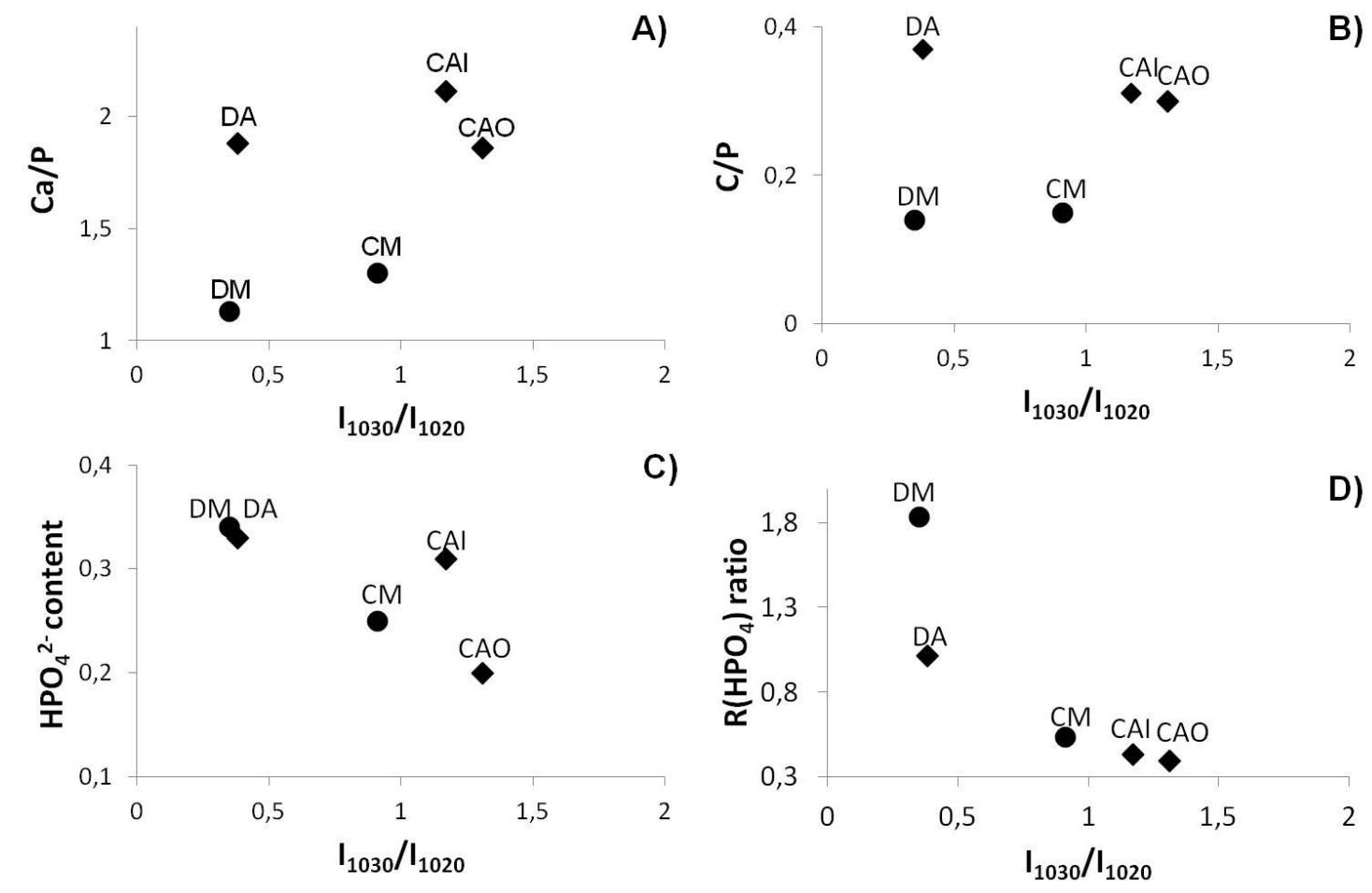

Figure 5S.- Diagrams: a) $\mathrm{Ca} / \mathrm{P}$ vs $\mathrm{I}_{1030} / \mathrm{I}_{1020}$, b) $\mathrm{C} / \mathrm{P} v s \mathrm{I}_{1030} / \mathrm{I}_{1020}$, c) $\mathrm{HPO}_{4}{ }^{2-}$ content $v s$ $\mathrm{I}_{1030} / \mathrm{I}_{1020}$ and d) $\mathrm{R}\left(\mathrm{PO}_{4}\right)$ ratio $v s \mathrm{I}_{1030} / \mathrm{I}_{1020}$. 


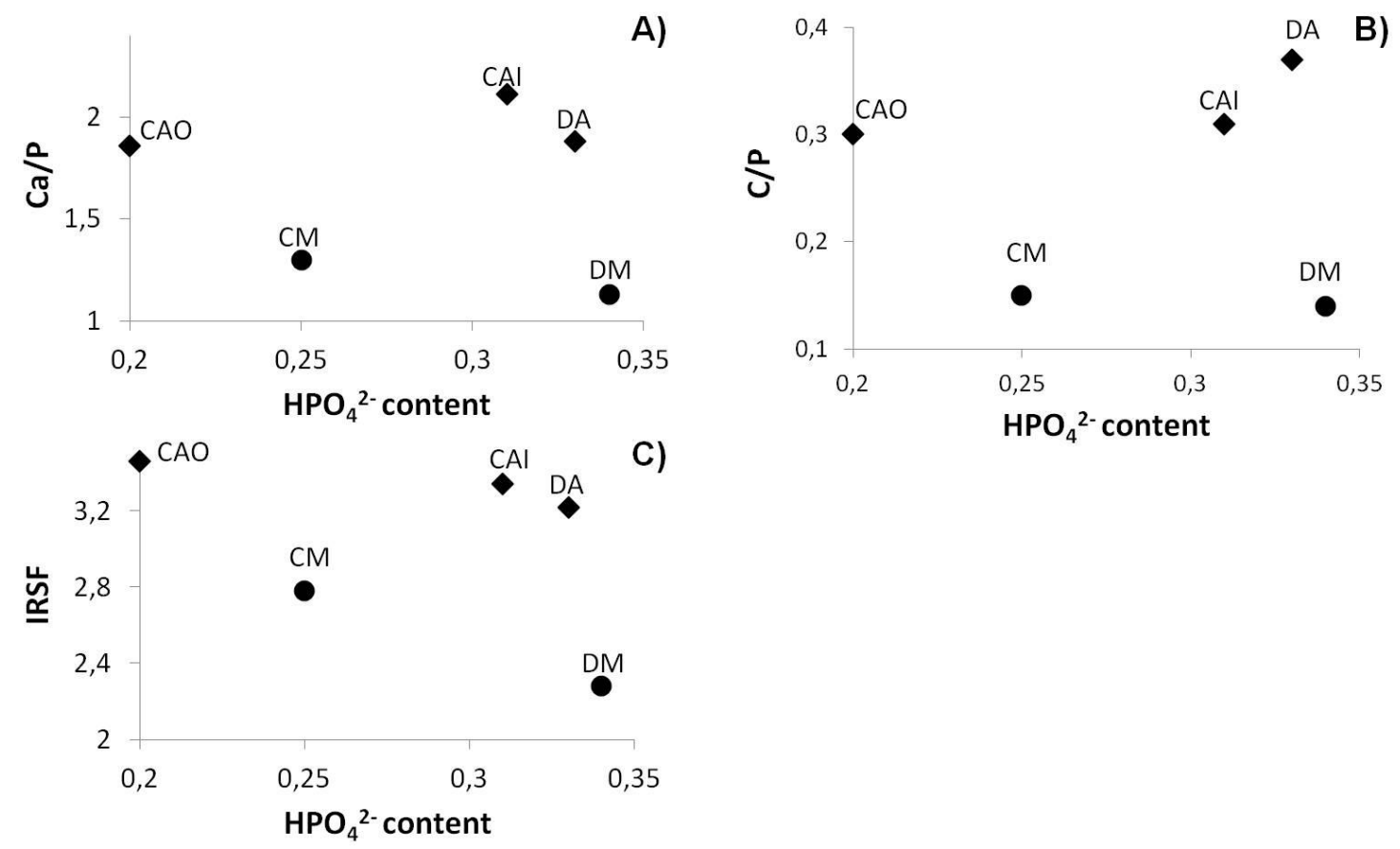

Figure 6S.- Diagrams: a) $\mathrm{Ca} / \mathrm{P} v s \mathrm{HPO}_{4}{ }^{2-}$ content, b) $\mathrm{C} / \mathrm{P} v s \mathrm{HPO}_{4}{ }^{2-}$ content, c) IRSF $v s$ $\mathrm{HPO}_{4}{ }^{2-}$ content. 

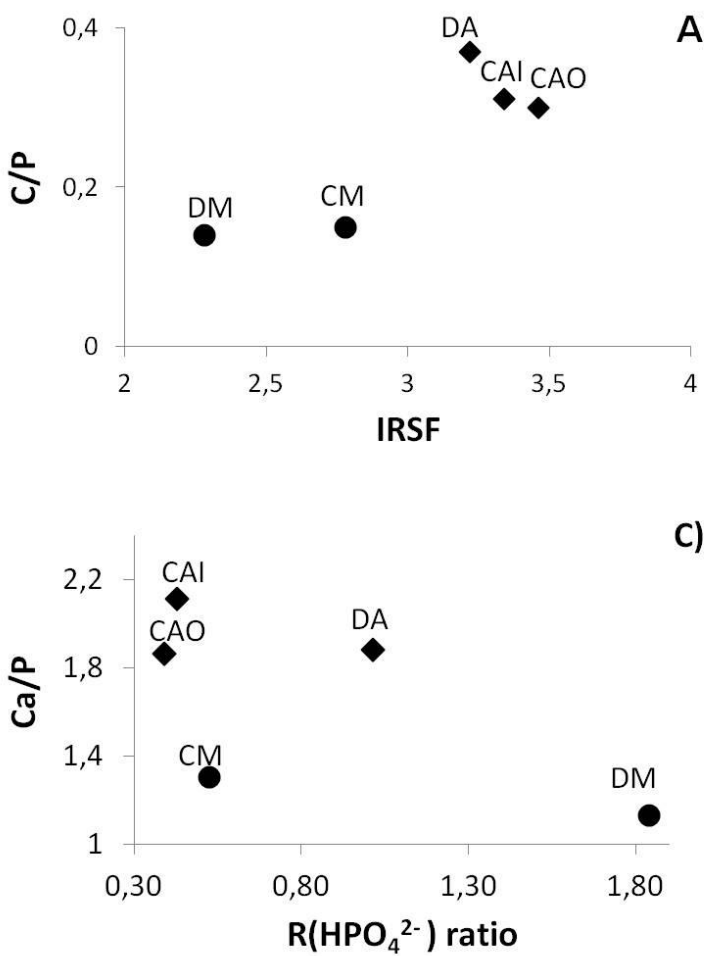

A)

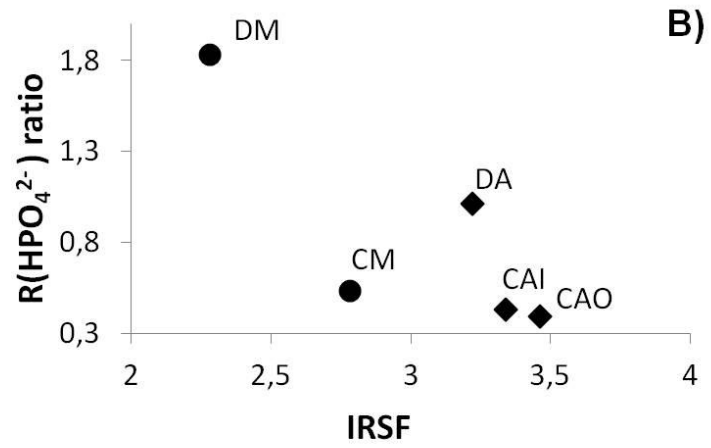

B)

C)

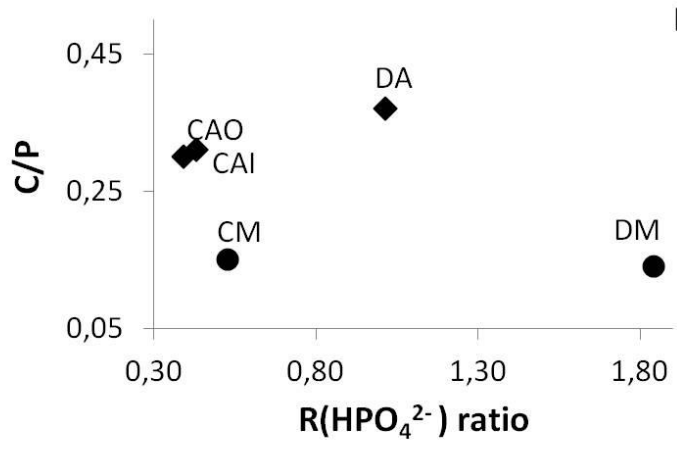

D)

Figure 7S.- Diagrams: a) C/P vs IRSF, b) $\mathrm{R}\left(\mathrm{PO}_{4}\right)$ ratio $v s$ IRSF. 

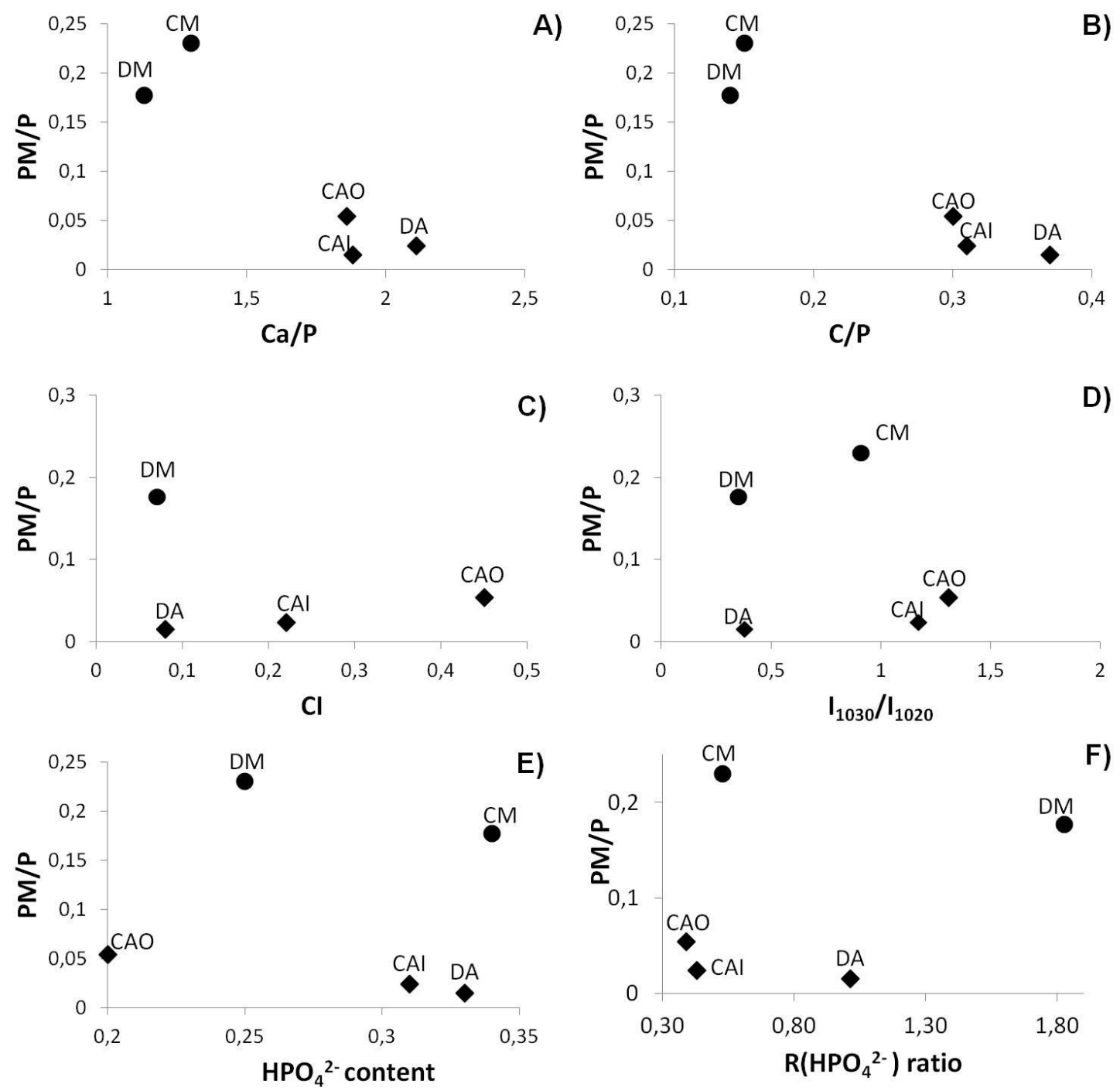

Figure 8S.- Diagrams: a) $\mathrm{PM} / \mathrm{P}$ vs $\mathrm{Ca} / \mathrm{P}$, b) $\mathrm{PM} / \mathrm{P}$ vs $\mathrm{C} / \mathrm{P}$, c) $\mathrm{PM} / \mathrm{P}$ vs $\mathrm{CI}$, d) $\mathrm{PM}$ vs $\mathrm{I}_{1030} / \mathrm{I}_{1020}$, e) PM/P vs $\mathrm{HPO}_{4}{ }^{2-}$ content, f) PM/P vs $\mathrm{R}\left(\mathrm{PO}_{4}\right)$ ratio. 
Table 1S.- Percentage area contribution calculated from curve fitting for the underlying bands appearing in the subdomains of the phosphate $v_{3} v_{1}\left(\mathrm{PO}_{4}\right)$ band. Maximum of each individual band in $\mathrm{cm}^{-1}$ is given in brackets. Wavenumber intervals where have reported characteristic individual bands in each subdomain are also indicated.

\begin{tabular}{|c|c|c|c|c|c|c|}
\hline \multirow[t]{2}{*}{ Subdomains in the $v_{3} v_{1} \mathrm{PO}_{4}{ }^{3-}$ band } & \multirow[t]{2}{*}{$\begin{array}{c}\text { Wavenumber } \\
\qquad\left(\mathrm{cm}^{-1}\right)\end{array}$} & \multicolumn{5}{|c|}{ Band area contribution } \\
\hline & & DM & CM & DA & CAI & CAO \\
\hline$v_{1} \mathrm{PO}_{4}^{3-}$ & $960-980$ & $23.2(974)$ & $\begin{array}{l}29.9(968) \\
19.9(972) \\
\end{array}$ & $20.8(971)$ & $19.2(968)$ & $27.5(971)$ \\
\hline \multirow{7}{*}{$\begin{array}{l}\text { Low wavenumber component of } \mathrm{v}_{3} \mathrm{PO}_{4}{ }^{3-} \text { band } \\
\text { Phosphate ions in stoichiometric/non } \\
\text { stoichiometric apatitic environments }\end{array}$} & $980-1000$ & $1.0(986)$ & $13.7(988)$ & $0.8(986)$ & - & 2.6(985) \\
\hline & $1000-1015$ & $8.0(1002)$ & $13.7(1005)$ & $10.4(1000)$ & $17.8(1009)$ & $5.9(996)$ \\
\hline & $1015-1025$ & $17.4(1021)$ & $10.7(1025)$ & $16.7(1017)$ & $5.9(1022)$ & $11.6(1019)$ \\
\hline & $1025-1040$ & $6.1(1037)$ & $10.8(1037)$ & $6.4(1034)$ & $6.9(1034)$ & $14.6(1027)$ \\
\hline & $1040-1075$ & $11.0(1053)$ & - & $17.2(1050)$ & $14.3(1047)$ & $\begin{array}{c}6.0(1043) \\
14.9(1059)\end{array}$ \\
\hline & $1075-1090$ & $1.5(1075)$ & 7.1(1071) & - & $10.8(1067)$ & - \\
\hline & $1090-1100$ & $14.3(1095)$ & $0.7(1090)$ & $11.0(1080)$ & 10.1(1094) & $6.1(1092)$ \\
\hline \multirow{2}{*}{$\begin{array}{l}\text { High wavenumber component of } \mathrm{v}_{3} \mathrm{PO}_{4}{ }^{3-} \text { band } \\
\text { Acid phosphate ions in non apatitic } \\
\text { environments }\end{array}$} & $1100-1110$ & $14.5(1100)$ & $7.0(1100)$ & $11.5(1101)$ & $10.3(1102)$ & $5.5(1100)$ \\
\hline & $1110-1150$ & $3.0(1152)$ & $0.2(1125)$ & $5.2(1117)$ & $4.7(1117)$ & $5.3(1116)$ \\
\hline
\end{tabular}


Table 2S.- Percentage area contribution calculated from curve fitting for the underlying bands appearing in the subdomains of the phosphate $v_{4}\left(\mathrm{PO}_{4}\right)$ band. Maximum of each individual band in $\mathrm{cm}^{-1}$ is given in brackets. Wavenumber intervals where have reported characteristic individual bands in each subdomain are also indicated.

Table 2S

\begin{tabular}{|c|c|c|c|c|c|c|c|c|c|c|c|}
\hline \multirow{3}{*}{ Assignation } & \multirow{3}{*}{$\begin{array}{c}\text { Wavenumber } \\
\left(\mathrm{cm}^{-1}\right)\end{array}$} & \multicolumn{10}{|c|}{$\begin{array}{c}\text { Band area contribution } \\
(\%)\end{array}$} \\
\hline & & \multicolumn{2}{|r|}{ DM } & \multicolumn{2}{|r|}{$\mathbf{C M}$} & \multicolumn{2}{|c|}{ DA } & \multicolumn{2}{|r|}{ CAI } & \multicolumn{2}{|c|}{ CAO } \\
\hline & & Total & Individual & Total & Individual & Total & Individual & Total & Individual & Total & Individual \\
\hline $\begin{array}{c}\text { Non apatitic } \mathrm{HPO}_{4}{ }^{2-} \\
\mathrm{R}\left(\mathrm{HPO}_{4}{ }^{2-}\right)_{\mathrm{a}}\end{array}$ & $500-530$ & 10.3 & $\begin{array}{l}8.1(527) \\
2.2(530)\end{array}$ & 10.6 & $\begin{array}{l}3.8(524) \\
6.8(528)\end{array}$ & 10.7 & $\begin{array}{l}2.8(516) \\
4.9(522) \\
3.0(527)\end{array}$ & 8.3 & $\begin{array}{l}3.0(519) \\
5.3(526)\end{array}$ & 9.6 & $\begin{array}{l}1.4(519) \\
3.9(523) \\
4.3(530)\end{array}$ \\
\hline $\begin{array}{l}\text { Apatitic } \mathrm{HPO}_{4}{ }^{2-} \\
\mathrm{R}\left(\mathrm{HPO}_{4}{ }^{2-}\right)_{\mathrm{na}}\end{array}$ & $530-555$ & 5.6 & $5.6(536)$ & 20.1 & $20.1(540)$ & 10.6 & $\begin{array}{l}2.3(532) \\
8.3(539)\end{array}$ & 19.5 & $\begin{array}{l}9.4(537) \\
1.6(543) \\
8.5(549)\end{array}$ & 24.6 & $\begin{array}{c}6.2(541) \\
7.5(549) \\
10.9(555)\end{array}$ \\
\hline $\begin{array}{c}\text { Apatitic } \mathrm{PO}_{4}^{3-} \\
\mathrm{R}\left(\mathrm{PO}_{4}{ }^{3-}\right)_{\mathrm{a}}\end{array}$ & $555-600$ & 66.2 & $\begin{array}{c}10.8(556) \\
1.5(559) \\
32.6(560) \\
1.8(571) \\
4.3(577) \\
1.1(581) \\
14.1(586)\end{array}$ & 51.9 & $\begin{array}{c}22.9(557) \\
6.9(566) \\
12.9(577) \\
9.2(589)\end{array}$ & 69.6 & $\begin{array}{c}9.3(556) \\
9.0(559) \\
8.8(563) \\
3.5(570 \\
20.5(577) \\
18.5(599)\end{array}$ & 63.4 & $\begin{array}{c}13.3(558) \\
9.2(565) \\
6.0(572) \\
15.6(579) \\
0.3(591) \\
19.0(598)\end{array}$ & 37.1 & $\begin{array}{c}8.8(561) \\
9.1(567) \\
19.2(576)\end{array}$ \\
\hline $\begin{array}{c}\text { Non apatitic } \mathrm{PO}_{4}^{3-} \\
\mathrm{R}\left(\mathrm{PO}_{4}{ }^{3-}\right)_{\mathrm{na}}\end{array}$ & $600-630$ & 17.9 & $\begin{array}{l}11.9(604) \\
6.0(618) \\
\end{array}$ & 17.4 & $\begin{array}{c}3.1(600) \\
14.3(604)\end{array}$ & 9.1 & $\begin{array}{l}1.3(616) \\
7.8(621)\end{array}$ & 8.8 & $8.8(612)$ & 28.7 & $28.7(600)$ \\
\hline
\end{tabular}


Figure 2

a)

a $\square \square$

b)

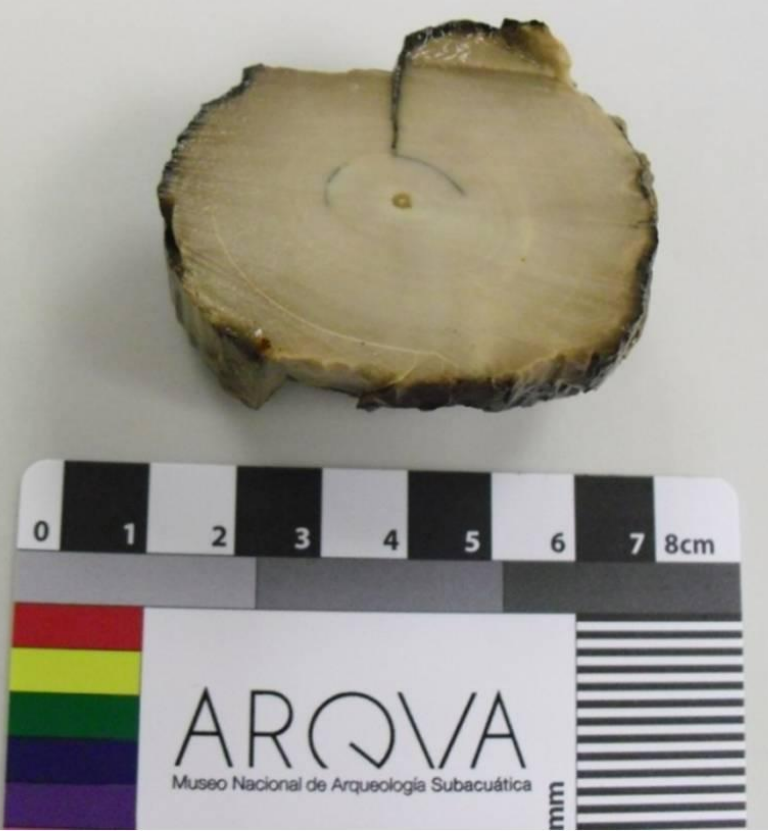


Figure 3

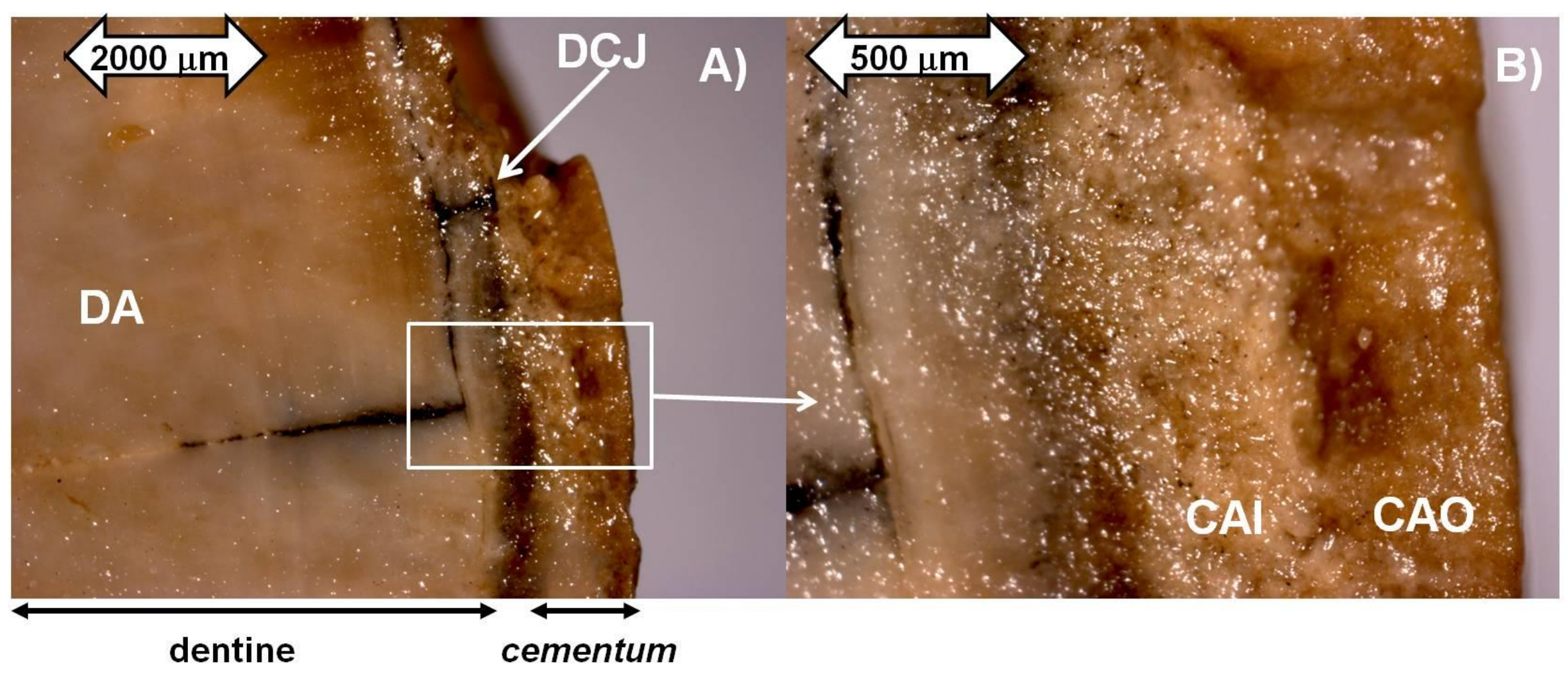


Figure 5

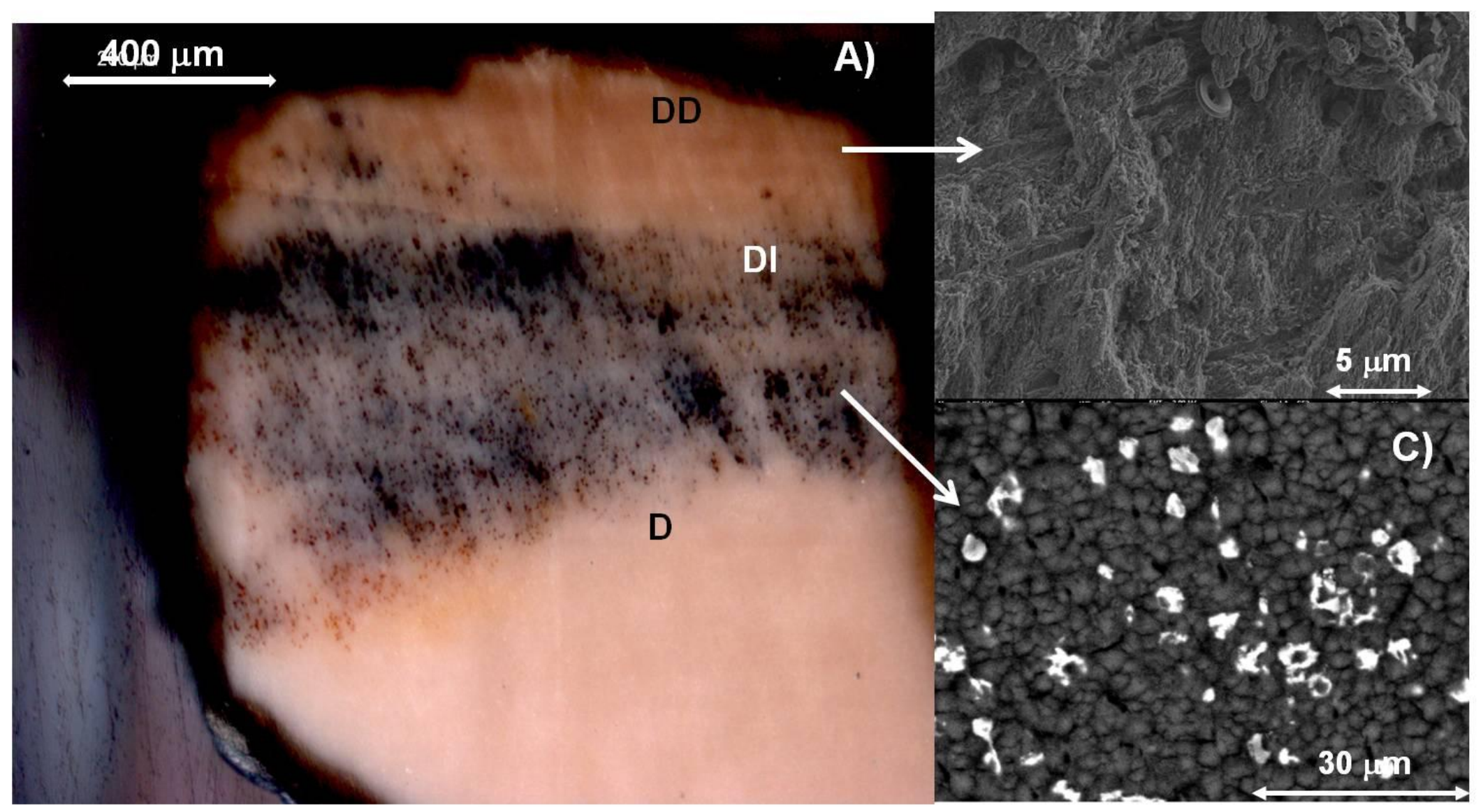

